\title{
Multimedia Environmental Pollutant Assessment System (MEPAS) Sensitivity Analysis of Computer Codes
}

P. G. Doctor

T. M. Miley

C. E. Cowan

April 1990

Prepared for the U.S. Department of Energy under Contract DE-AC06-76RLO 1830

Pacific Northwest Laboratory

Operated for the U.S. Department of Energy

by Battelle Memorial Institute 


\title{
DISCLAIMER
}

This report was prepared as an account of work sponsored by an agency of the United States Government. Neither the United States Government nor any agency thereof, nor Battelle Memorial Institute, nor any of their employees, makes any warranty, expressed or implied, or assumes any legal liability or responsibility for the accuracy, completeness, or usefulness of any information, apparatus, product, or process disclosed, or represents that its use would not infringe privately owned rights. Reference herein to any specific commercial product, process, or service by trade name, trademark, manufacturer, or otherwise, does not necessarily constitute or imply its endorsement, recommendation, or favoring by the United States Government of any agency thereof, or Battelle Memorial Institute. The views and opinions of authors expressed herein do not necessarily state or reflect those of the United States Government or any agency thereof.

\author{
PACIFIC NORTHWEST LABORATORY \\ operated by \\ BATTELLE MEMORIAL INSTITUTE \\ for the \\ UNITED STATES DEPARTMENT OF ENERGY \\ under Contract DE-AC06-76RLO 1830
}

Printed in the United States of America Available to DOE and DOE contractors from the Office of Scientific and Technical Information, P.O. Box 62, Oak Ridge, TN 37831; prices available from (615) $576-8401$. FTS 626-8401.

Available to the public from the National Technical Information Service, U.S. Department of Commerce, 5285 Port Royal Rd., Springfield, VA 22161.

NTIS Price Codes, Microfiche A01

Printed Copy

\begin{tabular}{cr}
\hline Price Code & Page Range \\
\hline A02 & $1-10$ \\
A03 & $11-50$ \\
A04 & $51-75$ \\
A05 & $76-100$ \\
A06 & $101-125$ \\
A07 & $126-150$ \\
A08 & $151-175$ \\
A09 & $176-200$ \\
A10 & $201-225$ \\
A11 & $226-250$ \\
A12 & $251-275$ \\
A13 & $276-300$ \\
A14 & $301-325$
\end{tabular}

\begin{tabular}{cc}
\hline Price Code & Page Range \\
\hline A15 & $326-350$ \\
A16 & $351-375$ \\
A17 & $376-400$ \\
A18 & $401-425$ \\
A19 & $426-450$ \\
A20 & $451-475$ \\
A21 & $476-500$ \\
A22 & $501-525$ \\
A23 & $526-550$ \\
A24 & $551-575$ \\
A25 & $576-600$ \\
A99 & $601-U p$
\end{tabular}


PNL-7296

UC-602, 630

MULTIMEDIA ENVIRONMENTAL POLLUTANT ASSESSMENT SYSTEM (MEPAS) SENSITIVITY ANALYSIS OF COMPUTER CODES

P. G. Doctor

T. B. Mi Tey

C. E. Cowan

ApriT 1990

Prepared for the U.S. Department of Energy under Contract DE-ACO6-76RLO 1830

Pacific Northwest Laboratory Richland, Washington 99352 
$\therefore$ 


\section{SUMMARY}

The Multimedia Environmental Pollutant Assessment System (MEPAS) is a computer-based methodology developed by the Pacific Northwest Laboratory (PNL) for the U.S. Department of Energy (DOE) to estimate health impacts from the release of hazardous chemicals and radioactive materials. The health impacts are estimated from the environmental inventory and release or emission rate, constituent transport, constituent uptake and toxicity, and exposure route parameters. As part of MEPAS development and evaluation, PNL performed a formal parametric sensitivity analysis to determine the sensitivity of the model output to the input parameters, and to provide a systematic and objective method for determining the relative importance of the input parameters. Results of MEPAS uncertainty analysis are not addressed here, but will be provided in a follow-on report.

The sensitivity analysis determined the sensitivity of the Hazard Potential Index (HPI) values to combinations of transport pathway and exposure routes important to evaluating environmental problems at DOE sites. Two combinations of transport pathways and exposure routes were evaluated. The sensitivity analysis focused on evaluating the effect of variation in userspecified parameters, such as constituent inventory, release and emission rates, and parameters describing the transport and exposure routes. The constituents used were strontium-90, yttrium-90, tritium, arsenic, mercury, polychlorinated biphenyls, toluene, and perchloroethylene. These represent constituents of concern at DOE sites and a range of physical, chemical, and toxicological properties.

For groundwater pathways, the sensitivity analysis considered two methods for defining the emission rate from the source, nonprecipitationdriven and precipitation-driven, and two representative sites. For the atmospheric pathways, the effect of three methods for estimating the emission rates on HPI values was evaluated: direct release represented by release from a stack, release through resuspension of particulates, and release through volatilization.

For the transport pathways and exposure routes analyzed, the parameters contributing significantly to the variability in the HPI are reasonable given 
the chemical nature and the biological activity of the constituents; therefore, the results from the sensitivity analysis based on the constituents and sites represented can be extrapolated to other sites and constituents that behave in a similar manner. Additional analyses may be needed to verify this for different assumptions of variability.

The range in HPI values for the groundwater pathways for most of the constituents and for the stack and resuspension release scenario for the atmospheric pathway was 1 to $2 \mathrm{HPI}$ units. Larger ranges of up to $85 \mathrm{HPI}$ units for groundwater pathways were seen for the radionuclides (strontium-90, yttrium-90, and tritium) and for constituents with large distribution coefficient, $K_{d}$ (arsenic), as a result of the effect of important variables such as pore-water velocity on travel times. Larger ranges of up to $16 \mathrm{HPI}$ units were also found for the volatilization release scenario for the atmospheric pathway, for reasons not known at this time. These results indicate that the models used to represent the pathways are well behaved.

A consistent approach was taken for the definition of variability of input parameters based on baseline ranges estimated for a well-characterized site. An arbitrary minimum variability of $\pm 10 \%$ was used; a greater variability was used for parameters for which special minimum-level influences were identified. The results of the sensitivity analysis can thus be used to determine the inherent baseline variability associated with the different components of MEPAS for a well-characterized and representative site. For less well-characterized sites, the increase in baseline variability is illustrated with case studies with increased variabilities for selected inputs. 


\section{CONTENTS}

SUMMARY...............................

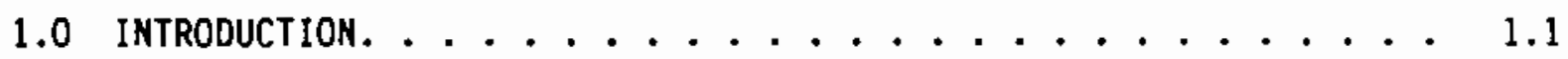

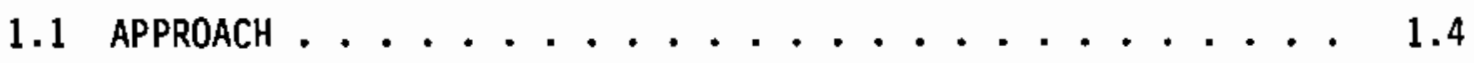

1.1.1 Transport Pathways and Exposure Routes. . . . . . 1.4

1.1 .2 Constituents. . . . . . . . . . 1.7

1.1 .3 Input variables .................... 1.8

1.1 .4 Sensitivity Analysis. . . . . . . . . 1.10

1.2 SCOPE OF SENSITIVITY ANALYSIS. . . . . . . . . 1.12

1.3 ORGANIZATION OF THE REPORT . . . . . . . . . . 1.12

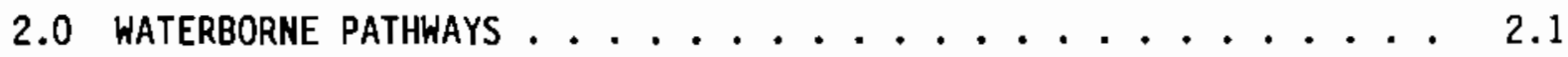

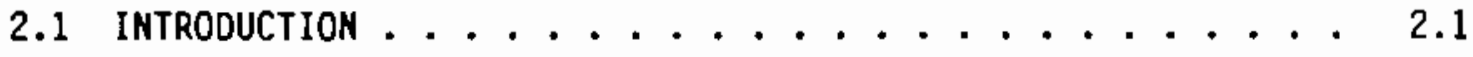

2.1 .1 Groundwater Pathway ............. 2.1

2.1.2 Surface-Water Transport Pathway ......... 2.3

2.1 .3 Overland Transport Pathway .......... 2.4

2.2 GROUNDWATER-TO-SURFACE-WATER TRANSPORT PATHWAY . . . . 2.5

2.3 NONPRECIPITATION-DRIVEN GROUNDWATER-TO-SURFACE-WATER

TRANSPORT PATHWAY .................. 2.6

2.3.1 Site Description ............ 2.6

2.3.2 Variable Descriptions . . . . . . . . 2.6

2.3.3 Sensitivity Analys is Cases .......... 2.11

2.3.4 Sensitivity Analysis Results ......... 2.14

2.3 .5 Conclusions ....................... 2.25

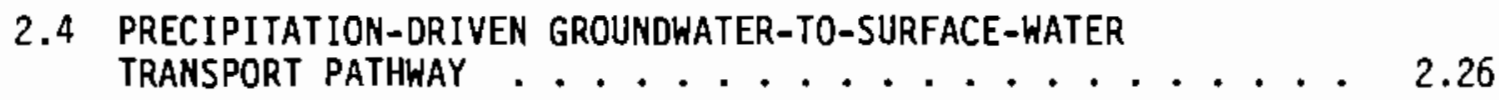

2.4 .1 Site Description ............. 2.26 
2.4.2 Variable Descriptions ............ 2.27

2.4.3 Sensitivity Analysis Results ......... 2.30

2.4 .4 Conclusions ........................ 2.34

2.5 OVERLAND-TO-SURFACE-WATER TRANSPORT PATHWAY $\ldots \ldots . . . .34$

2.5.1 Site Description ................. 2.34

2.5 .2 Variable Descriptions ............ 2.35

2.5.3 Sensitivity Analysis Results ......... 2.37

2.5 .4 Conclusions ...................... 2.40

3.0 ATMOSPHERIC PATHWAYS. . . . . . . . . . . . . 3.1

3.1 STACK RELEASE SCEMARIO . . . . . . . . . . . 3.4

3.1 .1 Site Description. ........... 3.4

3.1 .2 Variable Descriptions ........... 3.4

3.1.3 Stack Scenario Sensitivity Analysis Results .... 3.9

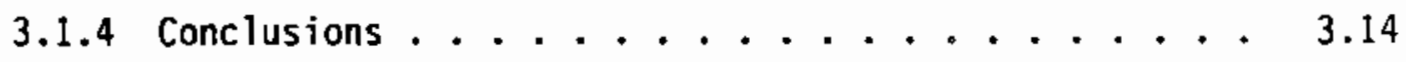

3.2 RESUSPENSION SCENARIO. . . . . . . . . . . 3.14

3.2 .1 Site Description. ...................... 3.14

3.2 .2 Variable Descriptions ........... 3.15

3.2.3 Resuspension Scenario Sensitivity Analysis Results. . 3.19

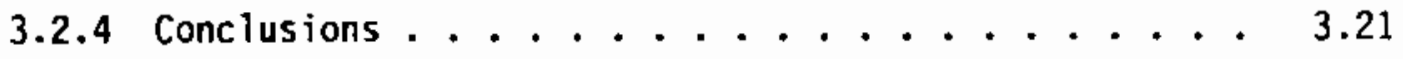

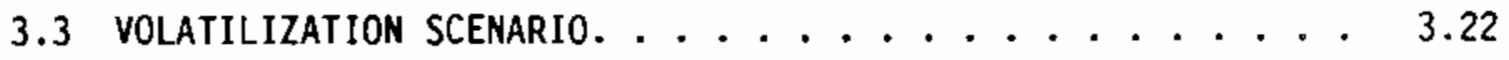

3.3.1 Site Description. ........... 3.24

3.3 .2 Variable Descriptions ................ 3.24

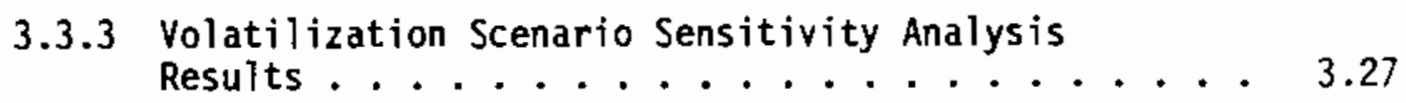

3.3 .4 Conctusions . . . . . . . . . . . 3.29

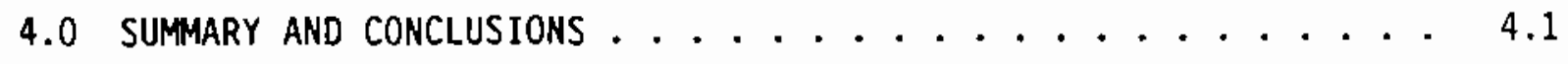




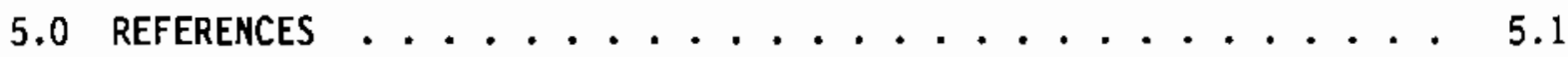

APPENDIX A - Constituent Database . . . . . . . . . . . A.1

APPENDIX B - Sensitivity Analys is Methodology . . . . . . . . . B.1

APPENDIX C - Wind Speed, Wind Direction, and Stability Summary . . . C.1

APPENDIX D - Exposure Route Parameters . . . . . . . . . . . D.1 


\section{FIGURES}

1.1 Simplified Diagram of Multimedia Environmental Pollutant Assessment Systen .................. . . 1.2

2.1 Waterborne Transport Pathway Illustrating Exposure Through Aquatic Life and Agricultural Operations . . . . . . . . 2.2

3.1 Atmospheric Transport Pathway Illustrating Exposure Through Inhalation, Deposition on Crops, and Uptake by Humans and Livestock 


\section{TABLES}

1.1 Tabulation of Transport Pathways and Exposure Routes in U.S.

Department of Energy Environmental Survey. . . . . . . . . 1.5

1.2 Characteristics of Constituents Selected for Sensitivity Analysis...................... . 1.9

2.1 Nominal Values and Variation Ranges of Variables for Nonprecipitation-Driven Groundwater-to-Surface-Water Transport Pathway ................. 2. 2.8

2.2 Classification of Conditions for Five Sensitivity Analyses for Nonprecipitation-Driven Groundwater-to-Surface-Water Transport Pathway .................. 2.12

2.3 Hazard Potential Index Score Ranges for Nonprecipitation-Driven Groundwater-to-Surface-Water Transport Pathways: Cases 1

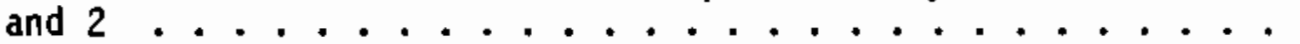

2.4 Most Important Variables Affecting Hazard Potential Index for Nonprecipitation-Driven Groundwater-to-Surface-Water Transport Pathway: Cases 1 and $2 \ldots . . . . . . .$.

2.5 Percent Contribution of Exposure Route to Dose from Groundwaterto-Surface and Overland-to-Surface Transport Pathways . . . . 2.18

2.6 Hazard Potential Index Score Ranges for Nonprecipitation-Driven Groundwater-to-Surface-Water Transport Pathway: Case 3 . . .

2.7 Most Important Variables Affecting Hazard Potential Index for Nonprecipitation-Driven Groundwater-to-Surface-Water Transport Pathway, Case 3, Summarized for Three Analyses . . . . . . .

2.8 Inventories and Associated Fluxes for Constituents in Groundwater: Cases 4 and 5............. . . 2.23

2.9 Hazard Potential Index Score Ranges for Nonprecipitation-Driven Groundwater-to-Surface-Water Transport Pathway: Cases 4 and 5

2.10 Most Important Variables Affecting Hazard Potential Index for Nonprecipitation-Driven Groundwater-to-Surface-Water Transport Pathway: Cases 4 and 5 ...............

2.11 Nominal Values and Variation Ranges of Variables for the Precipitation-Driven Groundwater-to-Surface-Water Transport Pathway 
2.12 Monthly Climatic Conditions Affecting the Precipitation-Driven Groundwater-to-Surface-Water Transport Pathway . . . . . . . .

2.13 Hazard Potential Index Score Ranges for Precipitation-Driven Groundwater-to-Surface-Water Transport Pathway . . . . . . .

2.14 Most Important Variables Affecting Hazard Potential Index for Precipitation-Driven Groundwater-to-Surface-Water Transport

Pathway .......................

2.15 Nominal Values and Variation Ranges of Variables

for Overland-to-Surface-Water Transport Pathway . . . . . . 2.36

2.16 Hazard Potential Index Score Ranges for Overland-to-Surface-Water Transport Pathway ....................

2.17 Most Important Variables Affecting Hazard Potential Index for Overland-to-Surface-Water Transport Pathway . . . . . . .

3.1 Nominal Values and Variation Ranges of Variables for Stack Release Scenario................ 3.6

3.2 Surface Roughness Values for the Areas Surrounding the Waste Ranking Unit .........................

3.3 Population Within 80.5-km Radius of the Stack Release Scenario.......................

3.4 Nominal Values for Production Rates by Town for Stack Release Scenario ......................

3.5 Hazard Potential Index Scores for the Stack Release Downwashing Case .......................

3.6 Most Important Variables for the Stack Release Scenario Downwashing Case . . . . . . . . . . . . . . . . . .

3.7 Percent Contribution of Exposure Route to Dose for Stack Release Scenario Downwashing Case. . . . . . . . . . . . . .

3.8 Hazard Potential Index Values for the Stack Release Nondownwashing Case ....................

3.9 Most Important Variables for Stack Release Scenario Nondownwashing Case. . . . . . . . . . . . . . . . .

3.10 Percent Contribution of Exposure Route to Dose from Stack Release Scenario Nondownwashing Case ..............

3.11 Nominal Values and Variation Range of Variables for Resuspension Scenario........................ 
3.12 Surface Roughness Values for Area Surrounding the Ranking

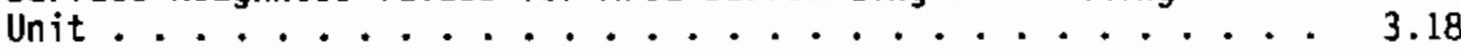

3.13 Population Data for the Site . . . . . . . . . . . 3.19

3.14 Production Rates for the Resuspension Scenario Site. . . . . 3.19

3.15 Hazard Potential Index Scores for the Resuspension Scenario. . . 3.20

3.16 Most Important Variables in Determining Hazard Potential Index Value for Resuspension Scenario. . . . . . . . . 3.20

3.17 Percent Contribution of Exposure Route to Dose for Resuspension Transport Pathway. ............... 3.22

3.18 Nominal Values and Variation Ranges of Variables for Volatilization Release Scenario............. 3.25

3.19 Surface Roughness Values for the Area Surrounding the Ranking Unit.................. 3.26

3.20 Population Distribution Data for the Hypothetical Site . . . . 3.27

3.21 Hazard Potential Index Scores for Volatilization Scenario. . . 3 3.28

3.22 Most Important Variables in Determining Hazard Potential Index values for the Volatilization Release Scenario . . . . 3.28

3.23 Percent Contribution of Exposure Routes to Dose for Volatilization Scenario.................. 3.28

4.1 Hazard Potential Index Values and Ranges ... . . . . . . 4.4

4.2 Important Variables for Groundwater and Overland Transport Pathways ....................... 4.6

4.3 Most Important Variables for the Atmospheric Transport Pathway. . . . . . . . . . . . . 4.9

4.4 Sensitivity Analysis Model Variability as a Function of Transport Scenarios and Constituent Type ......... 


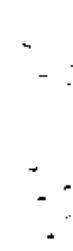




\subsection{INTRODUCTION}

The Multimedia Environmental Pollutant Assessment System (MEPAS) is being developed by Pacific Northwest Laboratory (PNL) for the U.S. Department of Energy (DOE). MEPAS is a tool that is being used to provide input to DOE's Environmental Survey ranking of DOE's environmental problems. MEPAS provides risk estimates based on impacts to human health in the surrounding populations.

MEPAS consists of a system of interconnected groundwater, surface water, and atmospheric transport models that interface with exposure pathway and dose models (Figure 1.1). Many of these models are similar to those presented in the U.S. Environmental Protection Agency (EPA) Superfund Exposure Assessment Manual (EPA 1988). The methodology is used to predict the transport of a contaminant from its source by evaluating the potential routes from a site (groundwater, surface water, overland, and atmosphere) to locations of human exposure and estimating the health effects. The output of the system of models includes the risk to both individuals and nearby populations. The organization of the MEPAS codes and the mathematical descriptions of the individual models and the HPI are given in whelan et al. (1987) and Droppo et al. (1989b).

An output from MEPAS that was used in the sensitivity analys is described in this report is a quantity called the Hazard Potential Index (HPI). The HPI was used in the preliminary ranking of DOE's 16 defense production facilities in a report sumarizing the Environmental Survey (DOE 1988). The HPI is a time-weighted measure of the risks based on health effects to the nearby population multiplied by the size of the affected population. The time weighting in the HPI calculation is used to discount health effects that occur in the distant future relative to those that could occur in the near term (i.e.., first $70 \mathrm{yr}$ ).

The computer codes composing MEPAS require definition of many input variables that are based on measured or site-specific quantities, such as hydrologic and meteorological parameters, and on the population distribution and land-use patterns in the areas surrounding the sites. These parameters are input to MEPAS through a user-friendly shell. Because of the sequential 


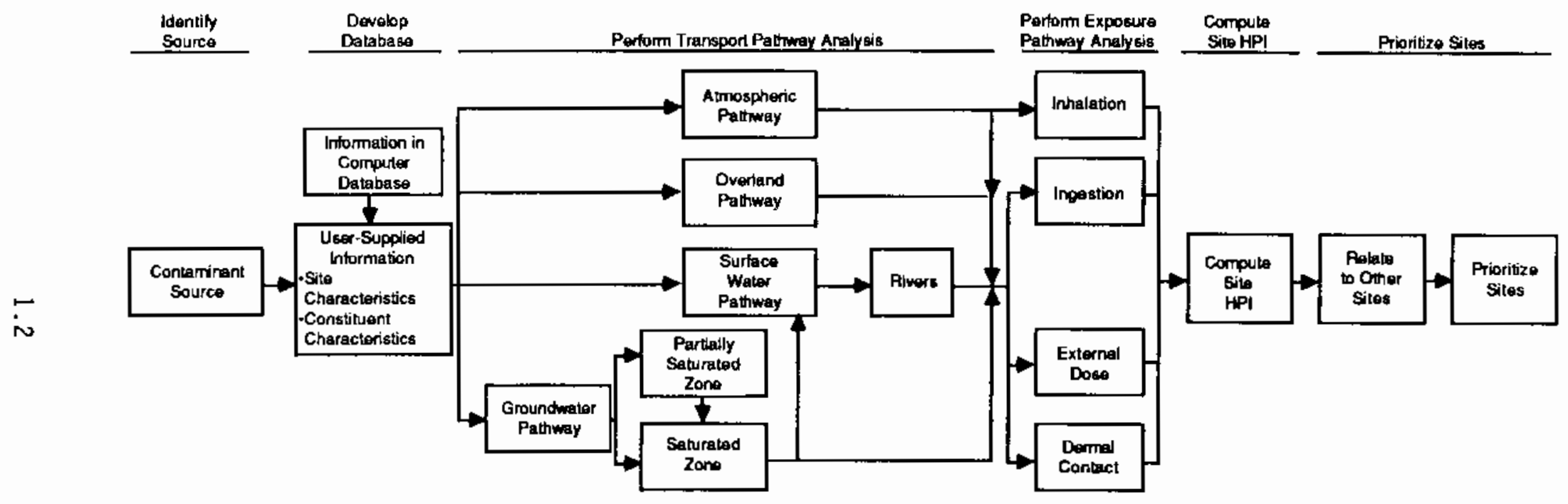

FIGURE 1.1. Simplified Diagram of Multimedia Environmental Pollutant Assessment System (after Whelan et a1. 1987) 
and flexible coupling of the transport and exposure codes, the effects of input variables on the resulting HPI score are not always readily apparent. Therefore, as part of the MEPAS development and evaluation, a formal parametric sensitivity analysis was performed to determine the sensitivity of the model output (HPI score) to the input variables. A formal parametric sensitivity analysis is a systematic objective method for determining the relative importance of input parameters to a model. This importance is determined by the amount of variability in the HPI explained by the input parameters.

There are two major benefits to be obtained from performing a formal parametric sensitivity analysis:

1. Determining which variables are most important in calculating the HPI. Ideally, these influential variables would also be plausible, lending credibility to the methodology.

2. Determining how sensitive the model results are to reasonable changes in the input data (i.e., those reflecting uncertainty in the values of the input parameters). Ideally, only small changes in HPI will result from small changes in any input parameters.

The results of the sensitivity analysis can be employed by users of MEPAS in several ways. First, the results of the sensitivity analysis can be used to determine the inherent baseline variability of the different components of MEPAS for a well-characterized site. Second, the results can be used to determine which input variables will have the greatest impact on HPI based on the predominant transport pathways for a particular environmental problem of interest. The user can direct resources to determining the value of variables with greater influence on the final HPI value. If accurate values of these variables are not available from previous site characterization studies, then the user may wish to conduct a simple perturbation analysis to evaluate the effect of reasonable alternative values of the variable on the HPI. In a perturbation analysis, input variables of interest are increased or decreased by a selected amount to determine that particular variable's influence on the HPI. 


\subsection{APPROACH}

To conduct a sensitivity analysis for MEPAS, we selected 1) a set of the transport pathways and exposure routes, 2) a set of constituents, and 3) ranges in the values for the input parameters. As described below, these exposure pathways, constituents, and input parameters were selected as representative of DOE's Environmental Survey (DOE 1988). The ranges for the input parameters were based on the limits of measurement techniques or inherent variability to represent a well-characterized site. Once the transport pathways and exposure routes and associated data are chosen, then the sensitivity analysis can be run.

\subsubsection{Transport Pathways and Exposure Routes}

Figure 1.1 shows a schematic of the steps in the risk assessment process and indicates the four major transport pathways and four exposure routes included in MEPAS. There are 22 possible combinations of transport pathways and exposure routes indicated on Figure 1.1. In addition, there are subpathways within the major pathways, so the number of possible combinations is much larger than presented in the figure. Not all combinations of transport pathways and exposure routes are possible because the exposure route depends on the final transport pathway. For example, use of the drinking water exposure route requires that the last transport pathway be surface water or groundwater, which is one of the 22 possible combinations.

A complete sensitivity analys is of MEPAS would require that the analysis be completed for all potential transport pathway and exposure route combinations, constituents, and potential ranges of the input variables. Such an analysis is prohibitive in terms of time and computer analyses.

To provide limits on the sensitivity analysis, the transport pathway and exposure route combinations were selected to represent those used to evaluate the potential environmental problems at DOE production sites (DOE 1988). In the Environmental Survey, DOE identifies environmental problems as ranking units, which are similar in practice but not necessarily equivalent to EPA's operable units. The results of this analys is of the transport pathways and exposure routes used to represent pathways from the ranking units are given in Table 1.1, which shows the frequency of use and therefore the relative 
IABLE 1.1. Tabulation of Transport Pathways and Exposure Routes in U.S. Department of Energy Environmental Survey

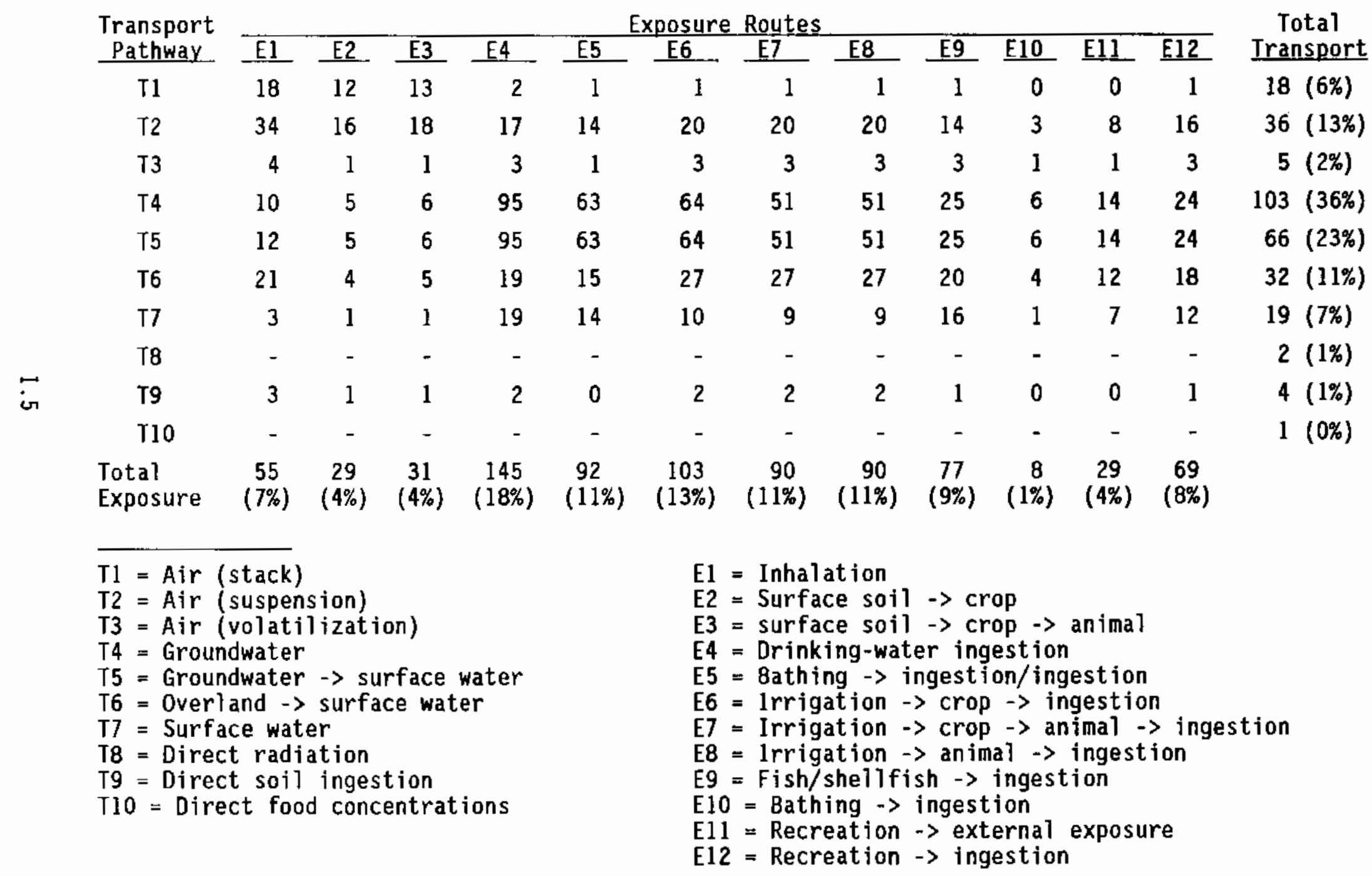


importance of the various transport-exposure pathway combinations for evaluating DOE's environmental problems. The transport pathways, T1 through T10, are listed by row, and the exposure routes, E1 through E12, are listed by column with the description of each pathway and route given at the bottom of the table. The number in each cell of Table 1.1 indicates the number of ranking units that used this combination of transport pathway and exposure route. The total number of ranking units using each transport pathway is listed in the first column of the table, and the total T1.1 number of times each exposure pathway was employed is listed in the last row of the table. The total number of ranking units (sum of last column) using all transport pathways does not necessarily add to 203 (the number of ranking units analyzed in DOE 1988), because more than one transport pathway can contribute to human exposures for a given ranking unit. Also, the total number of sites using a particular exposure route does not necessarily equal the number of sites using a transport pathway because multiple exposure pathways nomally occur for each transport pathway.

According to Table 1.1, the dominant transport pathways used in DOE's Environmental Survey are the atmospheric transport pathways, T1 through T3, and the waterborne pathways, T4 through $T 7$. The direct radiation (T8), soil ingestion (T9), and food concentration (T10) transport pathways were used to evaluate less than $2 \%$ of the ranking units. The waterborne transport pathways [groundwater (T4), groundwater to surface water (T5), overland runoff to surface water (T6), and surface water (T7)] constitute $77 \%$ of the pathways used. Therefore, the sensitivity analysis will evaluate only these atmospheric and waterborne transport pathways. Furthermore, because the groundwater transport pathway (T4) is one part of the broader groundwaterto-surface-water pathway (T5), and the surface-water pathway (T7) is included as part of both the groundwater-to-surface-water (T5) and overlandto-surface-water pathways (T6), it was decided that these two single-inedia transport pathways (T4 and T7) would not be analyzed separately for this report. Thus, the waterborne pathways that will be analyzed are the groundwater-to-surface-water (T5) and overland-to-surface-water (T6) transport pathways. All three atmospheric pathways were included in this analysis because of their potential for immediate exposure to nearby populations through inhalation. 
According to Table 1.1, the primary exposure routes for the waterborne transport pathways were drinking-water ingestion (E4), ingestion and inhalation during bathing (E5), irrigation to crop to ingestion (E6), irrigation to crop to animal to ingestion (E7), irrigation to animal to ingestion (E8), fish/shellfish to ingestion (E9), and ingestion by recreation (E12). To facilitate potential comparisons, the exposure routes E4 and E9 were used with all the waterborne transport pathways in this analysis. Exposure route E12 (ingestion by recreation) was not included in the analys is because this pathway normally contributes little to human exposure compared to the other pathways. The exposure routes E1 through E3 were used with the stack release and resuspension scenarios for atmospheric transport pathways because inhalation (E1), surface soil to crop (E2), and surface soil to crop to animal (E3) exposure routes have been shown to contribute the most to human exposure for these transport pathways. Only exposure route E1 was used for the volatilization scenario for the atmospheric pathway.

\subsubsection{Constituents}

The MEPAS chemical constituent database contains information on the physical/chemical and toxicological characteristics of 392 constituents (Strenge and Peterson 1989). Just as it was not feasible to conduct the sensitivity analysis for all potential transport pathways and exposure routes, it is impossible to conduct the sensitivity analysis for all 392 constituents. Therefore, a set of constituents that represent the range in types of chemicals and radionuclides found at DOE hazardous ranking units were selected from the chemical database for inclusion in the sensitivity analysis. Specifically, the selected constituents had to meet the following criteria.

- The list of constituents had to include radionuclides and inorganic and organic chemicals.

- The list of radionuclides had to include at least one radionuclide described by the standard exposure pathway models and one for which a special model must be used.

- The list of organic chemicals had to include volatile and nonvolatile chemicals.

- The list of volatile organic chemicals had to include at least one chemical that in the atmospheric pathway behaves as a nondepositing 
gas and one that is released to the atmospheric pathway as a gas but deposits as a particulate.

Eight constituents that satisfy the above criteria were selected for the analysis. Table 1.2 lists the chemical type, volatility, exposure model type, and air pathway deposition type. In the special model for tritium ( $3 \mathrm{H})$ in the atmospheric patiway, the specific activity of $3 \mathrm{H}$ in the plant is calculated by assuming it is equal to its specific activity in the atmospheric moisture. Yttrium, 90Y, is the decay product of strontium, $90 \mathrm{Sr}$. For the groundwater pathway, the concentration of $90 \mathrm{Y}$ is calculated from the decay of the $90 \mathrm{Sr}$. Furthermore, the transport parameters for $90 \mathrm{Y}$ in the groundwater are assumed to be identical to those for $90 \mathrm{Sr}$. In the atmosphere, polychlorinated biphenyls (PCBs) release as a gas but sorb onto particulates in the air and then deposit with the particulate phase. Tritium deposits as a gas. The constituent information is given in Appendix $A$.

\subsubsection{Input Variables}

MEPAS uses two types of data: a constituent database, and sitespecific input data. In typical MEPAS applications the existing constituent database will be used. Because the user does not input these data, the parameters in the constituent database were not evaluated in the sensitivity analysis. The second set of data, the site-specific data, must either be determined based on characterization or selected from typical values. Therefore, the sensitivity analyses focused on evaluating the impact on HPI of these site-specific variables, such as local hydrologic and atmospheric variables and local population and food production values. The transport and exposure pathways in most cases define which input variables are required.

The specific variables required for each combination of transport pathways and exposure routes and the nominal values for the variables with their uncertainty are given before the results of the sensitivity analysis.

Nominal values were selected for each of the input variables for each transport pathway and exposure route combination. These nominal values, used in the sensitivity analysis to provide a base case, were selected by adjusting inventory concentrations to obtain HPI scores of approximately 25. If adjusting constituent inventories did not result in the desired HPI score, 
TABLE 1.2. Characteristics of Constituents Selected for Sensitivity Analys is

\begin{tabular}{|c|c|c|c|c|}
\hline Constituent & $\begin{array}{l}\text { Chemical } \\
\text { Type }\end{array}$ & Volatile & $\begin{array}{c}\text { Exposure } \\
\text { Mode1 } \\
\text { Type } \\
\end{array}$ & $\begin{array}{c}\text { Air } \\
\text { Deposition Type }\end{array}$ \\
\hline Arsenic (As) & Inorganic & No & Standard & Particulate \\
\hline Mercury $(\mathrm{Hg})$ & Inorganic & No & Standard & Particulate \\
\hline $\begin{array}{l}\text { Polychlorinated } \\
\text { byphenyl (PCBs) }\end{array}$ & Organic & No & Standard & Gas as particulate \\
\hline Strontium-90 $\left({ }^{90} \mathrm{Sr}\right)$ & Radionuclide & No & Standard & Particulate \\
\hline $\begin{array}{l}\text { Perch loroethylene } \\
\text { (PCE) }\end{array}$ & Organic & Yes & Standard & Nondepositing gas \\
\hline Toluene & Organic & Yes & Standard & Nondepositing gas \\
\hline Tritium $(3 \mathrm{H})$ & Radionuclide & Yes & Special & Depositing gas \\
\hline Yttrium-90 (90Y) & Radionuclide & No & Standard & Particulate \\
\hline
\end{tabular}

site-specific variables were also adjusted in a physically reasonable fashion to obtain the target HPI value. The other variables were chosen to represent the conditions at a representative site. As a result, the transport and exposure pathways, constituents, and the nominal values of the input variables used for this sensitivity analys is do not necessarily describe any specific ranking unit in the Environmental Survey but rather a representative ranking unit.

In addition to selecting nominal values for each input variable, estimates of site-specific variation in the input variables were defined. It is difficult to estimate this variability because often there is little measured data at a ranking unit, and even less information on the spatial and temporal variability of the measurements. However, the lack of measured variability values does not limit the parametric sensitivity analys is because the effect of different choices for parameter variability can be evaluated. Generally, if the variable is considered to be relatively well known, then the variability would be approximately $* 10 \%$, which is representative of the typical variability resulting from measurement error. For less wellcharacterized parameters, and ones that have spatial or temporal variability as well, the range would increase. 
The variability in the site-specific parameters was chosen to be $\$ 10 \%$ to $\pm 20 \%$, depending on what was known about each parameter. By choosing the variability of all the parameters to be approximately equal, the influence of the parameters can be determined independent of the effect of their variability. However, for parameters with higher measurement errors or spatial and temporal variability, the influence of this higher variability on the ordering of the influential variables was evaluated.

\subsubsection{Sensitivity Analysis}

After the transport pathways and exposure route combinations, constituents, and nominal site variable values and uncertainties were selected, the sensitivity analysis was conducted. The term "sensitivity" is used in several ways when discussing mathematical models and the relationship anong their input and output variables. Sensitivity is referred to qualitatively as the importance of an input variable in determining the value of an output variable. An input variable is a "high-sensitivity" variable if, by changing its value by a "small" amount, there is a "large" change in the model output. Conversely, a low-sensitivity variable is one for which small changes in its value produce small changes in the value of the output variable. However, the terms "large" and "small" are not generally well defined.

Sensitivity can be defined quantitatively in terms of the value of a partial derivative that measures the change in an output variable for a unit change in an input variable. For example, for the output variable $Y=f\left(X_{1}\right.$, $\left.\ldots, x_{n}\right)$, which is a function or model of $n$ input variables $x_{1}, \ldots, x_{n}$, the instantaneous partial derivative with respect to input variable $x_{1}$ is

$$
\stackrel{c y}{c x_{1}} \mid x_{2}, \ldots, x_{n}
$$

The partial derivative is determined with respect to one input variable when the values of the other $n-1$ input variables $\left(x_{2}, \ldots, x_{n}\right)$ are fixed. Thus, there are potentialiy $n$ partial derivatives for each point. Methods for calculating these partial derivatives are discussed in Appendix $B$. 
The relative importance of the input variables can be determined by ordering the normalized partial derivatives (normalized to their nominal values). The variable with the largest nomalized partial derivative is the most important variable in determining the value of the output variable. This ranking is only valid if all of the input variables are unrelated (i.e., independent). If the input variables cannot be assumed to be mutually independent of each other, which may be the case for models with many input variables, such as MEPAS, then ranking the importance of the input variables based only on the value of the partial derivatives can be misleading. For example, two input variables may both have the same normalized partial derivative, but they may be highly correlated. The high correlation results in the amount of information relating to the output variables being the same and the variables being redundant in the analysis.

The statistical approach used in this sensitivity analysis (Appendix B) deals explicitly with the fact that the input variables may be correlated. In this approach, it is assumed that the input variables are random variables; that is, subject to measurement error and/or spatial or temporal uncertainty and not known exactly. The input variables are allowed to vary within their expected uncertainty and the model output determined for each combination or realization of the input variables. A linear model of input variables is then fit to the output of the multiple realizations of the model. The fitting of the linear model accounts for the correlations among the input variables. The partial regression coefficients (or equivalentiy, the partial $\mathrm{R}^{2}$ for the variable) are used to estimate the importance of the individual input variables in determining the value of the model output with the effects of the other variables removed. The input variables are ranked in a hierarchical fashion based on the value of the partial regression coefficients or the partial $R^{2}$ values. In this analysis, the partial $R^{2}$ of each variable, which is the fraction of the variation in the output variable (for this case the HPI) that is attributed to that variable, is used to rank the variables. A total $R^{2}$ of 1.0 denotes perfect agreement between the predicted and actual HPI scores. The larger the partial R2 for a variable, the more important that variable is in determining the value of the output variable. This approach factors out the redundancy of information in the input variables resulting from their correlation. 


\subsection{SCOPE OF SENSITIVITY ANALYSIS}

In summary, the sensitivity analysis performed for MEPAS focuses on determining the sensitivity of the HPI values to input parameters associated with combinations of transport pathway and exposure routes that are important to evaluating DOE's environmental problems. The combinations of transport pathways and exposure routes selected for analysis were described in Section 1.1.1. The constituents used in the sensitivity analysis (Table 1.2) were selected to represent constituents of concern at DOE sites and to represent a range in physical, chemical, and toxicological properties. Furthermore, the sensitivity analysis focuses on evaluating the effect on the HPI value of uncertainties in the site-specific information for which the user must specify or choose default values (Section 1.1.3).

The ranges in the site-specific parameters were chosen for a representative site that is generally well characterized. This wellcharacterized site represents the smallest HPI variability expected from MEPAS and defined the base case variability of MEPAS for the transport pathways and exposure route analyzed. Although the uncertainty in the physical, chemical, and toxicity parameters in the constituent database may have a significant impact on the HPI as well, in practice the user does not specify these data; therefore, they are not included in this analysis. The sensitivity analysis, therefore, focuses on evaluating the portion of the MEPAS application that the user can specify.

\subsection{ORGANIZATION OF THE REPORT}

The sensitivity analysis of the MEPAS code for the major transport pathways, waterborne and atmospheric, is described in Chapters 2.0 and 3.0 , respectively. The waterborne pathways are divided into groundwaterto-surface-water and overland-to-surface-water pathways. The groundwaterto-surface-water pathway is further divided into precipitation-driven and nonprecipitation-driven transport pathways. The atmospheric transport pathways are divided into stack release, resuspension, and volatilization. Each section on a transport pathway has subsections describing the salient features of the model, a site description, a description of the input variables that are included in the analysis with their associated uncertainties, 
and the results of the statistical sensitivity analysis (i.e., a description of the important variables). The overall results of the sensitivity analys is are summarized and the conclusions are discussed in Chapter 4.0. Chapter 5.0 lists references. The constituent database is given in Appendix A. Appendix $B$ provides a brief description of the formal sensitivity analysis methods that are used in the analyses. Appendix $C$ contains the joint frequency distribution for the atmospheric transport pathways, and the exposure assessment parameters used in the code are provided in Appendix D. 


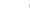




\subsection{WATERBORNE PATHWAYS}

\subsection{INTRODUCTION}

Human exposure to hazardous materials can occur as the result of movement of these materials in groundwater, in overland flow, and in surface water (Figure 2.1). The source of these materials may be disposal pits, landfills, ponds, or ground surfaces. Alternatively, the material may be directly discharged to groundwater or surface water.

\subsubsection{Groundwater Pathway}

Constituents released from contaminated soils, landfills, or ponds generally migrate through a partially saturated zone before reaching the groundwater. In MEPAS, water flow and contaminant movement are assumed to be in a vertically downward direction in the partially saturated zone, and the soils are assumed to be at unit hydraulic gradient conditions. The unit hydraulic gradient assumption allows a partially saturated zone velocity to be computed. Under the unit hydraulic gradient condition, if the infiltration rate is less than the soil transmission rate (partially saturated hydraulic conductivity), the water moves downward through the soil at the infiltration rate. If the infiltration rate is equal to or greater than the transmission rate, as is the case with ponded wastes, the water is assumed to move through the soil at the soil transmission rate.

Contaminant transport through the partially saturated zone is described by a one-dimensional, unsteady-state solution to the advection-dispersion equation (see Van Genuchten and Alves 1982; Donigian et al. 1983). In the analytical solution to the transport equation, the partially saturated zone soil parameters are assumed to be homogeneous and isotropic, and the moisture content is assumed to fluctuate between field capacity and saturation. Field capacity is a general term that describes the limit of soil-water drainage (see Hanks and Ashcroft 1980; Hillel 1980). In the partially saturated zone, dispersion is assumed to occur only in the longitudinal (vertical) direction.

Once contaminants reach the saturated zone or the groundwater, the predominant movement is assumed to be in the direction of groundwater flow. A one-dimensional advection/three-dimensional dispersion equation is used to 


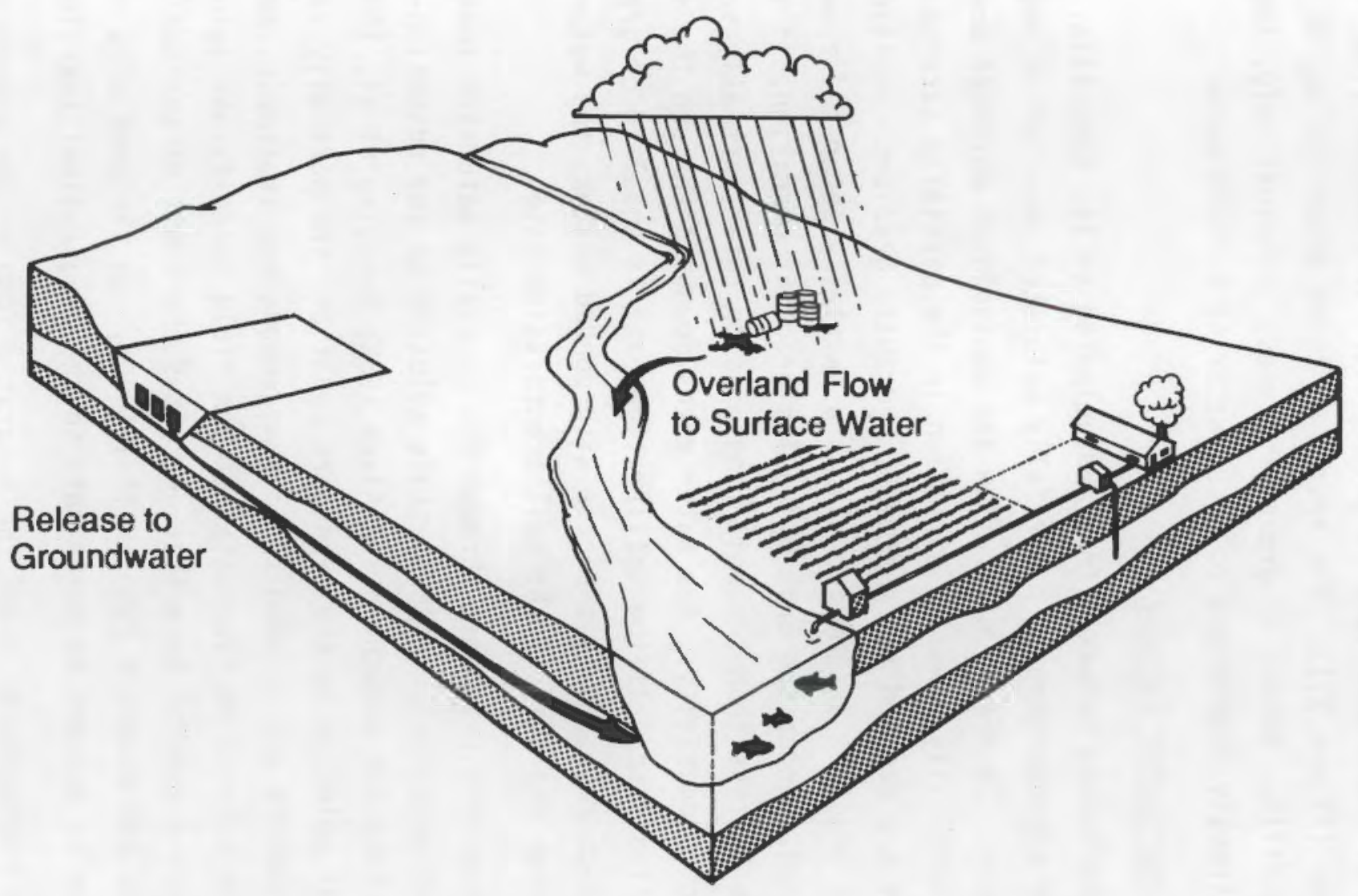

FIGURE 2.1. Waterborne Transport Pathway Illustrating Exposure Through Aquatic Life and Agricultural Operations 
describe the plume as it migrates and disperses in the groundwater. Advection represents the transport of contaminants caused by mass motion of the water. In MEPAS, the advection term is described by the groundwater velocity for steady-state conditions, which is defined by the user. The groundwater flow velocity can be determined based on simple hand calculations or by using more complex groundwater models that predict groundwater flow paths. Dispersion represents contaminant transport by variations in the fluid velocity and molecular motion. Dispersion is considered in the longitudinal (along the direction of mass movement), lateral, and vertical directions, providing three-dimensional definition to the transport solution. Aquifer and transport properties are assumed to be homogeneous.

The analytical solutions of the advection-dispersion equation for the partially saturated and saturated zones have been formulated in terms of instantaneous contaminant releases (i.e., pulse releases). MEPAS generalizes these solutions for time-varying contaminant releases by combining response functions (i.e., time-varying contaminant release or flow rates) with solutions for instantaneous contaminant releases. Thus, continuous releases are approximated by a series of instantaneous pulse releases. Contaminant fluxes from the groundwater environment to the surface-water environment are calculated, based on the concentrations at interfaces between groundwater and surface-water bodies.

Contaminant concentrations for exposure estimates are calculated as 70-yr averages at wells and the edges of surface-water bodies. The solution algorithms for contaminant concentrations and contaminant fluxes are based on Green's functions that have been reported by several researchers (e.g., Yeh 1981; Codell et al. 1982; Van Genuchten and ATves 1982). Mass balance is conserved between all the waterborne pathways to provide a complete simulation of contaminant movement through multiple media via multiple pathways.

\subsubsection{Surface-Water Transport Pathway}

The nontidal river component of MEPAS was addressed in the sensitivity analysis. Nontidal rivers refer to freshwater bodies with unidirectional flow in definable channels. 
In MEPAS, releases to the surface-water environment are assumed to be continuous, so they are evaluated over relatively long-term time frames. Therefore, in MEPAS, steady-state solutions of the advection-dispersion equations are used appropriately to describe surface-water transport.

A description of contaminant transport in nontidal rivers is based on steady, unidirectional flow in a straight, rectangular channel. Contaminants released into a river are transported by the processes of advection and dispersion. In riverine environments, longitudinal advection dominates longitudinal dispersion (Codell et a1. 1982), so the one-dimensional advective approach is appropriate. A one-dimensional, advective, steady-state, vertically averaged mass balance equation with two-dimensional (longitudinal and lateral) dispersion is used to describe contaminant transport in nontidal rivers.

\subsubsection{Overland Transport Pathway}

Overland flow is that portion of precipitation that appears as flowing water on the ground surface. Overland flow results when rainfall or snowmelt are in excess of the total amount of precipitation that is intercepted by vegetation, lost to the atmosphere by evapotranspiration, or infiltrated into the underlying soils. Overland flow also occurs when, as a result of geologic conditions, groundwater surfaces in springs and enters drainage pathways such as streams and rivers. As indicated in Figure 2.1, the overland transport pathway can connect with the surface waier pathway or directly provide contaminant levels to the exposure assessment component of MEPAS. Overland flow results in the migration of contaminated water and sediment from sites that have contaminated surface soils (e.g., exposed wastes at unprotected landfil1s). In addition to these uses of the overland transport component of MEPAS, the component is included in water balance calculations that determine the amount of infiltration for precipitationdriven transport. The mathematical algorithms describing the MEPAS overland pathway are summarized in whelan et al. (1987).

Characteristics of affected watersheds and hazardous ranking units are used to compute overland water movement and subsequent contaminant transport. MEPAS uses the curve number technique of the U.S. Department of Agriculture's Soil Conservation Service (SCS) as presented by SCS (1972, 1982), Kent 
(1973), the U.S. Bureau of Reclamation (USBR 1977), and Haun and Barfield (1978) to model overland flow. This method is similar to the method of characteristics illustrated by Eagleson (1970), Hjelmfelt (1976), Witinok (1979), Whelan (1980), and Witinok and the Tan (1980).

The empirical SCS curve number technique uses a number of site characteristics to compute the overland flow. These include soil classification, type of soil cover, past and current land-use treatment practices, hydrologic conditions for infiltration, locale (within the United States), initial moisture content, antecedent moisture conditions, and potential maximum moisture retention. Overland flow is calculated based on these site characteristics as well as local monthly climatological data.

The movement of contaminated sediments from a ranking unit is predicted using the Universal Soil Loss Equation (USLE). The USLE is an empirical method that was derived from considerable erosion data from field plots. The USLE considers 1) the erosive force and intensity of precipitation and runoff in a normal year, 2) the susceptibility of soil particles to detach and be transported by runoff, 3) the combined effects of slope length and gradient, and 4) the soil loss from lands with different types of vegetation coverage (Goldman et al. 1986).

The sensitivity analysis focused on determining the important variables affecting HPI from the groundwater, overland flow, and surface water transport pathways. The groundwater pathway was further divided into nonprecipitation-driven and precipitation-driven transport pathways. A major route to human exposure for the waterborne pathway is through drinking water. Because the sources of drinking water for many people are surface-water bodies, the groundwater and overland flow pathways were combined with a surface-water transport component. The combined transport pathways are consistent with those used in the DOE Environmental Survey (DOE 1988).

\subsection{GROUNDWATER-TO-SURFACE-HATER TRANSPORT PATHHAY}

The groundwater segment of the groundwater-to-surface-water transport pathway in MEPAS includes 1) the leachate generation at or contaminant release from a ranking unit, 2) the transport through the partially saturated 
(unsaturated or vadose) zone, and 3) the transport through the saturated zone (groundwater in an aquifer). The quantity of contaminants released from a ranking unit over a specified time (i.e., release rate) is an important input variable for determining quantity of constituent transported in the groundwater pathway. The release rate of contaminants into the partially saturated zone can be characterized in two ways: 1) cases where release rates are known and can be input directly to MEPAS are referred to as nonprecipitation-driven, and 2) cases where the contaminant release rate is unknown and computed by MEPAS based on climatological conditions are referred to as precipitation-driven.

\subsection{NONPRECIPITATION-DRIVEN GROUNDWATER-TO-SURFACE-WATER TRANSPORT PATHWAY}

The environmental problems that can be simulated with the nonprecipitation-driven groundwater-to-surface-water transport pathway include a landfill, pond, underground storage tank, and surface spill or surface contamination for which leachate or constituent release rates are known, have been measured, or can be estimated directly.

\subsubsection{Site Description}

The representative ranking unit for modeling nonprecipitation-driven groundwater transport is located in an arid environment. Contaminants are released from the source and migrate vertically through the partially saturated zone to the water table. The soil and subsurface material at the site is classified as sand to sandy loam. The contaminants are then transported in the direction of groundwater flow in an unconfined aquifer to a river that is $5 \mathrm{~km}$ away. Downstream from the point of groundwater discharge to the river, water is pumped from the river for domestic use by a city with a population of 100,000 . The exposures are through drinking water and through consumption of finfish from the river.

\subsubsection{Variable Descriptions}

Two types of input variables are required by MEPAS to describe the groundwater-to-surface-water transport pathway. The first type of variables describes the source term and soil and transport characteristics for each contaminant. For the nonprecipitation-driven groundwater transport pathway, 
properties of the source term that are specified include the constituent inventory, ranking unit dimensions, and liquid release rate to the partially saturated zone. Other input variables include the dimensions of the partially saturated zone (depth), soil characteristics (bulk density, porosity, field capacity, hydraulic conductivity, and soil-type exponent), and transport characteristics (longitudinal dispersivity and the constant describing partitioning of the constituent between water and soil, $K_{d}$ ). Saturated zone characteristics required by MEPAS include pore-water velocity, bulk density, porosity, aquifer depth, and distance to the river. The transport properties for the saturated zone are $\boldsymbol{K}_{\boldsymbol{d}}$ and longitudinal, transverse, and vertical dispersivities. The dispersivities are calculated from the distance to the river using a simple formula. Data required on the characteristics of the river are flow rate, depth, width, and distance to the receptor (referred to as length).

The second type of input variables are used to estimate exposures. The required information consists of the population using water for drinking and the river finfish production rate.

The variables included in the sensitivity analysis are listed in Table 2.1, along with their base case or nominal values and their assumed variations. The variables that are indented in the listing are calculated from the variable(s) preceding them. Because their values are completely determined by the values of the preceding variables, they were not included as independent variables in the sensitivity analysis. However, their values will vary dependently with the variation in the variables from which they are calculated.

The inventories for each of the constituents were chosen to ensure HPI values greater than zero. The inventories were varied $\pm 10 \%$ by assuming that the source at the representative site was well characterized. Larger variations in inventories will likely translate into a larger range in HPI values than those given in this report. Inventory and $K_{d}$ values are not given for $90 \mathrm{Y}$ because it is a $905 \mathrm{r}$ decay product. 
TABLE 2.1. Nominal Values and Variation Ranges of Variables for Nonprecipitation-Driven Groundwater-to-Surface-Water Transport Pathway

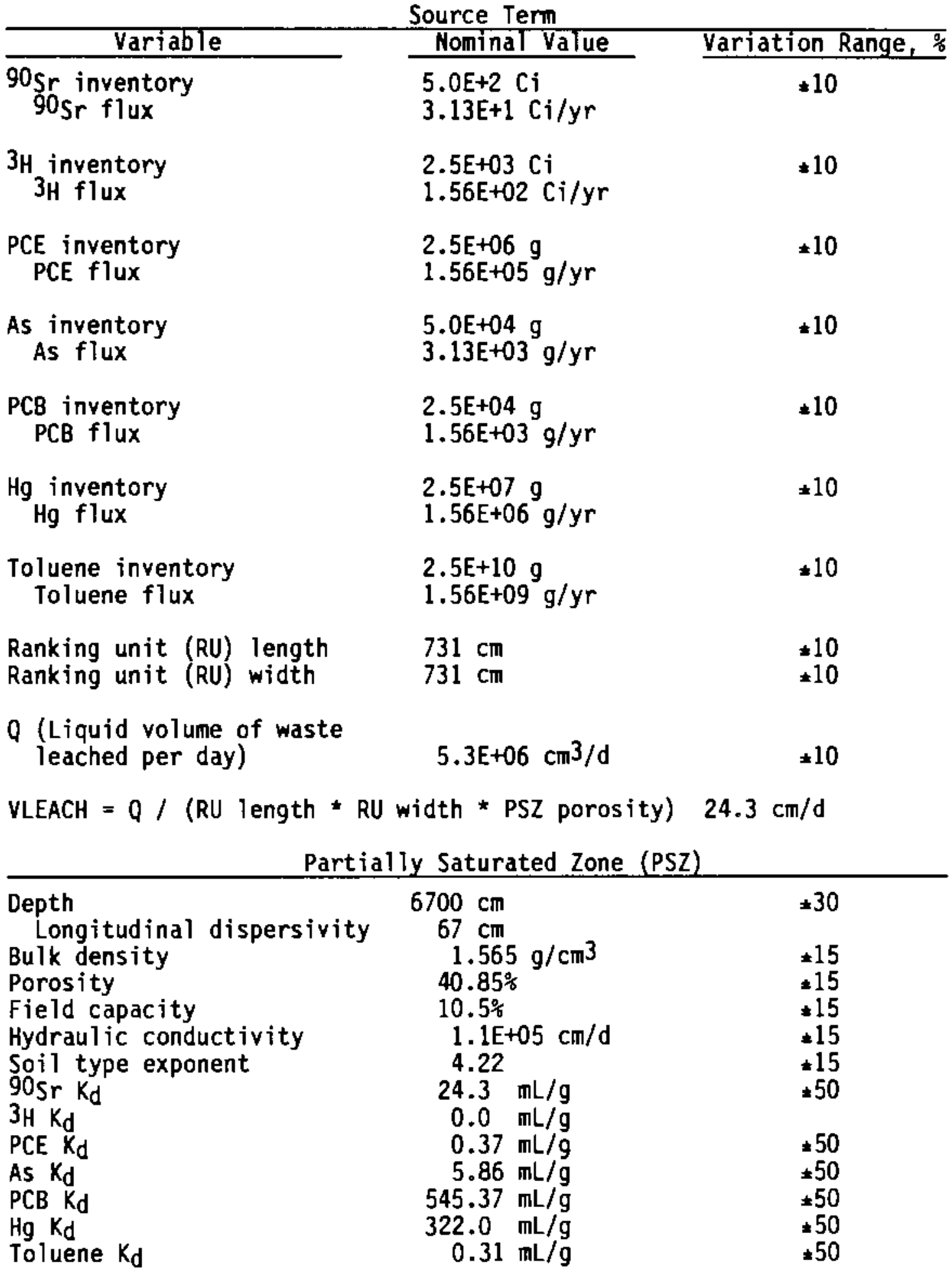


TABLE 2.1. (contd)

Saturated Zone

\begin{tabular}{|c|c|c|}
\hline Variable & Nominal value & Variation Range, \\
\hline $\begin{array}{l}\text { Pore-water velocity } \\
\text { Depth } \\
\text { Bulk density } \\
\text { Porosity } \\
\text { Field capacity } \\
\text { Distance downgradient } \\
\text { Longitudinal dispersivity } \\
\text { Transmissivity dispersivity } \\
\text { Vertical dispersivity } \\
90 S K_{d} \\
3 H K_{d} \\
\text { PCE } K_{d} \\
\text { As } K_{d} \\
\text { PCB } K_{d} \\
\text { Hg Kd } \\
\text { Toluene } K_{d}\end{array}$ & $\begin{array}{l}3.0 \mathrm{E}+02 \mathrm{~cm} / \mathrm{d} \\
8300 \mathrm{~cm} \\
1.565 \mathrm{~g} / \mathrm{cm}^{3} \\
40.85^{\circ} \\
10.5^{\circ} \\
5.0 \mathrm{E}+05 \mathrm{~cm} \\
5.00 \mathrm{E}+04 \mathrm{~cm} \\
1.00 \mathrm{E}+04 \mathrm{~cm} \\
5.80 \mathrm{E}+01 \mathrm{~cm} \\
24.3 \mathrm{~mL} / \mathrm{g} \\
0.0 \mathrm{~mL} / \mathrm{g} \\
0.25 \mathrm{~mL} / 9 \\
5.86 \mathrm{~mL} / \mathrm{g} \\
361.99 \mathrm{~mL} / \mathrm{g} \\
322.0 \mathrm{~mL} / \mathrm{g} \\
0.20 \mathrm{~mL} / 9\end{array}$ & $\begin{array}{l} \pm 15, \pm 95 \\
\pm 30 \\
\pm 15 \\
\pm 15 \\
\pm 15 \\
\pm 10\end{array}$ \\
\hline \multicolumn{3}{|c|}{ River } \\
\hline $\begin{array}{l}\text { Depth } \\
\text { Width } \\
\text { Length (distance to receptor) } \\
\text { Discharge }\end{array}$ & $\begin{array}{l}780.0 \mathrm{~cm} \\
3.66 \mathrm{E}+04 \mathrm{~cm} \\
5.95 \mathrm{E}+05 \mathrm{~cm}^{3} / \mathrm{d} \\
4.57 \mathrm{E}+13 \mathrm{~cm}^{3}\end{array}$ & $\begin{array}{l} \pm 10 \\
\pm 10 \\
\pm 10 \\
\pm 10\end{array}$ \\
\hline Flow $=$ Discharge $/($ depth * width) & $1.60 \mathrm{E}+06 \mathrm{~cm} / \mathrm{d}$ & \\
\hline \multicolumn{3}{|c|}{ Exposure } \\
\hline $\begin{array}{l}\text { Population (drink) } \\
\text { Finfish production }\end{array}$ & $\begin{array}{l}0,000 \\
1,500 \mathrm{~kg} / \mathrm{yr}\end{array}$ & $\begin{array}{l}\star 10 \\
\pm 10\end{array}$ \\
\hline
\end{tabular}

The flux of contaminants into the ground was assumed to be constant over $16 \mathrm{yr}$. The total inventory of each constituent was assumed to leach from the facility into the soil during those $16 \mathrm{yr}$. Thus, the flux for each constituent is directly proportional to the inventory. Furthermore, the variation in the flux will be directly proportional to the variation in the inventory. The liquid waste infiltration rate, VLEACH, is estimated from the total volume of liquid disposed, the area of the ranking unit, and the porosity of the soil at the ranking unit by the equation in Table 2.1. The volume of liquid leaching each day was estimated from liquid disposal records for the ranking unit. The length and width of the ranking unit were estimated from 
topographic maps. The variation in VLEACH is determined by the variation in the variables used to calculate it.

The depth of the partially saturated zone was estimated from the geologic profile and measurements of the position of the water table at the site. The longitudinal dispersivity for transport predictions was calculated from the depth of the partially saturated zone. For the partially saturated zone, zone depth was varied $\$ 30$ \% to account for spatial variability.

Soil properties (i.e., soil composition, saturated hydraulic conductivity, porosity, bulk density, soil type exponent, and field capacity) are used to calculate several subsidiary values in the MEPAS (e.g., adsorption parameters, unsaturated hydraulic conductivity for the partially saturated zone). If values are known for the soil properties, such as clay, sand, silt, and organic matter content, then these values should be used. When there are no measured data for the soil properties, then reasonable default values based on the general soil texture classification can be used. To facilitate the application of MEPAS for sites with limited data, values for soil properties by soil texture classification are given in Table 2.1 in Droppo et al. (1989a). Because many of the soil properties are interdependent, use of the default values prevents the user from entering physically unreasonable values.

The soil texture classification for the representative site is sand/loamy sand, which is consistent with an arid environment, the values of the soil parameters for the partially saturated and saturated zone chosen for this analysis are between those of sand and loamy sand. The soil type exponent, which is a fitting parameter characteristic of measured variation in soil properties, is used with the saturated hydraulic conductivity, moisture content, and porosity to calculate the unsaturated hydraulic conductivity. The value for the soil type exponent in Table 2.1 is midway between the values for sand and loamy sand. The soil properties were assumed to have a $\$ 15 \%$ variability for both the partially saturated and the saturated zones because Table 2.1 is constructed from data described in Droppo et al. (1989a) that varied $\pm 15 \%$.

The $k_{d}$ values for each of the constituents, which indicate the degree to which the constituent will partition between the soils and water, are set to 
representative values for the constituent and the soil type classification. The $K_{d} s$ for both the partially saturated and the saturated zone varied $* 50 \%$ because there is a large range in values reported in the literature.

The pore-water velocity was calculated from the saturated hydrologic conductivity and the hydraulic gradient, which is the difference in hydraulic head at two points divided by the distance between the two points. The porewater velocity can also be calculated using a groundwater model of the site. The depth of the aquifer was estimated from the geologic profile of the site, and the distance downgradient to the river was estimated from the topographic map of the site. For the saturated zone, pore-water velocity was varied by both $15 \%$ and $95 \%$, which is explained below; zone depth was varied $\pm 30 \%$ to be consistent with the variation for the same parameter in the partially saturated zone; and distance downgradient was varied $\pm 10 \%$.

The river data were obtained from river monitor stations and topographic maps. The parameters describing river flow were all varied $\star 10 \%$ to represent a well-characterized situation.

The population of the city was assumed, based on census records, to be 100,000 . The fish production rates were calculated from fish census data. The population and the fish production rate were allowed to vary $\pm 10 \%$ from the nominal values.

\subsubsection{Sensitivity Analysis Cases}

The sensitivity analysis for the nonprecipitation-driven groundwater transport pathway consists of five separate parametric sensitivity analysis cases. For each of the five cases (Table 2.2) certain assumptions and conditions on the input variables were changed to test the effects of blocks of variables (i.e., $K_{d}$ and treatment of saturated and unsaturated zones variables) or to test the effect of a single variable that is known, based on previous experience, to be a sensitive variable for the saturated zone transport models (i.e., pore-water velocity). The cases also define the base case variability in HPI values for a well-characterized site for constituents with low and high $K_{d}$ values and examine the effect of higher variability in important parameters on the base case variabitity. 
TABLE 2.2. Classification of Conditions for Five Sensitivity Analyses for Nonprecipitation-Driven Groundwater-to-Surface-Water Transport Pathway

\begin{tabular}{|c|c|c|c|}
\hline Case & $\begin{array}{l}\text { Treatment of } \\
\text { Groundwater } \\
\end{array}$ & $\begin{array}{l}\text { Variation in Pore- } \\
\text { Water Velocity, }\end{array}$ & $\underline{x_{d}}$ \\
\hline $\begin{array}{l}1 \\
2 \\
3 \\
4 \\
5\end{array}$ & $\begin{array}{l}\text { Dependent } \\
\text { Independent } \\
\text { Independent } \\
\text { Independent } \\
\text { Independent }\end{array}$ & $\begin{array}{l} \pm 95 \\
\pm 95 \\
\pm 15 \\
\pm 15 \\
\pm 95\end{array}$ & $\begin{array}{l}\text { Minimal } \\
\text { Minimal } \\
\text { Minimal } \\
\text { Realistic } \\
\text { Realistic }\end{array}$ \\
\hline
\end{tabular}

Column 2 in Table 2.2, Treatment of Groundwater, refers to whether the parameters of the saturated and unsaturated zones were varied together (designated dependent) or allowed to vary independently (designated independent). Dependent variation means that if one parameter was increased by a certain factor, then the other dependent parameters were increased or decreased by the same factor. Independent variation means that the value taken by one variable has no influence on the value taken by another variable. These two cases were run because definite relationships exist among the hydrologic parameters over large ranges of their possible values. For example, hydraulic conductivity, bulk density, and porosity are dependent on soil type and are therefore related to each other. However, for specific sites, the range of possible values may be smaller if the range in soil types is small. Thus, for a specific site, it may be reasonable to assume that, within measurement error, the parameter values would vary independently because measurement error is usually assumed to be independent of the nominal value of the parameter. The effects of spatial and temporal variation are not considered because much more data than are usually available would be required to characterize these types of variability.

Assuming strict dependency of the hydrologic parameters reduces the hydrologic variables considered in the statistical model to one per soil zone. The partially saturated zone parameters that were varied dependently are bulk density, porosity, field capacity, hydraulic conductivity, and soil type exponent. The saturated zone hydrologic parameters that were varied dependently are bulk density, porosity, and field capacity. The results of the statistical analysis for the dependent variation case provide a general 
indication of whether one or more of the hydrologic variables were important, but do not indicate which of the variables have the most influence on HPI. A comparison of the results of the statistical analyses for Cases 1 and 2 , which differ only in the way the variation in the hydrologic parameters are treated, will indicate any effect on HPI from using one composite hydrologic variable or using the several individual variables.

Previous experience has shown that saturated zone pore-water velocity is a very influential variable in determining constituent transport time. Therefore, to evaluate the effect of variation in this parameter, it was a) lowed to vary $\pm 95 \%$ for Cases 1,2 , and 5 and by $\pm 15 \%$ for Cases 3 and 4 (Table 2.2). Allowing one variable to vary much more than the others could result in that variable appearing to be significant partly as an artifact of its larger variation; therefore, two cases were run where the variation in saturated zone pore velocity was comparable to that of the other variables (i.e., $\pm 15 \%$ ). A comparison of the results of the statistical analysis of Cases 3 and 4 with those of Cases 2 and 5 , respectively, will determine the effect of changes in magnitude in variation on the ordering of the significant variables.

Experience with MEPAS has suggested that constituent $K_{d}$ values are also important variables in groundwater transport; therefore, variation in $K_{d}$ values was specifically evaluated in the five sensitivity analys is cases. For Cases 1, 2, and 3, minimal $K_{d}$ values, which represent the most conservative case for contaminant migration (i.e., little or no retardation), were used. For all constituents except $905 r$ and $90 \mathrm{Y}$, the $K_{d}$ for the minimal $K_{d}$ cases were set to zero and not allowed to vary. For $90 \mathrm{Sr}$, and of course $90 \mathrm{Y}$, the $K_{d}$ was set to $2.43 \mathrm{~mL} / 9$ and not varied. For Cases 4 and 5 , realistic values of $K_{d}$ for each of the constituents were used. The realistic values are given in Table 2.2. The importance of $K_{d}$ can be evaluated by comparing the values of the HPI for Cases 2 and 3 with Cases 5 and 4 , respectively. The two sets of comparisons can also be used to indicate if the range in variation in saturated zone pore velocity influences the effect of $K_{d}$ on the HPI.

Cases 2 and 5 also can be used to define the base case HPI range for constituents with low and high $K_{d}$ values, respectively. These two cases 
rather than Cases 3 and 4 were chosen to define the base case HPI range because in general, pore-water velocity can only be defined within $\$ 95 \%$ because of its large spatial and temporal variability. Comparing these base case HPI values with those of cases with lower variability in the pore-water velocity will indicate the influences of this decreased variability on the HPI range.

\subsubsection{Sensitivity Analysis Results}

Within the ranges that are appropriate, the input variables were assumed to be statistically independent unless the case specifically addresses the effect of dependent variation in the hydrologic parameters. For Cases 1, 2 , 4, and 5, one parametric sensitivity analysis was conducted, and three analyses were conducted for Case 3 . The variables were sampled randomly within the ranges defined in Table 2.1 using the Lat in Hypercube method described in Appendix B. Each analys is is based on 40 simulations or realizations of the model. Because there are more than 30 variables used in the analysis, this is close to the minimum number of realizations required by the statistical parametric sensitivity analysis method (Appendix B).

The results of the sensitivity analysis are presented in the context of the issues discussed in Section 2.3.3. These are 1) the effect of dependent versus independent variation in the hydrologic variables, 2) the effect of the magnitude of variation in saturated zone pore-water velocity on the ordering of the other input variables, and 3 ) the effect of $K_{d}$ on the magnitude of the HPI and the ordering of the other input variables.

\subsubsection{Dependence Versus Independence of the Groundwater Input Variables}

To evaluate the effect of dependent and independent variation among hydrologic parameters in the partially saturated and saturated zones, two different cases were used in the sensitivity analyses (Table 2.2). For the dependent variation case (Case 1), all constituents had 18 input variables except $90 \mathrm{Sr}$ and $90 \mathrm{Y}$, which had 20 input variables (because of the nonzero $\mathrm{K}_{\mathrm{d}}$ value). For the independent case (Case 2), all constituents had 24 input variables except $90 \mathrm{Sr}$ and $90 \mathrm{Y}$, which had 26 input variables. The variables for Case 1 are those listed in Table 2.1, with the five hydrologic variables 
for the partially saturated zone and the three hydrologic parameters for the saturated zone each treated as one parameter. For Case 2, all the variables in Table 2.1 were used except the $K_{d}$ values.

The minimum, median, and maximum values and range for HPI for Cases 1 and 2 are given in Table 2.3, and the most important variables for determining HPI and their partial $\mathrm{R}^{2}$ values for all eight constituents for Cases 1 and 2 are given in Table 2.4. The results for Cases 1 and 2 in Table 2.4 are paired by constituent to facilitate the comparison. The total $R^{2}$ value is also given at the bottom of the table and indicates the amount of information on HPI explained by the variables.

The range in HPI values for the chemical constituents is small (approximately 1.0 HPI units) and is not influenced by the assumption of dependent or independent variation in the hydrologic parameters. However, the range in HPI values for the radionuclides $90 \mathrm{Sr}$ and $90 \mathrm{Y}$ was quite large and depended on the type of variation in the hydrologic parameters. The similarity between the results for $90 \mathrm{Sr}$ and $90 \mathrm{Y}$ are not unexpected because $90 \mathrm{Y}$ is a decay product of $90 \mathrm{Sr}$ and its concentration is calculated from that of $90 \mathrm{Sr}$. The large variation in HPI for radionuclides is due in part to the decrease in radionuclide concentration with time because of radioactive decay, whereas the chemical constituents do not decay. The half-life of $90 \mathrm{Sr}$ is $29 \mathrm{yr}$; therefore, a travel time increase of $29 \mathrm{yr}$ would result in approximately half the concentration at the receptor and a lower HPI value resulting from just decay. For $3 \mathrm{H}$, which has a half-life of only $12.3 \mathrm{yr}$, only the effects of variation in travel times and thus radioactive decay are revealed in the range in HPI values because $3 \mathrm{H}$ does not sorb to subsurface materials. The larger range in HPI values for $90 \mathrm{Sr}$ and $90 \mathrm{Y}$ is due to the effects of sorption. Sorption tends to increase the HPI range if the $K_{d}$ is greater than 1.0 (see Section 2.3.4.3).

Because there are fewer input variables for Case 1, it is possible that the total $R^{2}$ would be smaller than that for Case 2. That was observed for three of the constituents, $90 \mathrm{Sr}, 90 \mathrm{Y}$, and $3 \mathrm{H}$, where the total $\mathrm{R}^{2}$ for Case 2 was larger by 0.10 than the corresponding $\mathrm{R}^{2}$ for Case 1 . However, the total $R 2_{S}$ for the other five constituents were within 0.01 to 0.02 for Cases 1 and 2 . 
TABLE 2.3. Hazard Potential Index Score Ranges for Nonprecipitation-Driven Groundwater-to-Surface-Hater Transport Pathways: Cases 1 and 2

Const ituent

\begin{tabular}{|c|c|c|c|c|c|c|c|c|c|}
\hline Case & $90 S r$ & $90 Y$ & $3 \mathrm{H}$ & PCE & As & PCBs & $\mathrm{Hg}$ & Toluene & Value \\
\hline 1 & $\begin{array}{r}-15.1 \\
28.4 \\
40.3 \\
55.4\end{array}$ & $\begin{array}{c}-26.0 \\
17.55 \\
29.4 \\
55.4\end{array}$ & $\begin{array}{l}16.8 \\
21.25 \\
22.0 \\
5.2\end{array}$ & $\begin{array}{r}24.5 \\
25.0 \\
25.4 \\
0.9\end{array}$ & $\begin{array}{r}22.2 \\
22.6 \\
23.1 \\
0.9\end{array}$ & $\begin{array}{l}25.3 \\
25.95 \\
26.4 \\
1.1\end{array}$ & $\begin{array}{c}21.5 \\
21.95 \\
22.4 \\
0.9\end{array}$ & $\begin{array}{r}22.5 \\
23.1 \\
23.5 \\
1.0\end{array}$ & $\begin{array}{l}\text { min } \\
\text { med } \\
\text { max } \\
\text { range }\end{array}$ \\
\hline 2 & $\begin{array}{r}5.2 \\
29.4 \\
37.0 \\
31.8\end{array}$ & $\begin{array}{l}-5.6 \\
18.6 \\
26.2 \\
31.8\end{array}$ & $\begin{array}{r}18.1 \\
21.3 \\
22.1 \\
4.0\end{array}$ & $\begin{array}{r}24.5 \\
25.0 \\
25.5 \\
1.0\end{array}$ & $\begin{array}{r}22.0 \\
22.7 \\
23.1 \\
0.9\end{array}$ & $\begin{array}{l}25.4 \\
25.95 \\
26.4 \\
1.0\end{array}$ & $\begin{array}{r}21.6 \\
22.0 \\
22.7 \\
1.1\end{array}$ & $\begin{array}{r}22.6 \\
23.1 \\
23.5 \\
0.9\end{array}$ & $\begin{array}{l}\min \\
\text { med } \\
\text { max } \\
\text { range }\end{array}$ \\
\hline
\end{tabular}

For the three radionuclides, $90 \mathrm{Sr}, 90 \mathrm{Y}$, and $3 \mathrm{H}$, the input variable accounting for the majority of the variation in HPI (i.e., 55\% to $73^{\circ} \%$ of the approximately 32- to 56-HPI unit range for 90Sr and 90Y and approximately 4 to $5 \mathrm{HPI}$ units for $3 \mathrm{H}$ ) for both cases was saturated zone pore-water velocity, which varied $\$ 95 \%$. This is because radioactive decay reduces the concentration; therefore, travel time, which is controlled by velocity, is important. The second most important variable for $90 \mathrm{Sr}$ and $90 \mathrm{Y}$ was the saturated zone $K_{d}$, which accounted for from $7 \%$ to $13 \%$ of the variation in HPI even though the nominal value used was small (i.e., $2.43 \mathrm{~mL} / \mathrm{g}$ ). For $3 \mathrm{H}$ there are no common variables between cases 1 and 2 among the ones of lesser importance.

For the chemical constituents, treating the variation in the hydrologic parameters as either dependent or independent did not significantly affect the selection of the important variables. For all the nonradionuclides, the two most important variables, accounting for $66 \%$ to $81 \%$ for $1.0 \mathrm{HPI}$ unit range in HPI scores, were waste unit constituent inventory and river discharge. These two variables affect the concentration of a constituent at the receptor point because drinking water (Table 2.5) is the major exposure route for all the constituents except PCBs and $\mathrm{Hg}$. The third most important variable for all nonradionuclide constituents, with the exception of $\mathrm{Hg}$, was the drinking-water population, which reflected the primary exposure scenario for these constituents. For $\mathrm{Hg}$ and PCBs, the primary exposure route is 
IABLE 2.4. Most Important Variables Affecting Hazard Potential Index for Nonprecipitation-Driven Groundwater-to-Surface-Water Transport Pathway: Cases 1 and 2

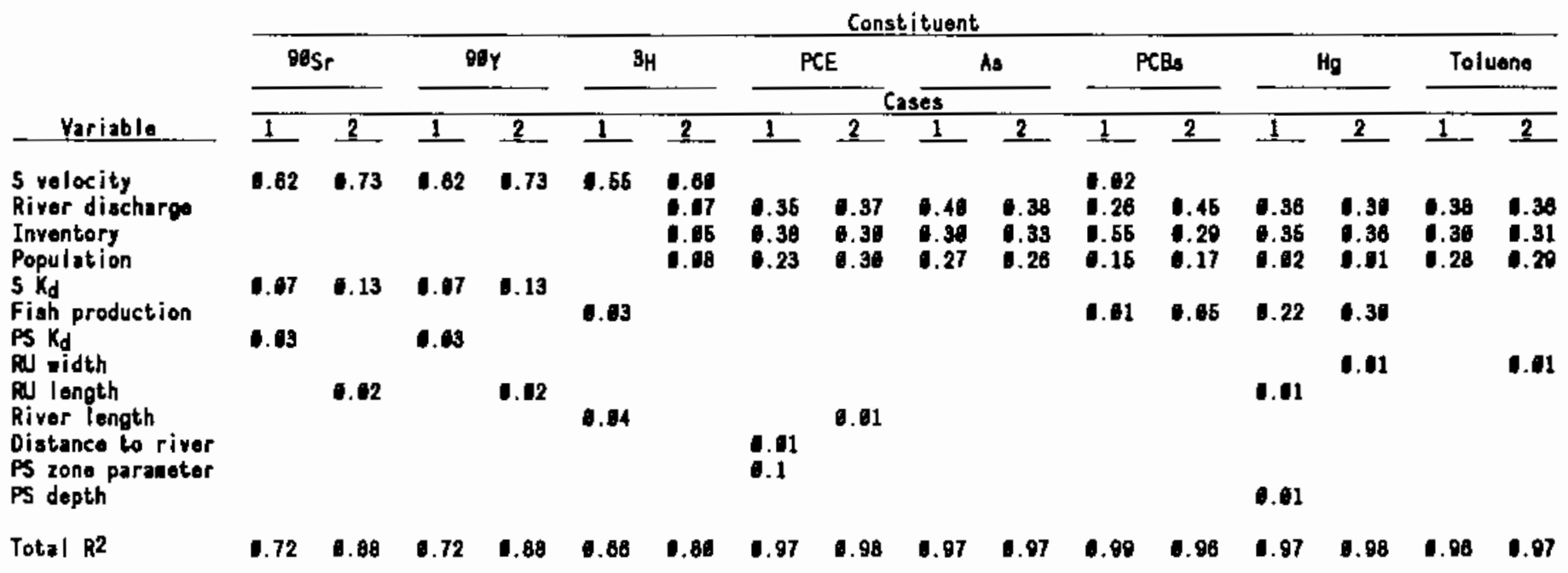

S = Saturated zone paraneter.

PS = Partially saturated zone paraneter.

RU = Ranking unit. 
TABLE 2.5. Percent Contribution of Exposure Route to Dose from Groundwaterto-Surface and Overland-to-Surface Transport Pathways

\begin{tabular}{|c|c|c|c|c|c|c|c|c|}
\hline Variable & As & $\underline{\mathrm{Hg}}$ & PCB & $\mathrm{PCE}$ & Toluene & $90 \mathrm{Sr}$ & $3 \mathrm{H}$ & $90 Y$ \\
\hline $\begin{array}{l}\text { Drinking water } \\
\text { Finfish }\end{array}$ & 100 & - & $2-5$ & $84-85$ & 83 & $90-92$ & 100 & $94-100$ \\
\hline consumption & - & 100 & $95-98$ & $5-6$ & 17 & $8-10$ & - & $0-6$ \\
\hline
\end{tabular}

consumption of contaminated fish; therefore, fish production is also an important variable for these two constituents.

The results of Cases 1 and 2 suggest that it is technically justifiable to assume that the hydrologic variables vary independently in the sensitivity analysis because the independent variation did not significantly affect the ordering of the significant variables. Furthermore, the independent variation case (Case 2) did result in an increased total R2 value for the radionuclides. Therefore, the hydrologic variables were assumed to vary independently in Cases 3, 4, and 5. Case 2 indicates that the base case HPI range for constituents with low $K_{d}$ values (i.e., <1.0) is approximately 4 for radionuclides with a short half-life.

\subsubsection{Magnitude of Variation in Saturated Zone Pore-Water Velocity}

The statistical analysis results for the radionuclides in Cases 1 and 2 indicated that saturated zone pore-water velocity accounted for the greatest proportion of the variability in the HPI value (Table 2.4). However, the variation in this paraneter was much greater than the variation in any of the other parameters. In Case 3, the saturated zone pore-water velocity was allowed to vary $\pm 15 \%$, a variation range that is commensurate with the variation range of the other variables. Because the variable values for the individual model runs are selected randomiy, it is important to determine to what extent (if any) the ordering of the important variables is influenced by the random effects of the selection process. Therefore, three complete sensitivity analyses were performed for Case 3 to test the stability of the ordering of the significant variables. All three analyses used the same assumptions and nominal variable values. All constituents had 24 input variables except $90 \mathrm{Sr}$ and $90 \mathrm{Y}$, which had 26 variables because of the 
inclusion of the $K_{d}$ values of $2.43 \mathrm{~mL} / g$ in the partially saturated and the saturated zones. The minimum, median, and maximum HPI values and the range for each analys is in Case 3 are shown in Table 2.6, and the most important variables for determining HPI and their partial $R^{2}$ values for each analys is in Case 3 are given in Table 2.7.

As with Cases 1 and 2, the highest range in the HPI values is found for the radionuclides $90 \mathrm{Sr}$ and $90 \mathrm{Y}$, probably reflecting a range in travel times based on the variation in velocity and the effect of sorption. The sorption, which is represented by the distribution coefficient, $K_{d}$, tends to spread the travel times. The small range in HPI for $3 \mathrm{H}$ also confirms the importance of sorption on the range in HPI values. The range is not as large as for Case 2. which suggests that the range in HPI for these three constituents is dependent on the range in variation in the saturated zone pore-water velocity. The range in the HPI values for the other constituents is comparable to that seen for other analyses (approximately 1.0 HPI units), suggesting that the variation in pore-water velocity had little effect on the HPI estimates.

For $90 \mathrm{Sr}$ and $90 \mathrm{Y}$, the most significant variable for all three analyses is the saturated zone $K_{d}$, accounting for about $71 \%$ of the variation in the HPI values of approximately 11 HPI units, and the second most important variable is saturated zone pore-water velocity, accounting for $7 \%$ of the variability in HPI values. Case 3, like Cases 1 and 2, assumed a small nonzero $(2.43 \mathrm{~mL} / \mathrm{g})$ nominal $\mathrm{K}_{d}$ value for $90 \mathrm{Sr}$ and $90 \mathrm{Y}$. These results contrast with those of Cases 1 and 2 where the saturated zone pore-water velocity was the dominant input variable and $K_{d}$ was the second most important variable for these constituents. These results indicate that the assumed variability of a parameter can affect the ordering of the important variables. Furthermore, these results imply that if a variable is shown to be important when a small variation in the value is assumed, then the user may want to determine the effect of a larger variation in the value especially if the variation range is not well known.

For $90 \mathrm{Sr}$ and $90 \mathrm{Y}$, the variables other than $\mathrm{K}_{d}$ and pore-water velocity in the saturated zone contributing significantly to HPI divide themselves into two groups. The first group of three variables represent important hydro 
TABLE 2.6. Hazard Potential Index Score Ranges for Nonprecipitation-Driven Groundwater-to-Surface-Water Transport Pathway: Case 3

Constituent

\begin{tabular}{|c|c|c|c|c|c|c|c|c|c|}
\hline \multirow[b]{2}{*}{ Analysis } & \\
\hline & $90 \mathrm{sr}$ & $90 Y$ & $3 \mathrm{H}$ & PCE & As & PCBs & $\mathrm{Hg}$ & Toluene & Value \\
\hline 1 & $\begin{array}{l}24.0 \\
29.7 \\
35.1 \\
11.1\end{array}$ & $\begin{array}{l}13.2 \\
18.85 \\
24.2 \\
11.0\end{array}$ & $\begin{array}{r}20.6 \\
21.3 \\
21.9 \\
1.3\end{array}$ & $\begin{array}{r}24.5 \\
25.0 \\
25.5 \\
1.0\end{array}$ & $\begin{array}{r}22.0 \\
22.7 \\
23.1 \\
0.9\end{array}$ & $\begin{array}{c}25.4 \\
25.95 \\
26.4 \\
1.0\end{array}$ & $\begin{array}{r}21.6 \\
22.0 \\
22.7 \\
1.1\end{array}$ & $\begin{array}{r}22.6 \\
23.1 \\
23.5 \\
1.1\end{array}$ & $\begin{array}{l}\text { min } \\
\text { med } \\
\text { max } \\
\text { range }\end{array}$ \\
\hline 2 & $\begin{array}{l}24.2 \\
29.65 \\
34.9 \\
10.7\end{array}$ & $\begin{array}{l}13.4 \\
18.75 \\
24.1 \\
11.3\end{array}$ & $\begin{array}{r}20.7 \\
21.3 \\
21.7 \\
1.0\end{array}$ & $\begin{array}{r}24.4 \\
25.0 \\
25.4 \\
1.0\end{array}$ & $\begin{array}{c}22.1 \\
22.65 \\
23.2 \\
1.1\end{array}$ & $\begin{array}{r}25.5 \\
26.0 \\
26.4 \\
1.1\end{array}$ & $\begin{array}{r}21.5 \\
22.0 \\
22.6 \\
1.1\end{array}$ & $\begin{array}{r}22.6 \\
23.1 \\
23.5 \\
1.1\end{array}$ & $\begin{array}{l}\text { min } \\
\text { med } \\
\text { max } \\
\text { range }\end{array}$ \\
\hline 3 & $\begin{array}{l}24.0 \\
29.75 \\
35.1 \\
11.1\end{array}$ & $\begin{array}{l}13.2 \\
18.85 \\
24.2 \\
11.0\end{array}$ & $\begin{array}{r}20.9 \\
21.3 \\
21.8 \\
0.9\end{array}$ & $\begin{array}{r}24.4 \\
24.9 \\
25.4 \\
1.0\end{array}$ & $\begin{array}{r}22.0 \\
22.7 \\
23.0 \\
1.0\end{array}$ & $\begin{array}{r}25.6 \\
26.0 \\
26.3 \\
0.7\end{array}$ & $\begin{array}{r}21.6 \\
22.0 \\
22.7 \\
0.9\end{array}$ & $\begin{array}{r}22.5 \\
23.1 \\
23.5 \\
1.0\end{array}$ & $\begin{array}{l}\text { min } \\
\text { med } \\
\text { max } \\
\text { range }\end{array}$ \\
\hline
\end{tabular}

logic parameters for the saturated zone (saturated zone field capacity, bulk density, and velocity). The amount of variability in the HPI accounted for by these three variables was nearly equal (i.e., approximately 0.07), and together they accounted for approximately $20 \%$ of the variation. The second group (partially saturated zone $K_{d}$ values and partially saturated zone depth) accounts for only $3 \%$ of the variability in the HPI value. The random selection of variable values had an insignificant effect on the ordering of the important variables.

For ${ }^{3} \mathrm{H}$, there are three variables (inventory, drinking water population, and river discharge) that are of roughly equal importance in explaining the HPI variability of approximately 1 HPI unit. The partial R2 values, and hence the order of these variables, varies among the three analyses. These three variables contribute to the concentration in and exposed population to drinking water, which is the primary exposure route for this constituent (Table 2.5). Together, the three variables account for between $85 \%$ and $88 \%$ of the variability in HPI. Saturated zone pore-water velocity, in contrast to the results for Cases 1 and 2 , is in a group of variables of secondary importance. It and two other variables (partially saturated zone depth and the saturated zone distance to the river) account for about $10 \%$ of the HPI variability. 
IABLE 2.7. Most Important Variables Affecting Hazard Potential Index for Nonprecipitation-Driven Groundwater-to-Surface-Water Transport Pathway, Case 3, Summarized for Three Analyses

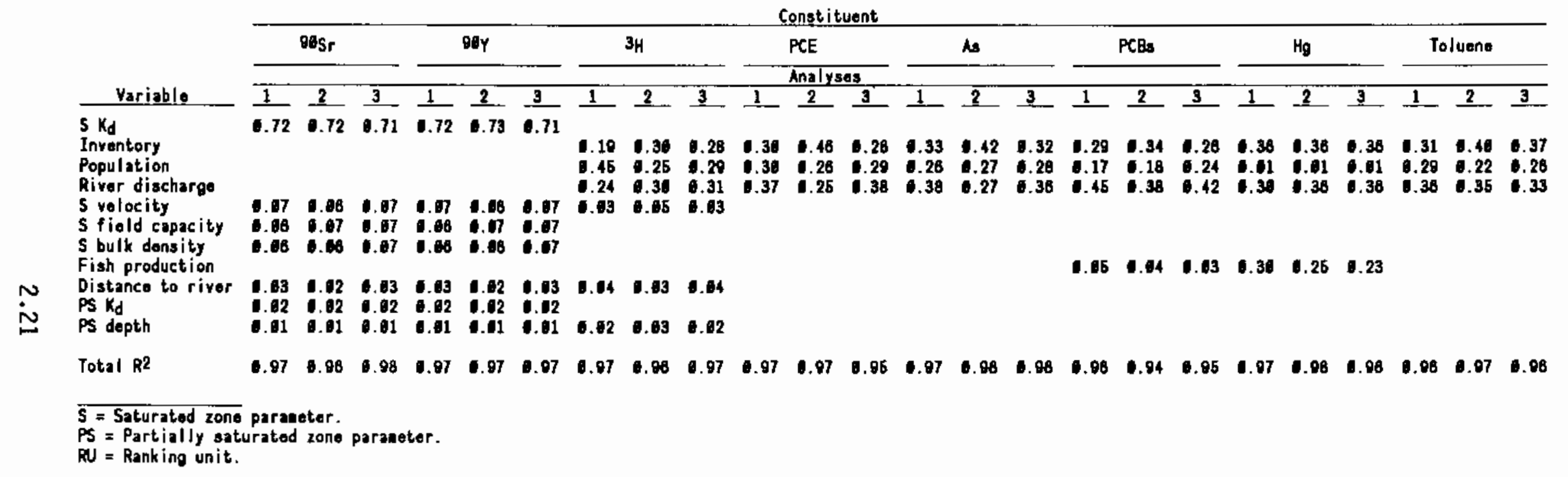


For the chemical constituents, the results from the Case 3 sensitivity analyses and the range of approximately $1.0 \mathrm{HPI}$ unit are similar to those for Cases 1 and 2. The total $R^{2}$ and the partial $R^{2}$ values for the three variables, drinking-water population, waste unit constituent inventory, and river discharge, suggest that the differences in variable order in Cases 1 and 2 can be attributed to the random selection of variable values in Latin Hypercube sampling rather than the type of variation in the hydrologic parameters. The fish production rate continues to be a small, but significant, contributor to HPI for PCBs and mercury because this is an important exposure route for these constituents (Table 2.5).

\subsubsection{Effect of Variation in $K_{d}$}

In Cases 4 and 5 , the effect of assuming a realistic retardation ( $K_{d}$ values in Table 2.1) was investigated. Because the effects of $K_{d}$ on HPI may not be the same under different assumptions for the variability of pore-water velocity (Section 2.3.3), the saturated zone pore-water velocity was varied by $\pm 15 \%$ for Case 4 and $\pm 95 \%$ for Case 5 . To ensure HPI values greater than -250 (i.e., minimum reported score for HPI), the inventories for the constituents were increased to the values shown in Table 2.8. The variability in the inventories was $\$ 10 \%$. The minimum, median, and maximum HPI values for these two cases are given in Table 2.9, and the most important variables for determining HPI and their partial $\mathrm{R}^{2}$ values are given in Table 2.10 .

Inventories and results are not given for PCBs or $\mathrm{Hg}$ (NC in Table 2.9) because the realistic $K_{d}$ values for these two constituents were very large and resulted in HPI values of -250 . These results indicate that $K_{d}$ is by far the most important variable for determining the HPI values for these two constituents.

As observed for the previous cases, the range in HPI values varies with the constituent as a result of the effects of travel time for the radionuclides and as the result of differences in the magnitude of the $K_{d}$ value for both the radionuclides and the nonradionuclides. The range of all the HPI values is greater than the corresponding range for the other cases analyzed. For the nonradionuclides, the greater the $K_{d}$ value the larger the range of HPI values. Because of the different initial inventories, the 
TABLE 2.8. Inventories and Associated Fluxes for Constituents in Groundwater: Cases 4 and 5

\begin{tabular}{|c|c|}
\hline Variable & Nominal Value \\
\hline $90 \mathrm{Sr}$ inventory & $2.5 \mathrm{E}+11 \mathrm{Ci}$ \\
\hline $90 \mathrm{sr}$ flux & $1.56 \mathrm{E}+10 \mathrm{Ci} / \mathrm{yr}$ \\
\hline $3 \mathrm{H}$ inventory & $2.5 \mathrm{E}+3 \mathrm{Ci}$ \\
\hline $3 \mathrm{H}$ flux & $1.56 \mathrm{E}+2 \mathrm{Ci} / \mathrm{yr}$ \\
\hline PCE inventory & $2.5 \mathrm{E}+6 \mathrm{~g}$ \\
\hline PCE flux & $1.56 \mathrm{E}+5 \mathrm{~g} / \mathrm{yr}$ \\
\hline As inventory & $2.5 \mathrm{E}+6 \mathrm{~g}$ \\
\hline As flux & $1.56 \mathrm{E}+5 \mathrm{~g} / \mathrm{yr}$ \\
\hline Toluene inventory & $2.5 \mathrm{E}+10 \mathrm{~g}$ \\
\hline Toluene flux & $1.56 \mathrm{E}+9 \mathrm{~g} / \mathrm{yr}$ \\
\hline
\end{tabular}

TABLE 2.9. Hazard Potential Index Score Ranges for Nonprecipitation-Driven Groundwater-to-Surface-Water Transport Pathway: Cases 4 and 5

Constituent

\begin{tabular}{|c|c|c|c|c|c|c|c|c|c|}
\hline Case & $90 \mathrm{sr}$ & $90 Y$ & $3 \mathrm{H}$ & PCE & As & PCBS & $\underline{\mathrm{Hg}}$ & Toluene & Value \\
\hline 4 & $\begin{array}{l}9.1 \\
29.35 \\
53.2 \\
44.1\end{array}$ & $\begin{array}{l}-1.7 \\
18.55 \\
42.4 \\
44.1\end{array}$ & $\begin{array}{r}20.8 \\
21.3 \\
21.8 \\
1.0\end{array}$ & $\begin{array}{r}24.0 \\
24.6 \\
25.3 \\
1.3\end{array}$ & $\begin{array}{l}20.5 \\
25.6 \\
30.2 \\
10.3\end{array}$ & $\begin{array}{l}N C \\
N C \\
N C\end{array}$ & $\begin{array}{l}N C \\
N C \\
N C\end{array}$ & $\begin{array}{r}22.2 \\
22.8 \\
23.5 \\
1.3\end{array}$ & $\begin{array}{l}\min \\
\text { med } \\
\text { max } \\
\text { range }\end{array}$ \\
\hline 5 & $\begin{array}{l}-24.6 \\
33.05 \\
60.4 \\
85.0\end{array}$ & $\begin{array}{l}-35.5 \\
22.25 \\
49.6 \\
85.1\end{array}$ & $\begin{array}{r}19.4 \\
21.2 \\
21.9 \\
2.5\end{array}$ & $\begin{array}{l}23.6 \\
24.55 \\
25.2 \\
1.6\end{array}$ & $\begin{array}{l}12.7 \\
25.45 \\
30.7 \\
18.0\end{array}$ & $\begin{array}{l}N C \\
N C \\
N C\end{array}$ & $\begin{array}{l}\mathrm{NC} \\
\mathrm{NC} \\
\mathrm{NC}\end{array}$ & $\begin{array}{l}21.8 \\
22.75 \\
23.5 \\
1.7\end{array}$ & $\begin{array}{l}\min \\
\text { med } \\
\max \\
\text { range }\end{array}$ \\
\hline
\end{tabular}

NC = Not calculated.

absolute values of the HPI values cannot be compared between Cases 1,2 , and 3 and Cases 4 and 5 . However, Case 5 indicates that the base case HPI range for constituents with high $K_{d}$ values is at least 18 HPI units for inorganic constituents and at least 85 HPI units for radionuclides with short half-lives.

The decrease in the total $R 2$ values for the constituents between Cases 4 and 5 indicates that less of the total HPI variability can be explained by the important variables when the velocity variation is increased. However, a 
TABLE 2.10. Most Important Variables Affecting Hazard Potential Index for Nonprecipitation-Driven Groundwater-toSurface-Water Transport Pathway: Cases 4 and 5

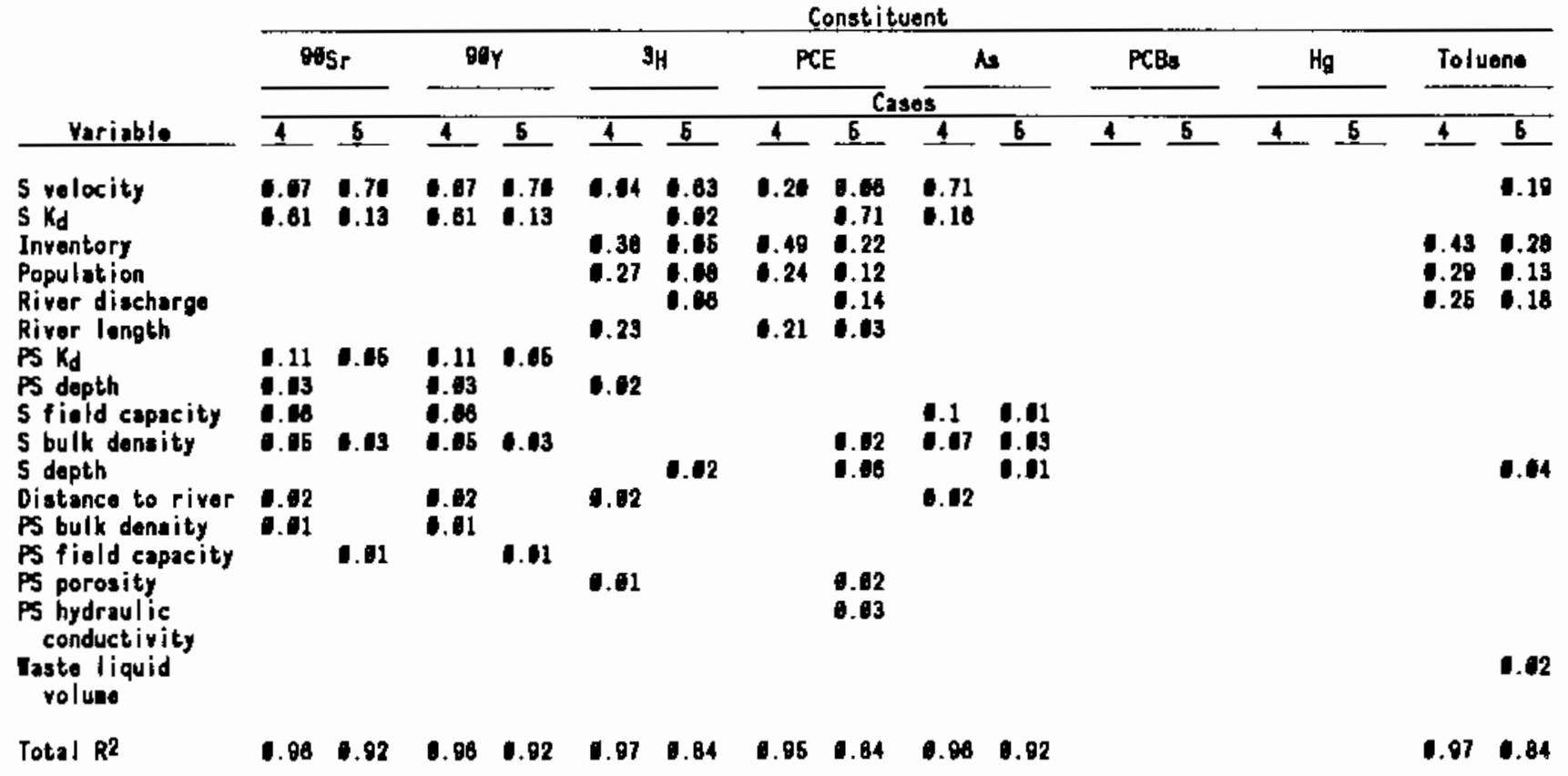

$\bar{S}=$ Saturated zone parameter.

PS = Partially azturated zone paraneter.

a = Ranking unit paranoter. 
comparison of Cases 2 and 5 shows that the combination of a large velocity variation and realistic $K_{d} s$ tends to mitigate the effect of large velocity alone for the radionuclides and increase it for the nonradionuclides. The exception, of course, is $3 \mathrm{H}$. Because $3 \mathrm{H}$ is known to move with the groundwater flow and has a zero $K_{d}$ value, the results for this constituent for Cases 4 and 3 and Cases 5 and 2 are similar. For Case 4 , the constituents with $K_{d} s$ larger than $1.0(90 \mathrm{Sr}, 90 \mathrm{Y}$, and As) show that the most important variable is $K_{d}$ in one or both of the groundwater zones (e.g., saturated zone only for As and both saturated and partially saturated zones for the two radionuclides). When pore-water velocity is also allowed to vary $\$ 95 \%$ (Case 5), it becomes the dominant one. As noted previously for Case 2, the important variables when the variation in hydrologic parameters is small and for constituents with low $K_{d}$ values (i.e., less than 1.0 ) are the initial inventory, the population drinking the water, and the river length. These variables are related to the dominant exposure route of drinking water (Table 2.5).

\subsubsection{Conclusions}

The results of the sensitivity analyses on the nonprecipitation-driven groundwater-to-surface-water transport pathways indicate that the variation in HPI values for the representative site evaluated is quite small (i.e., HPI range is approximately 1 to 2 HPI units) for all chemical constituents that have small sorption constants (i.e., $K_{d}$ values less than approximately 1.0). For radionuclides and for chemical constituents that have large sorption constants (i.e., $K_{d}$ values greater than approximately 1.0 ), the variation in HP1 values for one representative site is much larger (i.e., 11 to 85 HPI units), because the large $K_{d}$ values amplify the effects of variation in hydrologic parameters on travel times.

Several specific issues were addressed by the cases given in Table 2.2. The comparison of the results indicated that the assumption of independent or dependent variation in the hydrologic parameters did not result in significant effects on the importance of the key variables. Therefore, the hydrologic variables were assumed to vary independently in all the subsequent cases. The ordering of important variables and the range in MPI 
values, especially for radionuclides, was dependent on the magnitude of variation in pore-water velocity in the saturated zone. Finally, the results indicated that $\boldsymbol{K}_{\boldsymbol{d}}$ was indeed an important variable, and its value influenced the ordering of the other important variables.

The most important variables for explaining the variability in HPI values are also dependent on whether the constituent is a radionuclide or nonradionuclide and on the value of the sorption constant. For radioactive constituents, pore-water velocity was the nost important variable because of its influence on travel times for the constituents. For the chemical constituents when $K_{d}$ was less than approximately 1.0 , the waste unit inventories and variables that relate to the exposure pathways for the constituent are found to be important. For example, for PCE and toluene, the drinking-water population and the distance to the receptor are important variables reflecting the importance of the drinking-water exposure pathway. For $\mathrm{Hg}$, the fish production rate is also important because consumption of contaminated fish is the most important exposure pathway for this constituent. If $\boldsymbol{K}_{\mathbf{d}}$ values are large, the $\boldsymbol{K}_{\boldsymbol{d}}$ is always an important variable. The chemical constituents had a different set of important variables because radioactive constituents decay and chemical constituents do not decay.

\subsection{PRECIPITATION-DRIVEN GROUNDWATER-TO-SURFACE-WATER TRANSPORT PATHWAY}

For situations where the leachate rates from the ranking unit are not known or the effects of precipitation or other sources of added water (e.g.. through irrigation) are to be evaluated, the precipitation-driven groundwater transport pathway can be used. Most often, climatic parameters that describe the infiltration rate are more easily measured than the infiltration rate itself.

\subsubsection{Site Description}

The representative ranking unit used to evaluate precipitation-driven groundwater transport is located south of a river between two towns in a mountain valley. The site is approximately $11.2 \mathrm{~km}$ long and $4.8 \mathrm{~km}$ wide, and constituents were deposited onto the surface soil as the result of past industrial activities. The climate is moderate with $77.2 \mathrm{~cm}$ of total rainfall per year. Constituents are transported through silty loam surface 
soil, a partially saturated zone of sand, and a saturated zone of compacted sand with clay and then to a neighboring river. A population of 100,000 is located downriver. Exposure occurs through drinking water and through consumption of contaminated fish.

\subsubsection{Variable Descriptions}

The variables used in the analysis for this scenario along with their nominal values and variation ranges are given in Table 2.11. The data required to characterize this pathway include those discussed at the beginning of Section 2.3.2 for the nonprecipitation-driven groundwater transport pathway. The monthly climatic conditions over the year are listed in Table 2.12. The variables that are indented in the listing in Table 2.11 are calculated from the variable(s) preceding them. Because their values are completely detemined by the values of the preceding variables, they were not included as independent variables in the sensitivity analysis. However, their values will vary dependently with the variation in the variables from which they are calculated.

The inventories for four of the eight constituents, $3 \mathrm{H}, \mathrm{PCE}$, As, and toluene are given in Table 2.11. The other four constituents, $90 \mathrm{Sr}, 90 \mathrm{Y}, \mathrm{Hg}$, and PCBs, are not included in the sensitivity analysis because they produced HPIs of -250 . The very low HPI values for these four constituents were due both to high sorption, which resulted in low releases from the contaminated soil, and radioactive decay for the radionuclides. Because the representative site is assumed to be well characterized, the inventories varied by $\pm 10 \%$. The dimensions of the ranking unit can be determined from topographic maps, and for this hypothetical site, the dimensions of the ranking unit were chosen to be $1.1 \mathrm{E}+6 \mathrm{~cm}$ by $4.8 E+5 \mathrm{~cm}$ with a variability of $\pm 10 \%$.

The site soil is silty loam. The moisture content and bulk density of the ranking unit were taken from Table 2.1 of Droppo et al. (1989a) for the silty loam soil type classification. For the analysis, the moisture content of the ranking unit was assumed to be equal to the field capacity of the surface soil. The nominal values for the soil characteristics for the partially saturated and saturated zones were also taken from Table 2.1 of Oroppo et al. (1989a) for sand and compacted sand with clay, respectively. 
TABLE 2.11. Nominal Values and Variation Ranges of Variables for the Precipitation-Driven Groundwater-to-Surface-Water Transport Pathway

\begin{tabular}{|c|c|c|}
\hline Variable & Nominal Value & Variation Range, \\
\hline $\begin{array}{l}3 \mathrm{H} \text { inventory } \\
3 \mathrm{H} \text { concentration } \\
\text { PCE inventory } \\
\text { PCE concentration } \\
\text { As inventory } \\
\text { As concentration } \\
\text { Toluene inventory } \\
\text { Toluene concentration }\end{array}$ & $\begin{array}{l}2.5 \mathrm{E}+3 \mathrm{Ci} \\
2.83 \mathrm{E}-11 \mathrm{Ci} / \mathrm{mL} \\
2.5 \mathrm{E}+6 \mathrm{~g} \\
2.83 \mathrm{E}-8 \mathrm{~g} / \mathrm{mL} \\
2.5 \mathrm{E}+8 \mathrm{~g} \\
2.83 \mathrm{E}-6 \mathrm{~g} / \mathrm{mL} \\
2.5 \mathrm{E}+10 \mathrm{~g} \\
2.83 \mathrm{E}-4 \mathrm{~g} / \mathrm{mL}\end{array}$ & $\begin{array}{l} \pm 10 \\
\pm 10 \\
\pm 10\end{array}$ \\
\hline $\begin{array}{l}\text { Surface } K_{d} \text { - PCE } \\
\text { Surface } K_{d} \text { - Arsenic } \\
\text { Surface } K_{d} \text { - Toluene }\end{array}$ & $\begin{array}{c}1.78 \mathrm{~mL} / \mathrm{g} \\
19.4 \mathrm{~mL} / \mathrm{g} \\
1.48 \mathrm{~mL} / \mathrm{g}\end{array}$ & $\begin{array}{l} \pm 50 \\
\pm 50 \\
\pm 50\end{array}$ \\
\hline $\begin{array}{l}\text { Ranking Unit length } \\
\text { RU width } \\
\text { RU moisture content } \\
\text { RU bulk density } \\
\text { Soil moisture capacity } \\
\text { SCS curve number } \\
\text { Depth } \\
\text { Long. dispersivity } \\
\text { Bulk density } \\
\text { Porosity } \\
\text { Field capacity } \\
\text { Hydraulic conductivity } \\
\text { Soi I type exponent } \\
\text { PCE Kd } \\
\text { As Kd } \\
\text { Toluene } K_{d}\end{array}$ & $\begin{array}{l}1.1 \mathrm{E}+6 \mathrm{~cm} \\
4.8 \mathrm{E}+5 \mathrm{~cm} \\
27.5 \% \\
1.42 \mathrm{~g} / \mathrm{cm}^{3} \\
1.2 \mathrm{~cm} \\
67.5 \\
335.5 \mathrm{~cm} \\
3.0 \mathrm{~cm} \\
1.64 \mathrm{~g} / \mathrm{cm}^{3} \\
38 . \% \\
9.0 \% \\
3500.9 \mathrm{~cm} / \mathrm{d} \\
4.05 \\
0.37 \mathrm{~mL} / \mathrm{g} \\
5.86 \mathrm{~mL} / \mathrm{g} \\
0.31 \mathrm{~mL} / \mathrm{g}\end{array}$ & $\begin{array}{l} \pm 10 \\
\pm 10 \\
\pm 15 \\
\pm 15 \\
\pm 15 \\
\pm 10 \\
\pm 30 \\
\pm 15 \\
\pm 15 \\
\pm 15 \\
\pm 15 \\
\pm 15 \\
\pm 50 \\
\pm 50 \\
\pm 50\end{array}$ \\
\hline \multicolumn{3}{|c|}{ Saturated Zone } \\
\hline $\begin{array}{l}\text { Pore-water velocity } \\
\text { Depth } \\
\text { Bulk density } \\
\text { Porosity } \\
\text { Field capacity } \\
\text { Distance } \\
\text { Long. dispersivity } \\
\text { Transverse disp. } \\
\text { Vertical disp. }\end{array}$ & $\begin{array}{l}\text { 52. } \mathrm{cm} / \mathrm{d} \\
820 . \mathrm{cm} \\
1.98 \mathrm{~g} / \mathrm{cm}^{3} \\
25 . \% \\
25 . \% \\
3.6 \mathrm{E}+5 \mathrm{~cm} \\
3.6 \mathrm{E}+4 \mathrm{~cm} \\
7.2 \mathrm{E}+3 \mathrm{~cm} \\
42 . \mathrm{cm}\end{array}$ & $\begin{array}{l} \pm 15 \\
\pm 30 \\
\pm 15 \\
\pm 15 \\
\pm 15 \\
\pm 10\end{array}$ \\
\hline $\begin{array}{l}\text { PCE } K_{d} \\
\text { As } K_{d} \\
\text { Toluene } K_{d}\end{array}$ & $\begin{array}{l}0.37 \mathrm{~mL} / \mathrm{g} \\
5.86 \mathrm{~mL} / \mathrm{g} \\
0.31 \mathrm{~mL} / \mathrm{g}\end{array}$ & $\begin{array}{l} \pm 50 \\
\pm 50 \\
\pm 50\end{array}$ \\
\hline
\end{tabular}


TABLE 2.11. (contd)

\begin{tabular}{|c|c|c|}
\hline Variable & Source Term & Variation Range, $\frac{\circ}{6}$ \\
\hline \multicolumn{3}{|c|}{ River } \\
\hline $\begin{array}{l}\text { Depth } \\
\text { Width } \\
\text { Length } \\
\text { Discharge }\end{array}$ & $\begin{array}{l}\text { 61. } \mathrm{cm} \\
2200 . \mathrm{cm} \\
\text { 4.5E+5 cm } \\
6.3 \mathrm{E}+12 \mathrm{~cm}^{3} / \mathrm{d}\end{array}$ & $\begin{array}{l} \pm 10 \\
\pm 10 \\
\pm 10 \\
\pm 10\end{array}$ \\
\hline \multicolumn{3}{|c|}{ Velocity $=$ Discharge $/$ (depth * width) $4.7 \mathrm{E}+7 \mathrm{~cm} / \mathrm{d}$} \\
\hline & Exposure Vari & \\
\hline $\begin{array}{l}\text { Drinking population } \\
\text { Finfish production }\end{array}$ & $\begin{array}{l}1.0 E+5 \\
1.0 E+4 \mathrm{~kg} / \mathrm{yr}\end{array}$ & $\begin{array}{l} \pm 10 \\
\pm 10\end{array}$ \\
\hline
\end{tabular}

TABLE 2.12. Monthly Climatic Conditions Affecting the PrecipitationDriven Groundwater-to-Surface-Water Transport Pathway

Meteorological Data

\begin{tabular}{lcc} 
& & \\
Jemperature ${ }^{\circ} \mathrm{F}$ & Raín, in. \\
\cline { 2 - 3 } Jan & 27.5 & 4.38 \\
Feb & 33.3 & 2.99 \\
Mar & 37.4 & 2.57 \\
Apr & 45.7 & 2.23 \\
May & 54.2 & 2.42 \\
Jun & 61.2 & 2.24 \\
Ju1 & 67.9 & .92 \\
Aug & 66.4 & 1.33 \\
Sep & 58.5 & 1.67 \\
Oct & 47.7 & 2.22 \\
Nov & 36.4 & 3.27 \\
Dec & 30.4 & 4.14 \\
& & \\
& RH max, & RH min, \\
Jan & 84. & 77. \\
Feb & 83. & 69. \\
Mar & 80. & 55. \\
Apr & 76. & 44. \\
May & 76. & 41. \\
Jun & 74. & 36. \\
Jul & 63. & 27. \\
Aug & 62. & 28. \\
Sep & 71. & 35. \\
Oct & 79. & 49. \\
Nov & 87. & 75. \\
Dec & 87. & 81.
\end{tabular}


The topsoil water capacity of $1.2 \mathrm{~cm}$ was estimated from SCS County Soil Survey data for the site. The $K_{d}$ values for constituents were chosen to be consistent with those for the types of geologic media. The soil characteristics varied by $\pm 15 \%$, zone depth $\pm 30 \%$, and the $K_{d}$ values $\pm 50 \%$.

In the precipitation-driven case for MEPAS, the infiltration of contaminants into the groundwater system is driven by groundwater recharge, several climatic variables are included as input variables for this pathway. The required climatic variables are mean air temperature, mean rainfall, mean wind speed, mean cloud cover, mean number of precipitation days, minimum relative humidity, and maximum relative humidity for each of the 12 months of the year. The wind speed variables were varied $\pm 8 \%$. All other climatic variables were varied $\pm 20 \%$. The climatic variables were varied dependently in groups. For example, the mean rainfall for each of the months was increased or decreased by the same percentage of the nominal value. The other groups of dependent variables are monthly temperature, monthly wind speed, monthly days of cloud cover, monthly days of precipitation, and monthly minimum and maximum relative humidity.

The SCS number, which is used to compute the portion of the precipitation that results in overland flow as part of the water balance, was chosen to represent the average SCS value for soils with moderate to slow infi]tration rates with moderate vegetation coverage (i.e., $20 \%$ to $60 \%$ ) and varied by $\pm 10 \%$. SCS vaTues for various soils and surface covers are given in Table 2.2 of Droppo et al. (1989a).

The sources of the river flow data are the same as those for the nonprecipitation-driven groundwater transport pathway analysis. These sources include river monitoring data and topographic maps for the river characteristics and census data for the population and fish production rates. The population of the city was assumed to be 100,000 . The parameters describing river flow, population, and fish production were all varied $\pm 10 \%$.

\subsubsection{Sensitivity Analysis Results}

The 37 independent variables for those constituents with nonzero $K_{d}$ values were varied within the ranges in Table 2.11 subject to the appropriate 
dependency constraints for the monthly meteorological variables. The variables were sampled randomly within the ranges defined in Table 2.11 using the Latin Hypercube method described in Appendix B. Sixty input vectors were obtained, and 60 runs of the code were completed. The minimum, median, and maximum HPI results obtained from the 60 runs are given in Table 2.13.

Analyses were not run for the $90 \mathrm{Sr}, 90 \mathrm{Y}, \mathrm{PCBs}$, and $\mathrm{Hg}$ because the nominal values were never greater than -250 , as discussed previously. For three of the four remaining constituents (i.e., $3 \mathrm{H}, \mathrm{PCE}$, and toluene), the range in HPI values of 2 to 3 HPI units is slightly larger than the range for the nonprecipitation-driven groundwater transport pathway Case 4 of approximately 1 HPI unit. The HPI range for arsenic of nearly $27.6 \mathrm{HPI}$ units is much larger than the 10.3-HPI-unit range for the nonprecipitation groundwater transport pathway Case 4. The larger range in HPI values for the precipitation-driven pathway as compared to Case 4 of the nonprecipitationdriven pathway illustrates that the variation in the climatic variables contribute to the variability in the HPI value. The most likely reason for that variability is that the variation in the climatic parameters used to estimate recharge result in variation in the release rate from the site to the groundwater and thus an increased variability in the concentrations reaching the receptor point than would be expected from the nonprecipitationdriven pathway where the release rates are constant with time.

Table 2.14 gives the results of the sensitivity analyses for the four constituents for which HPI scores were calculated. The total $R^{2}$ values for the four constituents is very high (i.e., 93\% to 97\%). As with the previous nonprecipitation-driven groundwater cases, the importance of the different variables depends on the properties of each constituent and the primary exposure routes for the constituent. The radionuclide $3 \mathrm{H}$ has a zero $\mathrm{K}_{\mathrm{d}}$ but is subject to radioactive decay; therefore, the saturated zone velocity and the partially saturated zone depth, which influence travel time, and the rainfall, which influences the release of contaminants, exert the most influence on the HPI. There is, however, little difference in the amount of the variability in the HPI that is accounted for by these variables and the other important variables that define the important exposure route (i.e., drinkingwater population and the initial inventory available for release). 
IABLE 2.13. Hazard Potential Index Score Ranges for PrecipitationDriven Groundwater-to-Surface-Water Transport Pathway

Constituents

\begin{tabular}{|c|c|c|c|c|c|c|c|c|}
\hline $90 s r$ & $90 Y$ & $3 \mathrm{H}$ & PCE & As & PCBS & Hg & Toluene & Value \\
\hline $\begin{array}{l}\mathrm{NC} \\
\mathrm{NC} \\
\mathrm{NC}\end{array}$ & $\begin{array}{l}N C \\
N C \\
N C\end{array}$ & $\begin{array}{r}22.4 \\
23.5 \\
24.5 \\
2.1\end{array}$ & $\begin{array}{r}27.1 \\
28.6 \\
30.0 \\
2.9\end{array}$ & $\begin{array}{l}14.6 \\
29.6 \\
42.2 \\
27.6\end{array}$ & $\begin{array}{l}N C \\
N C \\
N C\end{array}$ & $\begin{array}{l}\text { NC } \\
N C \\
N C\end{array}$ & $\begin{array}{r}26.1 \\
27.3 \\
28.8 \\
2.7\end{array}$ & $\begin{array}{l}\text { min } \\
\text { med } \\
\text { max } \\
\text { range }\end{array}$ \\
\hline
\end{tabular}

$\overline{N C}=$ Not run.

As shown in Table 2.5, the dominant exposure route for the four constituents analyzed is drinking water. For the other three constituents (PCE, As, and toluene), which can sorb to the surface soil and the subsurface material, the $K_{d}$ values in the partially saturated and/or saturated zones are among the most important input variables. The range in HPI and amount of HPI variability explained by $K_{d}$ is related to its value, with the larger $K_{d}$ of As accounting for more of the variability than the smaller $K_{d} S$ of PCE and toluene. The only atmospheric variable that appears among the list of important variables is rainfall, which directly influences recharge and, therefore, the release rate from the site. In general, the higher the rainfall, the larger the recharge and the release rate from the site, depending on the soil type. The ranking of the less important variables and the amount of variability explained by them were remarkably similar for PCE and toluene. These less-important variables include ones contributing to the movement of the constituent through the media to the receptor and the population affected through the primary exposure route; that is, drinking water (see Table 2.5).

A comparison of the results of this precipitation-driven analysis and Case 4 of the nonprecipitation-driven analysis, where the pore water was aiso varied $\pm 15 \%$ and realistic $K_{d} s$ were used (Table 2.10 ), demonstrates that the sensitivity analysis results can be generalized for combinations of pathways. These two analyses are not directly comparable because the sites are different (one has an arid climate; the other a moderate climate) and thus 
IABLE 2.14. Most Important Variables Affecting Hazard Potential Index for Precipitation-Driven Groundwater-to-SurfaceWater Transport Pathway

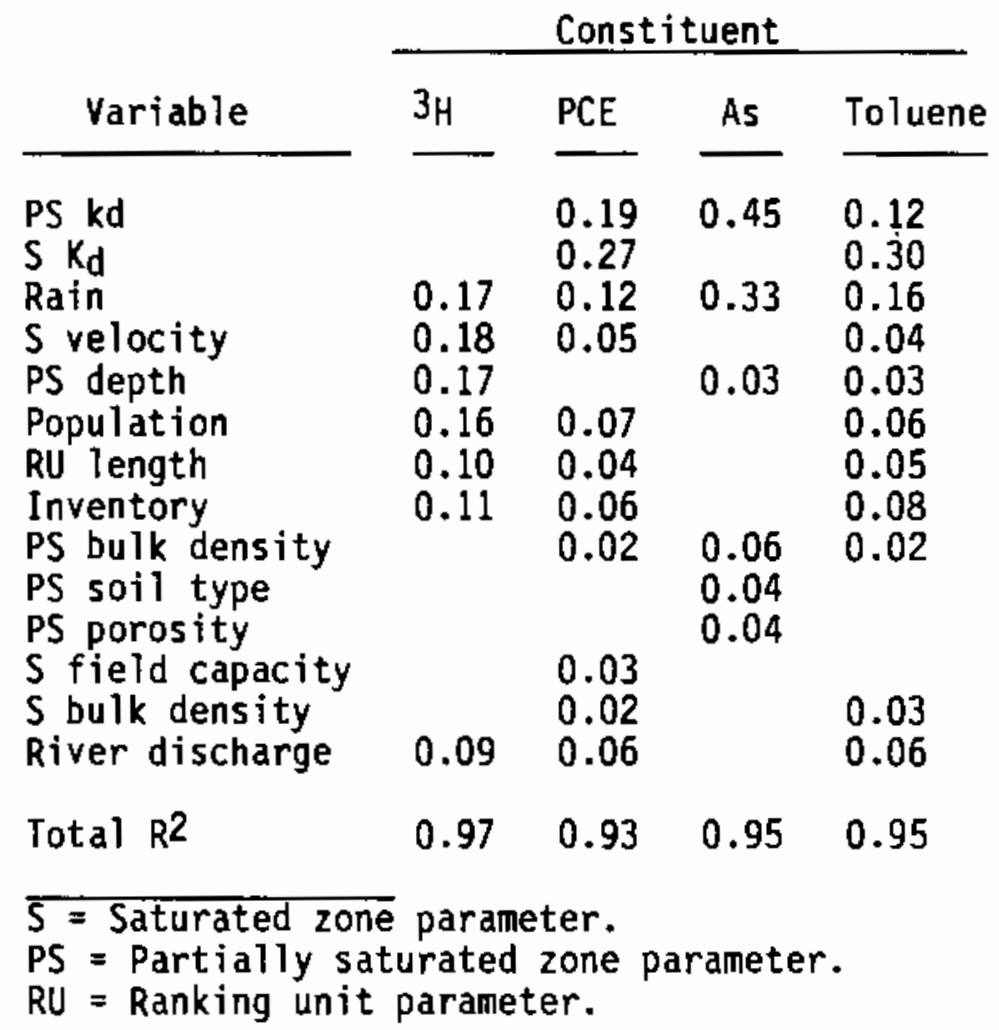

the nominal values for the variables (such as soil properties and the resulting leach rates) are different. In addition, the precipitation-driven analysis includes the effects of climatic conditions on the leach rate from the ranking unit, whereas the nonprecipitation-driven analysis assumes a constant release of the inventory over time. When the primary climatic variable, rainfall, is removed from the list in Table 2.14, it is apparent that there is some similarity in the list of important variables between the two analyses; however, the ordering of the variables is different. Thus, the precipitation-driven transport pathway behaves similarly to the comparable nonprecipitation-driven groundwater pathways with the addition of rainfall, illustrating that the results of the different pathway combinations can be partially extended to other pathways. 


\subsubsection{Conclusions}

The range in HPI values for the precipitation-driven groundwater pathway for a well-characterized site is larger than the range for case 4 of the nonprecipitation-driven groundwater transport pathway, which also assumed a $\$ 15 \%$ variability in the pore-water velocity and realistic $K_{d} S$. (The HPI range depends on the $K_{d}$ values assumed; the larger $K_{d}$ values produced larger HPI ranges.) The variation in climatic variables contributes to an increased variability in release rate from the site and subsequent HPI score compared to the nonprecipitation-driven groundwater transport pathway. The precipitation-driven pathway results in a much more diverse set of important variables than the nonprecipitation-driven pathway in part because it starts with a more diverse data set. The important variables for the precipitationdriven groundwater pathway are similar to the important variables for the comparable nonprecipitation-driven analysis. Rainfall is the only climatic variable that was found to be important and it accounts for only $12 \%$ to $33 \%$ of the observed variability in the HPI value of approximately 27 HPI units for As and approximately 2 to 3 HPI units for $3 \mathrm{H}, P C E$, and toluene.

\subsection{OVERLAND-TO-SURFACE-WATER TRANSPORT PATHWAY}

In addition to the transport of constituents via groundwater, which can be modeled using either the nonprecipitation-driven or precipitation-driven transport pathways, constituents can be transported over the ground surface with the water and sediment by overland water flow to other water bodies such as a river. This section presents the results of the sensitivity analysis for this overland-to-surface-water transport pathway.

\subsubsection{Site Description}

Because the site description and climatic variables needed for the overland-to-surface-water transport pathway are the same as those required for the precipitation-driven groundwater-to-surface-water pathway (Section $2.4)$, the same representative ranking unit was used for the analysis of the overland-to-surface-water transport pathway. The representative ranking unit is located south of a river between two towns in a mountain valley with a moderate climate. The site is approximately $11.2 \mathrm{~km} l o n g$ and $4.8 \mathrm{~km}$ wide, 
and constituents were deposited onto the surface soil as the result of past industrial activities. Contaminated soils are carried to the river by overland runoff, and human exposures result through drinking water and through the consumption of contaminated fish.

\subsubsection{Variable Descriptions}

The input variables required to describe transport through this pathway include the properties of the ranking unit, river and exposure pathways, the climatic data, and surface $K_{d} s$. These parameters have the same values as those used in the precipitation-driven groundwater-to-surface-water transport pathway (Section 2.4). However, this pathway also requires additional parameters to describe the soil loss associated with the runoff. The additional parameters used for this pathway, their nominal values, and variation ranges are given in Table 2.15. The variables that are the same as those for the precipitation-driven transport pathway (i.e., the ranking unit properties, river, exposure route, partially saturated and saturated zone characteristics, and meteorological data) are given in Tables 2.11 and 2.12 and explained in Section 2.4.2.

The inventories and concentrations in the ranking unit and the surface $K_{d}$ values for the eight constituents are given in Table 2.15. The inventories, concentrations, and $K_{d}$ values for the four constituents that were evaluated in the precipitation-driven pathways analysis are the same for this analysis.

The SCS curve number is used to calculate the proportion of the precipitation that occurs as overland flow. The value for the SCS curve number is the same value chosen for the water balance included as part of the precipitation-driven transport pathway analysis. The 2-yr recurrence interval, 6-h-duration precipitation event (P26 number) was used to calculate the $R$ factor in the USLE. The value for the P26 number of 1.0 in. was estimated from the Precipitation-Frequency At las of the Western United States as described in Droppo et al. (1989a). For the representative ranking unit, the overland slope value, which is the percent change in surface elevation over the length of the ranking unit, is used to calculate the LS factor 
TABLE 2.15. Nominal Values and Variation Ranges of Variables for Overland-to-Surface-Water Transport Pathway

\begin{tabular}{|c|c|c|}
\hline Variable & Nominal Value & Variation Range, \\
\hline $\begin{array}{l}90 \text { Sr inventory } \\
90 \text { Sr concentration } \\
3 \mathrm{H} \text { inventory } \\
3 \mathrm{H} \text { concentration } \\
\text { PCE inventory } \\
\text { PCE concentration } \\
\text { As inventory } \\
\text { As concentration } \\
\text { PCBS inventory } \\
\text { PCBs concentration } \\
\text { Hg inventory } \\
\text { Hg concentration } \\
\text { Toluene inventory } \\
\text { Toluene concentration }\end{array}$ & $\begin{array}{l}5.0 \mathrm{E}+03 \mathrm{Ci} \\
5.66 \mathrm{E}-11 \mathrm{Ci} / \mathrm{mL} \\
2.5 \mathrm{E}+03 \mathrm{Ci} \\
2.83 \mathrm{E}-11 \mathrm{Ci} / \mathrm{mL} \\
2.5 \mathrm{E}+06 \mathrm{~g} \\
2.83 \mathrm{E}-08 \mathrm{~g} / \mathrm{mL} \\
5.0 \mathrm{E}+05 \mathrm{~g} \\
5.66 \mathrm{E}-09 \mathrm{~g} / \mathrm{mL} \\
5.0 \mathrm{E}+06 \mathrm{~g} \\
5.66 \mathrm{E}-08 \mathrm{~g} / \mathrm{mL} \\
2.5 \mathrm{E}+09 \mathrm{~g} \\
2.83 \mathrm{E}-05 \mathrm{~g} / \mathrm{mL} \\
2.5 \mathrm{E}+10 \mathrm{~g} \\
2.83 \mathrm{E}-04 \mathrm{~g} / \mathrm{mL}\end{array}$ & $\begin{array}{l} \pm 10 \\
\pm 10 \\
\pm 10 \\
\pm 10 \\
\pm 10 \\
\pm 10 \\
\pm 10\end{array}$ \\
\hline $\begin{array}{l}\text { Surface } K_{d}-90 S r \\
\text { Surface } K_{d}-P C E \\
\text { Surface } K_{d}-A S \\
\text { Surface } K_{d}-P C B s \\
\text { Surface } K_{d}-H g \\
\text { Surface } K_{d}-\text { toluene } \\
\text { Surface } K_{d}-3 H\end{array}$ & $\begin{array}{c}100.0 \mathrm{~mL} / \mathrm{g} \\
1.78 \mathrm{~mL} / \mathrm{g} \\
19.4 \mathrm{~mL} / \mathrm{g} \\
2614.23 \mathrm{~mL} / \mathrm{g} \\
580.0 \mathrm{~mL} / \mathrm{g} \\
1.48 \mathrm{~mL} / 9 \\
0\end{array}$ & $\begin{array}{l} \pm 50 \\
\pm 50 \\
\pm 50 \\
\pm 50 \\
\pm 50 \\
\pm 50\end{array}$ \\
\hline \multicolumn{3}{|l|}{ Overland Data } \\
\hline $\begin{array}{l}\text { SCS curve number } \\
\text { P26 number } \\
\text { Overland slope } \\
K \text { factor } \\
C \text { factor } \\
p \text { factor }\end{array}$ & $\begin{array}{l}67.5 \\
1.0 \mathrm{in} . \\
2.3 \% \\
0.48 \\
0.29 \\
1.0\end{array}$ & $\begin{array}{l} \pm 10 \\
\pm 20 \\
\pm 20 \\
\pm 20 \\
\pm 20 \\
\pm 20\end{array}$ \\
\hline
\end{tabular}

(see Droppo et al. 1989a). The value for the overland slope was selected to represent the slope of a valley bottom. This value can be determined from topographic maps. The soil erodibility factor, which is estimated from the soil type classification and the organic matter content of the soil, was taken from Table 2.1 in Droppo et al. (1989a) for silty loam with low organic matter content $(<0.05 \%)$. The vegetative cover ( $C$ factor) and surface roughness ( $P$ factor) factors for the ranking unit were selected from Tables 2.4 and 2.5, respectively, in Droppo et al. (1989a) to be consistent with a site with moderate vegetation coverage $(20 \%$ to $60 \%)$. 
The movement of contaminated sediments from a ranking unit is predicted with the USLE, which is an empirically derived method (see Section 2.1.3 for description). The five factors included in the USLE were varied in this analysis (Table 2.15). They are 1) the recurrence interval for precipitation events (P26 number), 2) the overland slope of the waste unit, 3) the erodibility factor ( $K$ factor), 4) the vegetative cover factor ( $C$ factor), and 5) the surface roughness of the ranking unit (P factor).

The site was assumed to be well characterized for these analyses. Therefore, most of the variables were assumed to vary $\neq 10 \%$. The surface Kds were assumed to vary $\$ 50 \%$ because the range in literature values is quite large. The overland variables (P26 number; overland slope; $K, C$, and $P$ factors) were varied $\pm 20 \%$ based on the range in values given in Droppo et al. (1989a).

\subsubsection{Sensitivity Analys is Results}

The variable dependencies for the climatologic parameters discussed in Section 2.4.2 were also used for this analysis. When these dependencies are considered, there were 26 variables that were varied independently for this transport pathway. These variables are those used in the precipitationdriven analysis except for the minimum and maximum relative humidity and the partially saturated and saturated zone parameters (i.e., 21 remaining variables) plus the five variables, in addition to the SCS curve number, that describe the overland transport pathway. The variables were sampled randomly within the ranges defined in Table 2.15 using the Latin Hypercube method described in Appendix 8 . Sixty vectors of input variables were generated. Eleven of the 60 runs produced an HPI of -250 for all constituents. The minimum, median, and maximum HPI scores for each constituent from the remaining 49 runs are given in Table 2.16 .

The range in HPI values for all constituents is very large. For several of the constituents, notably PCE and toluene, this range is the largest seen of any of the transport pathways analyzed. The range is much larger than that seen for the precipitation-driven transport pathway, which used the same site and input data but evaluated the groundwater pathway instead of the overland pathway. The large range in HPI values that are independent of the 
constituent being considered is probably representative of the step-function relationships in the overland transport pathway that will be discussed below.

The total R2 values of 0.53 to 0.61 from the analysis of the overland pathway are much smaller than those obtained for the other waterborne pathways. These low $R^{2}$ values indicate that a substantial amount of variation in the HPI values of approximately 21 to $44 \mathrm{HPI}$ units cannot be explained by the linear statistical model. For this reason, the partial $R^{2}$ values for the independent variables are somewhat unreliable measures of the importance of the variables. However, the patterns in the variables selected by the sensitivity analysis and their order are instructive to consider. For all constituents, air temperature, which is related to number of months with temperatures below freezing (see explanation below), was the dominant variable, with a partial $R 2$ value between 0.28 and 0.38 . For the remaining five or six variables with a significant contribution to the variability in the HPI values, the partial $R^{2}$ values were roughly equal with $R^{2}$ values between 0.03 and 0.08 . These variables were the number of precipitation days (related to rainfall), river depth, and finfish production rate. Significantly, the drinking-water population, which is the primary exposure route for all the constituents except $\mathrm{Hg}$ (see Table 2.5), and the $K_{d}$ values, which were important in the other groundwater pathways, do not appear on any of the lists.

Because of the large range in HPI values, the large number of runs with HPI values of -250 , and the low total $R^{2}$ values, a second analysis was made using the same assumptions and nominal values for the input variables. For this analysis, 10 of the runs resulted in HPI scores of -250 for all constituents compared to 11 runs for the first analysis. Although the range in the remaining HPI values is comparable to that reported in Table 2.16 for the first analysis, the total $R^{2}$ values for this second analysis indicate that even less of the variability in the HPI values was explained by the important variables than for the first analysis (Table 2.17). Further evaluation of the results indicated that several low HPI scores in addition to the ones at -250 were produced for each of the analyses. The combined results of the two analyses suggest that this pathway results in less stable estimates of the HPI values and/or that there is nonlinearity in the relationship between the 
TABLE 2.16. Hazard Potential Index Score Ranges for Overland-toSurface-Water Transport Pathway

Constituent

\begin{tabular}{|c|c|c|c|c|c|c|c|c|}
\hline $90 S r$ & $90 Y$ & $3 \mathrm{H}$ & PCE & As & PCBs & $\mathrm{Hg}$ & Toluene & Value \\
\hline $\begin{array}{l}42.0 \\
49.0 \\
30.2\end{array}$ & $\begin{array}{r}-11.1 \\
12.1 \\
32.7 \\
43.8\end{array}$ & $\begin{array}{r}8.7 \\
26.1 \\
29.9 \\
21.2\end{array}$ & $\begin{array}{l}3.1 \\
28.3 \\
32.9 \\
29.80\end{array}$ & $\begin{array}{r}2.0 \\
25.2 \\
34.3 \\
32.3\end{array}$ & $\begin{array}{r}1.1 \\
25.1 \\
33.8 \\
32.7\end{array}$ & $\begin{array}{r}3.2 \\
28.0 \\
37.3 \\
34.1\end{array}$ & $\begin{array}{r}3.6 \\
26.4 \\
30.9 \\
27.3\end{array}$ & $\begin{array}{l}\text { min } \\
\text { med } \\
\text { max } \\
\text { range }\end{array}$ \\
\hline
\end{tabular}

TABLE 2.17. Most Important Variables Affecting Hazard Potential Index for Overland-to-Surface-Water Transport Pathway

Constituent

\begin{tabular}{|c|c|c|c|c|c|c|c|c|}
\hline Variable & $90 s r$ & $90 Y$ & $3 \mathrm{H}$ & PCE & As & $\underline{\mathrm{PCBs}}$ & $\mathrm{Hg}$ & Toluene \\
\hline $\begin{array}{l}\text { Air temperature } \\
\text { Precipitation days } \\
\text { SCS curve number } \\
\text { River depth } \\
\text { Fish production } \\
\text { C factor } \\
\text { Kd } \\
\text { AW factor }\end{array}$ & $\begin{array}{l}0.32 \\
0.08 \\
0.05 \\
0.06 \\
0.05\end{array}$ & $\begin{array}{l}0.38 \\
0.08 \\
0.08 \\
0.03 \\
0.04\end{array}$ & $\begin{array}{l}0.31 \\
0.05 \\
0.08 \\
0.05 \\
0.06\end{array}$ & $\begin{array}{l}0.28 \\
0.05 \\
0.08 \\
0.05 \\
0.05 \\
0.06\end{array}$ & $\begin{array}{l}0.33 \\
0.08 \\
0.05 \\
0.06 \\
0.04\end{array}$ & $\begin{array}{l}0.33 \\
0.08 \\
0.04 \\
0.07 \\
0.04\end{array}$ & $\begin{array}{l}0.33 \\
0.08 \\
0.07 \\
0.03 \\
0.04 \\
0.03\end{array}$ & $\begin{array}{l}0.28 \\
0.05 \\
0.08 \\
0.04 \\
0.08\end{array}$ \\
\hline Total R2 & 0.56 & 0.61 & 0.55 & 0.57 & 0.56 & 0.56 & 0.58 & 0.53 \\
\hline
\end{tabular}

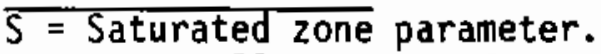

PS = Partially saturated zone parameter.

$\mathrm{RU}=$ Ranking unit parameter.

important variables and the HPI values that are not accounted for in the statistical analyses.

An examination of the mathematical approach used to model the overland flow pathway indicates that this pathway is dominated by step functions. 0verland flow will occur if enough precipitation occurs in a certain time period or if precipitation is stored as snowfall during a cold period, then released as snowmelt. Therefore, if enough overland flow occurs, then some portion of the inventory of constituents will be transported to the river, and HPI values can be calculated. However, if overland flow does not occur, then no transport to the river will occur, resulting in HPI values of -250 . 
Because precipitation that occurs during the winter is stored and released in the spring when temperatures above freezing are reached, the overland flow is dependent on the number of consecutive months of below-freezing air temperatures and the amount of precipitation received during that period. Thus, the temperature and number of precipitation days were always identified as important variables in the sensitivity analyses. A combination of the number of months with temperatures below freezing and the total amount of precipitation in those months may explain the variation in the HPI values better than the single temperature and precipitation variables used. These results of the statistical analyses indicate that the present linear model will be unable to adequately explain the overland transport pathway, which is described by step functions in MEPAS rather than continuous processes.

\subsubsection{Conclusions}

For the overland-to-surface-water pathway, the range in HPI scores is very large (21 to $44 \mathrm{HPI}$ units) for all eight constituents, and the amount of this variability accounted for by the important variables is less than that for all the other groundwater cases. These results indicate that this pathway results in less consistent estimates of the HPI values and suggest that there are nonlinearities in the functional relationship between HPI value and the important variables. The most important variable is air temperature for all the constituents. The number of precipitation days is also an important variable. These two variables are important because overland flow is strongly influenced by snowmelt, which depends on the number of consecutive months of below-freezing temperatures and the amount of precipitation received during that period. The other variables, which are reasonably consistent among constituents, are finfish production rate and river transport parameters. The discontinuous nature of the overland transport pathways and the use of step functions to model the transport probably accounts for the large range in HPI values and the inability of a simple linear statistical model between the variables and the HPI values to explain this variability. Further evaluation of the data would require that the parameters of the linear model be modified and that interaction terms be included. 


\subsection{ATMOSPHERIC PATHWAYS}

Exposure to humans can occur as the result of the release to the atmosphere of hazardous materials from ranking units (Figure 3.1). These releases may occur from both point and area sources. Exposure via the atmospheric pathways occurs both as the result of atmospheric concentrations and from resultant surface concentrations on soil and crops.

To analyze the movement of hazardous material through the atmospheric pathway, three sequential steps must be completed. First, the release rate of the constituents from the hazardous material are defined. Second, the effect of the release characteristics on the initial dispersion and height of the plume (plume rise) are defined. Third, the plume transport, dispersion, and deposition are calculated to provide estimates of the environmental concentrations at receptor locations, which are then used to calculate the HPI.

Constituents may be released to the atmosphere from point sources (e.g., stacks, vents) or area sources (e.g., landfills, disposal pits, storage ponds). Releases from active operations generally occur through stacks and vents and thus could be modeled as point sources. Releases from inactive operations, as the result of volatilization of gases and/or suspension of particulate matter from storage sites or contaminated soil, could be modeled as area sources. The emission rates for point sources are generally known. In contrast, the emission rates for area sources may not be known. In that case, emission rates can be estimated using MEPAS component codes. For example, particulate and gaseous emissions may be estimated using the suspension and volatilization components of MEPAS, respectively. These component codes of the atmospheric transport pathway model calculate the emission rate using empirical relationships and site and constituent characteristics (Cowherd et al. 1984; EPA 1988).

The release characteristics affect the initial dispersion and plume rise. The initial dispersion for an area release is determined by the size of the area. The minimum initial dispersion for a "point" release is determined by the exit size and velocity. The height of a plume, important in 


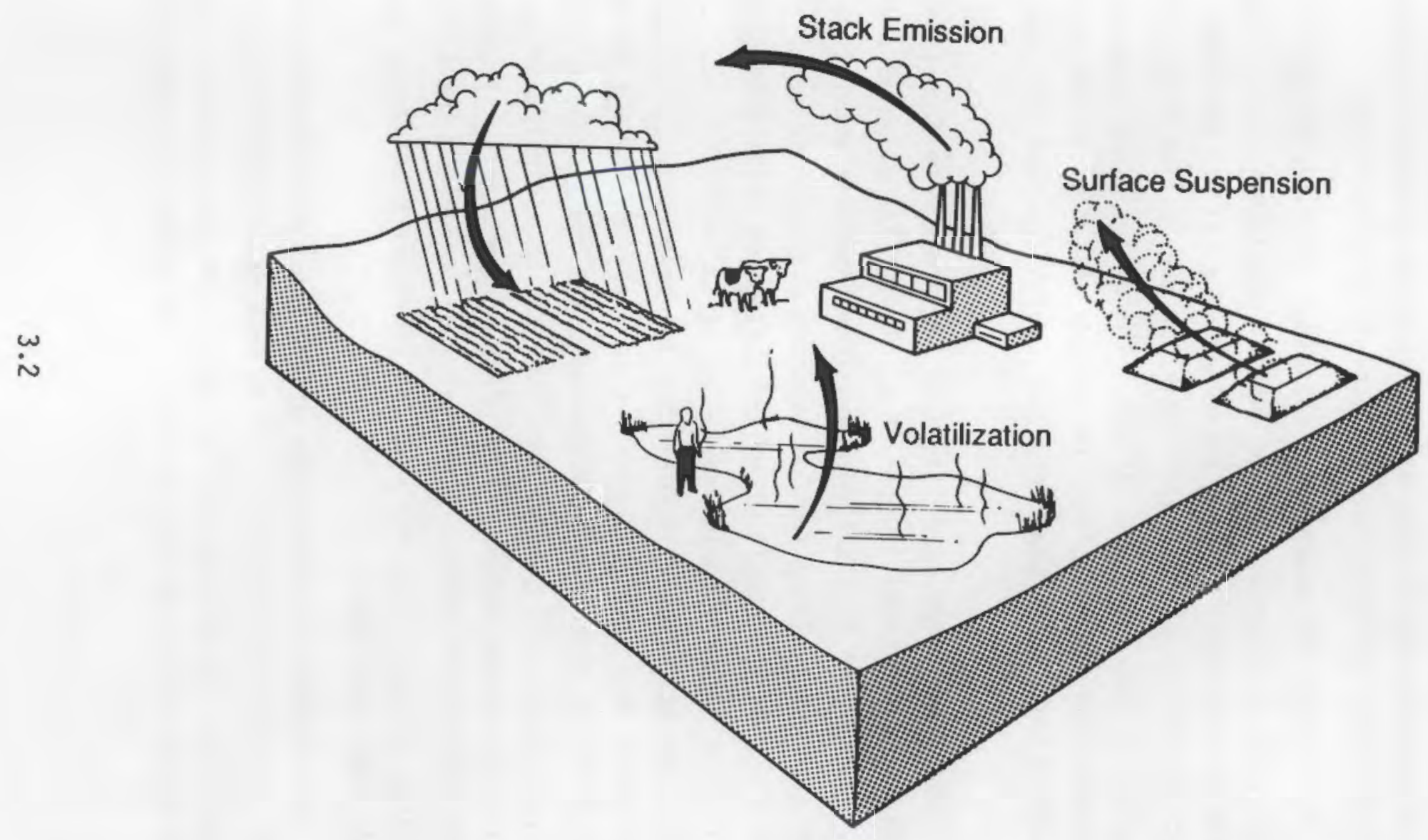

FIGURE 3.1. Atmospheric Transport Pathway Illustrating Exposure Through Inhalation, Deposition on Crops, and Uptake by Humans and Livestock 
calculating near-source concentrations, is the sum of stack height and plume rise. The plume rise is a function of the exit characteristics, such as temperature, radius, and exit velocity, and is limited by the mixing height. For low stacks whose plume is caught in the wake of an adjacent building, the plume rise is assumed to be equal to zero; however, the initial dispersion is enhanced. For vent releases from buildings, the initial dispersion may be similarly enhanced by the building wake.

The atmospheric transport and dispersion component uses a sector-average Gaussian dispersion model similar to those proposed by Busse and Zimmerman (1973) with dispersion relationships that are dependent on local site characteristics (Pasquill and Smith 1983). The characteristics of the local terrain, distance to receptors, dispersion climatology, and constituent properties are used to calculate the environmental concentrations at receptor locations. The dispersion climatology is defined by a joint frequency summary of wind speed, wind direction, and atmospheric stability conditions, commonly referred to as joint frequency distribution. Data on precipitation, surface roughness, and constituent property are used to calculate wet and dry deposition rates from empirical algorithms. Total deposition (i.e., surface concentration) is the sum of wet and dry deposition.

To determine the potential human health impacts of inhaling contaminated air and ingesting farm products that have become contaminated via wet and dry deposition, contaminant air concentrations and surface concentrations as a function of the direction and distance for each identified receptor within $80.5 \mathrm{~km}$ of the site are used. In addition to the air and surface concentrations, the HPI value will depend on the size of the exposed population. For an HPI based on food uptake pathways, the potentially exposed population is also dependent on regional food production rates. Thus, depending on the exposure pathway, the HPI sensitivity to the exposed populations may be expressed as sensitivity to either the regional population size or to food production rates.

In an atmospheric pathway, decay products were not included in the sensitivity analysis; therefore, $90 \mathrm{Y}$ is not included. 


\subsection{STACK RELEASE SCENARIO}

\subsubsection{Site Description}

The representative site for the stack release scenario is located within the southern city limits of a moderate-sized town. The site is about $16 \mathrm{~km}$ south-southwest of a large city and $48 \mathrm{~km}$ north-northeast of another large city. The major geographic feature in the region surrounding the site is a river that flows from northeast to southwest through the town in which the site is located. The river valley is highly industrialized. The rest of the region is predominantly farmland with some light industry and small communities. About $10 \%$ of the agricultural land is assumed to be used for pasturing livestock.

Releases from the stack are transported in the atmosphere to receptor points by dispersion immediately and in the future by resuspension caused by wind erosion. The exposure routes are inhalation, soil ingestion, ingestion of contaminated crops (i.e., leafy vegetables and other vegetables), and ingestion of animal products (i.e., meat and milk) tainted by contaminated crops. The immediate area is exposed via the inhalation and soil ingestion pathway, while resuspension and downwind transport cause exposure to people in the area surrounding the site via all the above exposure routes.

\subsubsection{Variable Descriptions}

The atmospheric model used for the stack release requires several types of data, such as source description, meteorological data, exposure data, and population distribution data. The source and meteorological data are used to describe the transport pathway. The source data defines the source type and emission potential of the ranking unit. The meteorological data are developed from local meteorological measurements and include both climate and land features information. The population distribution and exposure data, which describe the affected population and the routes by which humans may become exposed to the contaminants, are used to calculate the effects on the population from the exposure routes.

There are two ways to model the stack release; with and without downwashing. Downwashing occurs when the building close to the stack is higher than good engineering practices allow, causing the plume to get caught in the 
building wake and mix to the ground prematurely. If the stack is sufficientiy taller than surrounding buildings, release occurs at the stack height. If the stack height is less than two-and-a-half times the height of the surrounding buildings, the contaminant plume undergoes downwashing. In effect, this results in release at ground level. With downwashing, exposure to the nearby population is maximized, because the plume travels downward at ground level. On the other hand, the elevated plume may result in greater exposures at greater distances as a result of its smaller initial dispersion.

The required input variables for the stack release transport pathways and exposure scenario, their nominal values, and associated variability are listed in Table 3.1. The variation range chosen for most source description parameters is $\pm 10 \%$. Only the morning and afternoon mixing heights have a larger variation $(* 25 \%)$, representing the uncertainty in estimating values from Droppo et al. (1989a). The low variation in stack release parameters is typical of a well-characterized or representative site.

The constituent concentrations, which are normally obtained from samples taken at the particular site, were defined with high enough values to ensure that HPI values obtained from the model runs would be greater than zero.

The meteorological data were obtained from National Weather Service measurements. The values for the morning and afternoon mixing heights were estimated using Figures 3.1 and 3.2 in Droppo et al. (1989a). On the map of afternoon mixing height data, the stack facility is assumed to lie between the 1200- and 1400-m isopleths; therefore, the afternoon mixing height for the stack release site was estimated to be $1375 \mathrm{~m}$. The facility lies between the 400- and 500-m isopleths for morning mixing height; therefore, the nominal value of $475 \mathrm{~m}$ was chosen for the morning mixing height. Other meteorological data, such as the number of days per year that precipitation measured greater than $0.025 \mathrm{~cm}$, the number of thunderstorm days per year, and the average annual rainfall, were also obtained from National Weather Service data.

The required input data include surface roughness values for the area surrounding the point of the stack release. A surface roughness length is 
TABLE 3.1. Nominal Values and Variation Ranges of Variables for Stack Release Scenario

\begin{tabular}{|c|c|c|}
\hline Variable & Nominal Value & Variation Range, $\frac{:}{6}$ \\
\hline As emission rate $(g / s)$ & $5.00 \mathrm{E}-04$ & \pm 10 \\
\hline $\mathrm{Hg}$ emission rate $(\mathrm{g} / \mathrm{s})$ & $5.00 \mathrm{E}-02$ & \pm 10 \\
\hline PCBs emission rate $(g / s)$ & $5.00 \mathrm{E}-05$ & $\star 10$ \\
\hline${ }^{90} \mathrm{Sr}$ emission rate $(\mathrm{pCi} / \mathrm{s})$ & $5.00 E+02$ & \pm 10 \\
\hline Toluene emission rate $(\mathrm{g} / \mathrm{s})$ & $5.00 E+03$ & \pm 10 \\
\hline PCE emission rate $(g / s)$ & $5.00 \mathrm{E}-01$ & $\$ 10$ \\
\hline 3H emission rate $(\mathrm{pCi} / \mathrm{s})$ & $5.00 E+06$ & \pm 10 \\
\hline Exit velocity $(\mathrm{m} / \mathrm{s})$ & 8.20 & \pm 10 \\
\hline Exit radius $(\mathrm{m})$ & 1.50 & \pm 10 \\
\hline Stack height $(\mathrm{m})$ & 42.0 & \pm 10 \\
\hline Exit temperature $\left({ }^{\circ} \mathrm{K}\right)$ & $2.92 \mathrm{E}+02$ & \pm 10 \\
\hline Building height (m) & $35.0,10.0$ & \pm 10 \\
\hline Morning mixing height (m) & 475.0 & \pm 25 \\
\hline Afternoon mixing height (m) & 1375.0 & \pm 25 \\
\hline Precipitation days/year & 132.0 & \pm 10 \\
\hline $\begin{array}{l}\text { Average thunderstorm } \\
\text { days/year }\end{array}$ & 43.0 & \pm 10 \\
\hline $\begin{array}{l}\text { Average annual precipitation } \\
(\mathrm{cm})\end{array}$ & 223.8 & \pm 10 \\
\hline Ambient air temperature $\left({ }^{\circ} \mathrm{K}\right)$ & $2.84 \mathrm{E}+02$ & \pm 10 \\
\hline
\end{tabular}

used to characterize the sizes of surface elements that can influence both the suspension and atmospheric dispersion processes. An order-of-magnitude estimate of roughness length is assumed to be sufficient for the model. For the area surrounding the facility, roughness lengths were defined for the 16 standard compass directions at six predetermined distances from the facility (Table 3.2). The surface roughness values are representative of areas covered with urban to woodland forest based on Figure 3.9 in Droppo et al. (1989a). The surface roughness values are varied dependently in the same manner as for the meteorological variables in the precipitation-driven and overland transport pathways in Sections 2.4 and 2.5. Each of the values in 
TABLE 3.2. Surface Roughness Values for the Areas Surrounding the Ranking Unit

\begin{tabular}{|c|c|c|c|c|c|c|}
\hline $\begin{array}{l}\text { Direction } \\
\text { from the } \\
\text { Facility }\end{array}$ & $0-0.1$ & $\begin{array}{r}0 \\
0.1-1.0 \\
\end{array}$ & $\begin{array}{l}\text { nce fron } \\
1.0-3.4\end{array}$ & $\begin{array}{r}\text { Facility } \\
3.4-9.8 \\
\end{array}$ & $9.8-27$ & $27-75$ \\
\hline $\begin{array}{l}N \\
N N E \\
N E \\
\text { ENE } \\
\text { E } \\
\text { ESE } \\
\text { SE } \\
\text { SSE } \\
S \\
\text { SSW } \\
\text { SW } \\
W S W \\
W \\
W N W \\
\text { NW } \\
\text { NNW }\end{array}$ & $\begin{array}{l}150 \\
150 \\
150 \\
150 \\
150 \\
150 \\
150 \\
150 \\
150 \\
150 \\
150 \\
150 \\
150 \\
150 \\
150 \\
150\end{array}$ & $\begin{array}{l}150 \\
150 \\
150 \\
150 \\
150 \\
150 \\
150 \\
150 \\
150 \\
150 \\
150 \\
150 \\
150 \\
150 \\
150 \\
150\end{array}$ & $\begin{array}{r}150 \\
150 \\
150 \\
90 \\
80 \\
80 \\
80 \\
80 \\
80 \\
80 \\
80 \\
80 \\
80 \\
80 \\
80 \\
80\end{array}$ & $\begin{array}{r}90 \\
150 \\
150 \\
150 \\
80 \\
80 \\
80 \\
80 \\
80 \\
80 \\
80 \\
80 \\
80 \\
80 \\
80 \\
80\end{array}$ & $\begin{array}{r}80 \\
150 \\
150 \\
150 \\
80 \\
80 \\
80 \\
80 \\
80 \\
80 \\
80 \\
80 \\
80 \\
80 \\
80 \\
80\end{array}$ & $\begin{array}{r}80 \\
150 \\
150 \\
150 \\
80 \\
80 \\
80 \\
80 \\
80 \\
80 \\
80 \\
80 \\
80 \\
80 \\
80 \\
80\end{array}$ \\
\hline
\end{tabular}

Table 3.2 was multiplied by the same proportionality constant. For example, if the variation value for a realization was chosen to be $8 \%$, then all the roughness values in Table 3.2 were multiplied by 1.08 .

The joint frequency distribution (Appendix $C$ ) that was used to describe the site was compiled for six wind speed groups, seven stability classes, and 16 direction sectors. The frequency of occurrence is reported for each wind speed by stability class and direction. A midpoint in meters per second is also specified for each wind speed category. In this analysis, the wind joint frequency distribution data were not varied.

All of the exposure input variables are indexed to a geographic location corresponding to a portion of area surrounding the site. To derive these geographic locations, the area surrounding the facility was partitioned into 16 sectors corresponding to the 16 standard compass directions. Within each direction sector, 10 distances were chosen to further partition the area. These 160 annular segments are used to define the population grid.

Population data are designated for the total $80.5-\mathrm{km}$ radius area and for each of the 160 annular segments of the population grid. The total 
population was $2,938,799$. The distribution of the population (Table 3.3 ) is dependent on the geographic features around the facility, with most of the population occurring in settlements congregated in valleys and along river banks. The 160 segments are al1 used to detemine the health effects from inhalation and soil ingestion. Because it is assumed that the population is estimated with the same precision within each sector, the population data were varied as a group (i.e., dependently) rather than individually (i.e, independently) using the same procedure as described for the roughness values. The variation range was chosen to be $\pm 10 \%$.

The exposure data also include annual production rates for leafy regetables, other vegetables, meat, and milk. The annual production rates are estimated by receptor location. The amount of a crop produced in a receptor Tocation is assumed to be consumed by the population in that sector unless production exceeds the limit of consumption of the local population, in which case the food is exported from that sector and consumed. The nominal annual rates of production used in this analysis are averages (medians) of representative values reported in various literature sources. Table 3.4 gives the nominal production rates by town number at each of the 28 receptor locations. Because production rates are easily estimated, the production rate variables were assumed to vary independently $\neq 10^{\circ}$ about the nominal values reported in

\section{TABLE 3.3. Population Within $80.5-\mathrm{km}$ Radius of the Stack Release Scenario}

Total $=2,938,790$

\begin{tabular}{|c|c|c|c|c|c|c|c|c|c|c|}
\hline \multirow[b]{2}{*}{ Sector } & \multicolumn{10}{|c|}{ Distance fron Roloase Unit, kn } \\
\hline & -1.6 & $1.6-3.2$ & $3.2-4.8$ & $4.8-8.4$ & $6.4-8.0$ & 0.0-16.1 & 16.1-32.2 & $32.2-48.3$ & $48.3-64.4$ & $64.4-80.5$ \\
\hline $\mathbf{N}$ & 1557 & 6 & 1 & 0 & 5 & 12760 & 65590 & 29660 & 39360 & 29900 \\
\hline NNE & 593 & $1840^{\circ}$ & 1100 & 2200 & 1800 & 49040 & & 0 & 1131 & 8660 \\
\hline NE & 40. & 470 & 3909 & 8706 & 4896 & 38000 & 143090 & 34600 & 105060 & 21900 \\
\hline ENE & 510 & 1739 & 2850 & 6 & 5360 & 39848 & 50080 & 28690 & 10000 & 13390 \\
\hline $\mathbf{E}$ & 280 & & 1606 & & & 19800 & 18600 & 8190 & 8400 & 19398 \\
\hline ESE & 228 & 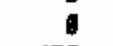 & 6 & i & 750 & Ese0 & 6004 & 15400 & 7090 & 7290 \\
\hline SE & 69 & 470 & 6 & 1 & & 1380 & 4000 & 7200 & 8500 & 12800 \\
\hline SSE & $\theta$ & o & - & & 8761 & 5086 & 18706 & 19700 & 10000 & 19400 \\
\hline $\mathbf{S}$ & 73 & 770 & 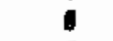 & 3448 & 3600 & 7884 & 15600 & 99806 & 143100 & 46196 \\
\hline SSI & 6 & 6 & 0 & 6 & 5680 & 29081 & 28649 & 148606 & 685000 & 169606 \\
\hline ST & 486 & 6 & - & - & 0 & 13490 & 2889: & 93068 & 30000 & 25900 \\
\hline TST & 40. & 6 & - & - & 0 & 2906 & 4400 & 30900 & 4600 & 10500 \\
\hline I & $45 \%$ & 2100 & - & 4460 & 2889 & 860 & 8890 & 3080 & 5300 & 29260 \\
\hline Wh & 201 & 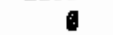 & 0 & o & 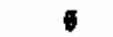 & 1080 & 8606 & 9080 & 59060 & 12800 \\
\hline in & 145 & 0 & 0 & $\emptyset$ & $\emptyset$ & 5590 & 5808 & 8480 & 8760 & 13760 \\
\hline NM & 385 & 1580 & 6 & 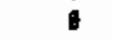 & 9 & 3904 & 11806 & 18300 & 23980 & 13280 \\
\hline
\end{tabular}


IABLE 3.4. Nominal Values for Production Rates by Town for Stack Release Scenario

\begin{tabular}{|c|c|c|c|c|}
\hline Location & $\begin{array}{c}\text { Leafy Vegetable, } \\
\mathrm{kg} / \mathrm{yr}\end{array}$ & $\begin{array}{c}\text { Vegetable, } \\
\mathrm{kg} / \mathrm{yr}\end{array}$ & $\begin{array}{l}\text { Meat, } \\
\mathrm{kg} / \mathrm{yr}\end{array}$ & $\begin{array}{l}\text { Milk, } \\
\text { L/yr }\end{array}$ \\
\hline $\begin{array}{l}\text { City } \# 1 A \\
\text { City } \# 1 B \\
\text { City } \# 1 C \\
\text { City } \# 10 \\
\text { City } \# 2 \\
\text { City } \# 3 \\
\text { City } \# 4 \\
\text { City } \# 5 \\
\text { City } \# 6 \\
\text { City } \# 7 \\
\text { City } \# 8 \\
\text { City } \# 9 \\
\text { City } \# 10 \\
\text { City } \# 11 \\
\text { City } \# 12 \\
\text { City } \# 13 \\
\text { City } \# 14 \\
\text { City } \# 15 \\
\text { City } \# 16 \\
\text { City } \# 17 \\
\text { City } \# 18 \\
\text { City } \# 19 \\
\text { City } \# 20 \\
\text { City } \# 21 \\
\text { City } \# 22 \\
\text { City } \# 23 \\
\text { City } \# 24 \\
\text { City } \# 25\end{array}$ & $\begin{array}{l}6.0 \mathrm{E}+4 \\
6.0 \mathrm{E}+4 \\
6.0 \mathrm{E}+4 \\
6.0 \mathrm{E}+4 \\
0.0 \mathrm{E}+0 \\
0.0 \mathrm{E}+0 \\
0.0 \mathrm{E}+0 \\
2.5 \mathrm{E}+4 \\
0.0 \mathrm{E}+0 \\
0.0 \mathrm{E}+0 \\
0.0 \mathrm{E}+0 \\
0.0 \mathrm{E}+0 \\
0.0 \mathrm{E}+0 \\
0.0 \mathrm{E}+0 \\
0.0 \mathrm{E}+0 \\
0.0 \mathrm{E}+0 \\
1.0 \mathrm{E}+5 \\
6.6 \mathrm{E}+4 \\
3.1 \mathrm{E}+5 \\
1.3 \mathrm{E}+4 \\
0.0 \mathrm{E}+0 \\
0.0 \mathrm{E}+0 \\
0.0 \mathrm{E}+0 \\
0.0 \mathrm{E}+0 \\
0.0 \mathrm{E}+0 \\
0.0 \mathrm{E}+0 \\
0.0 \mathrm{E}+0 \\
0.0 \mathrm{E}+0\end{array}$ & $\begin{array}{l}4.25 \mathrm{E}+6 \\
4.25 \mathrm{E}+6 \\
4.25 \mathrm{E}+6 \\
4.25 \mathrm{E}+6 \\
2.9 \mathrm{E}+7 \\
2.12 \mathrm{E}+7 \\
5.0 \mathrm{E}+6 \\
2.27 \mathrm{E}+7 \\
3.29 \mathrm{E}+7 \\
9.5 \mathrm{E}+6 \\
2.4 \mathrm{E}+7 \\
3.0 \mathrm{E}+7 \\
2.5 \mathrm{E}+7 \\
2.5 \mathrm{E}+7 \\
8.0 \mathrm{E}+6 \\
1.1 \mathrm{E}+7 \\
4.0 \mathrm{E}+6 \\
1.3 \mathrm{E}+7 \\
5.4 \mathrm{E}+6 \\
1.8 \mathrm{E}+6 \\
2.6 \mathrm{E}+6 \\
9.8 \mathrm{E}+6 \\
9.8 \mathrm{E}+6 \\
9.6 \mathrm{E}+6 \\
2.1 \mathrm{E}+7 \\
6.8 \mathrm{E}+7 \\
2.5 \mathrm{E}+7 \\
8.0 \mathrm{E}+6\end{array}$ & $\begin{array}{l}1.1 \mathrm{E}+6 \\
1.1 \mathrm{E}+6 \\
1.1 \mathrm{E}+6 \\
1.1 \mathrm{E}+6 \\
6.7 \mathrm{E}+6 \\
8.3 \mathrm{E}+6 \\
1.5 \mathrm{E}+6 \\
7.8 \mathrm{E}+6 \\
7.1 \mathrm{E}+6 \\
3.1 \mathrm{E}+6 \\
1.03 \mathrm{E}+7 \\
6.5 \mathrm{E}+6 \\
8.0 \mathrm{E}+6 \\
1.29 \mathrm{E}+7 \\
4 \cdot 0 \mathrm{E}+6 \\
4.5 \mathrm{E}+6 \\
2 \cdot 0 \mathrm{E}+6 \\
6.7 \mathrm{E}+6 \\
9.0 \mathrm{E}+5 \\
1.3 \mathrm{E}+6 \\
1.2 \mathrm{E}+6 \\
7.0 \mathrm{E}+6 \\
8.6 \mathrm{E}+6 \\
7.6 \mathrm{E}+6 \\
1.0 \mathrm{E}+7 \\
1.8 \mathrm{E}+6 \\
9.0 \mathrm{E}+6 \\
3.0 \mathrm{E}+6\end{array}$ & $\begin{array}{l}1.9 \mathrm{E}+6 \\
1.9 \mathrm{E}+6 \\
1.9 \mathrm{E}+6 \\
1.9 \mathrm{E}+6 \\
1.21 \mathrm{E}+7 \\
4.92 \mathrm{E}+7 \\
9.0 \mathrm{E}+6 \\
1.6 \mathrm{E}+7 \\
4.25 \mathrm{E}+7 \\
2.0 \mathrm{E}+7 \\
1.03 \mathrm{E}+7 \\
1.8 \mathrm{E}+7 \\
4.0 \mathrm{E}+6 \\
1.09 \mathrm{E}+7 \\
3.0 \mathrm{E}+6 \\
1.18 \mathrm{E}+7 \\
5.4 \mathrm{E}+6 \\
2.4 \mathrm{E}+7 \\
4.0 \mathrm{E}+6 \\
4.3 \mathrm{E}+6 \\
1.9 \mathrm{E}+6 \\
4.3 \mathrm{E}+6 \\
1.36 \mathrm{E}+7 \\
3.9 \mathrm{E}+6 \\
2.8 \mathrm{E}+7 \\
4.9 \mathrm{E}+6 \\
1.1 \mathrm{E}+7 \\
1.4 \mathrm{E}+7\end{array}$ \\
\hline
\end{tabular}

Table 3.4; however, each production rate was varied dependently at the 28 locations for each of the four production rates; that is, leafy vegetables, vegetables, meat, and milk.

\subsubsection{Stack Scenario Sensitivity Analys is Results}

Within the ranges that are appropriate for the input variables, the variables are assumed to be statistically independent. The population size and production rates for the individual receptor locations are not independent, but if population and production rates are treated as single variables, they can be treated independently. Likewise, the roughness values at the different geographic locations are assumed to vary dependently, although the 
total roughness varies independently of the other variables. Therefore, 24 variables (i.e., the 18 variables in Table 3.1, roughness, population size, and the four production rates) were varied independently in this analysis. In addition, two cases were run, with and without downwashing.

\subsubsection{Downwashing Case}

For the sensitivity analys is of the stack release with downwashing, the 24 variables were sampled randomly within the ranges defined in Table 3.1 using the Latin Hypercube method described in Appendix B. Sixty input vectors were obtained that resulted in 60 runs of the code. The minimum, median, and maximum HPI values and the ranges obtained from the 60 runs are summarized in Table 3.5, and the most important variables for determining HPI and their partial $R^{2}$ values are summarized in Table 3.6.

As shown in Table 3.6, constituent emission rate is the most important variable for determining HPI for all seven constituents, accounting for from $42 \%$ to $68 \%$ of the variability in the HPI score, which was approximately 1.0 HPI units. The importance of the other variables is dependent on the predominant exposure routes for the constituent (Table 3.7). For toluene and PCE, the dominant exposure route is inhalation, and for As, inhalation is a significant exposure route. Thus, the important variables for these constituents are population, building height, and morning mixing height, with population size being by far the most important of the three. For all the constituents except PCE and toluene, exposure occurs primarily through consumption of contaninated vegetables, meat, or milk (Table 3.7); therefore,

TABLE 3.5. Hazard Potential Index Scores(a) for the Stack Release Oownwashing Case

Constituent

\begin{tabular}{|c|c|c|c|c|c|c|c|}
\hline \multirow[b]{2}{*}{ Value } & \\
\hline & $90 \mathrm{Sr}$ & $3 \mathrm{H}$ & PCE & As & PCBS & $\mathrm{Hg}$ & Toluene \\
\hline $\begin{array}{l}\text { min } \\
\text { med } \\
\text { max } \\
\text { range }\end{array}$ & $\begin{array}{l}39.9 \\
40.2 \\
40.5 \\
0.6\end{array}$ & $\begin{array}{l}35.0 \\
35.4 \\
35.9 \\
0.9\end{array}$ & $\begin{array}{l}38.9 \\
39.5 \\
40.0 \\
1.1\end{array}$ & $\begin{array}{l}53.4 \\
53.9 \\
54.4 \\
1.0\end{array}$ & $\begin{array}{l}45.2 \\
45.8 \\
46.1 \\
0.9\end{array}$ & $\begin{array}{l}46.3 \\
46.8 \\
47.2 \\
0.9\end{array}$ & $\begin{array}{l}44.3 \\
45.3 \\
45.6 \\
1.3\end{array}$ \\
\hline
\end{tabular}

(a) The HPI score varies approximately 1 HPI unit for all the constituents. 
TABLE 3.6. Most Important Variables for the Stack Release Scenario Downwashing Case

Constituent, Partial R2 Values

\begin{tabular}{|c|c|c|c|c|c|c|c|}
\hline Variable & As & $\mathrm{Hg}$ & PCBs & $90 \mathrm{~s} r$ & Toluene & PCE & $3 \mathrm{H}$ \\
\hline & $\begin{array}{l}.46 \\
.40\end{array}$ & & $\begin{array}{r}0.65 \\
-\end{array}$ & $\begin{array}{l}0.57 \\
0.04\end{array}$ & & $\begin{array}{l}0.42 \\
0.42\end{array}$ & $\begin{array}{l}0.68 \\
0.13\end{array}$ \\
\hline & -- & 0. & 0.14 & 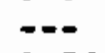 & -- &.- & \\
\hline iction & 00 & 0.02 & 0.10 & 0.24 & $\cdots$ & $a_{12}$ & 0.11 \\
\hline & 0.09 & & 0.03 & & & 0.13 & 0.0 \\
\hline height & $\cdots$ & & 0.02 & 0.03 & 0.01 & -- & \\
\hline &.- & & -- & & & & \\
\hline $\begin{array}{l}\text { Annual } \\
\text { Total }\end{array}$ & $\ddot{0.95}$ & $\begin{array}{l}0.01 \\
0.93\end{array}$ & $\overline{0.94}$ & $\begin{array}{l}0.01 \\
0.95\end{array}$ & $\overline{0.97}$ & $\overline{0.97}$ & 0.97 \\
\hline & & & & & & & \\
\hline
\end{tabular}

variables related to these exposure routes are important. For example, exposure to $\mathrm{Hg}$ is due mostly to consumption of meats; therefore, the second most important variable for determining the HPI for $\mathrm{Hg}$ is meat production rate. Similarly, consumption of contaminated meat and vegetables contributes significantly to the HPI value for PCBs; therefore, the meat and vegetable production rates are the most important variables after contaminant concentration.

IABLE 3.7. Percent Contribution of Exposure Route to Dose for Stack Release Scenario Downwashing Case

Const jtuent

\begin{tabular}{|c|c|c|c|c|c|c|c|}
\hline \multirow[b]{2}{*}{ Variable } & \\
\hline & As & $\underline{\mathrm{Hg}}$ & PCB & $90 S r$ & Toluene & $\underline{\mathrm{PCE}}$ & $3 \mathrm{H}$ \\
\hline $\begin{array}{l}\text { Leafy vegetable } \\
\text { consumption }\end{array}$ & 6 & 3 & 1 & 13 & 8 & 12 & 9 \\
\hline $\begin{array}{l}\text { Other vegetable } \\
\text { consumption }\end{array}$ & 59 & 19 & 31 & 85 & - & 8 & 56 \\
\hline Meat consumption & 4 & 66 & 63 & - & - & - & 13 \\
\hline Milk consumption & 4 & 11 & 4 & 4 & - & - & 16 \\
\hline Soil ingestion & $-(a)$ & - & - & - & - & - & - \\
\hline Inhalation & 26 & - & - & - & 92 & 78 & - \\
\hline
\end{tabular}

(a) - indicates less than $1 \%$ contribution. 


\subsubsection{Nondownwashing Case}

Because the high building height used in the previous case $(35 \mathrm{~m})$ triggered a switch controlling the occurrence of downwashing, a second analys is was run with a much lower building height $(10 \mathrm{~m})$ to prevent downwashing. The resulting HPI scores for the stack release nondownwashing case are given in Table 3.8, and the most important variables for determining HPI and their partial $R^{2}$ values are given in Table 3.9.

The HPI values without downwashing are lower than those obtained for the case with downwashing, because the elevated contaminant plume has dispersed to a greater extent by the time it reaches ground level. Downwashing causes immediate downwind exposure to the maximum contaminant concentrations, resulting in higher HPI values. The HPI values for the stack release case without downwashing show greater range than the case with downwashing, which had an average difference of approximately 1 HPI unit (Table 3.5).

TABLE 3.8. HPI VaTues for the Stack Release Nondownwashing Case

\begin{tabular}{|c|c|c|c|c|c|c|c|}
\hline \multirow[b]{2}{*}{ Value } & \multicolumn{7}{|c|}{ Constituent } \\
\hline & $90 \mathrm{sr}$ & $3 \mathrm{H}$ & PCE & As & PCBs & $\mathrm{Hg}$ & Toluene \\
\hline $\begin{array}{l}\min \\
\text { med } \\
\text { max } \\
\text { range }\end{array}$ & $\begin{array}{l}36.7 \\
37.85 \\
38.6 \\
1.9\end{array}$ & $\begin{array}{r}31.6 \\
33.0 \\
33.7 \\
2.1\end{array}$ & $\begin{array}{r}33.4 \\
35.5 \\
36.3 \\
2.9\end{array}$ & $\begin{array}{r}48.2 \\
50.1 \\
50.9 \\
2.7\end{array}$ & $\begin{array}{r}41.7 \\
43.4 \\
44.0 \\
2.3\end{array}$ & $\begin{array}{r}43.6 \\
44.7 \\
45.2 \\
1.6\end{array}$ & $\begin{array}{r}38.9 \\
41.1 \\
41.7 \\
2.8\end{array}$ \\
\hline
\end{tabular}

TABLE 3.9. Most Important Variables for Stack Release Scenario Nondownwashing Case

\begin{tabular}{|c|c|c|c|c|c|c|c|}
\hline \multirow[b]{2}{*}{ Variable } & \multicolumn{7}{|c|}{ Constituent, Partial $R^{2}$ value } \\
\hline & As & $\mathrm{Hg}$ & PCBS & $\underline{90 s r}$ & Toluene & $\underline{P C E}$ & $3 \mathrm{H}$ \\
\hline $\begin{array}{l}\text { Average annual temperature } \\
\text { Plume exit temperature } \\
\text { Contaminant emission rate } \\
\text { Population }\end{array}$ & $\begin{array}{l}0.42 \\
0.40 \\
0.05 \\
0.03\end{array}$ & $\begin{array}{l}0.38 \\
0.35 \\
0.09 \\
-.-\end{array}$ & $\begin{array}{l}0.38 \\
0.40 \\
0.10 \\
-.-\end{array}$ & $\begin{array}{l}0.36 \\
0.34 \\
0.13 \\
---\end{array}$ & & $\begin{array}{l}0.39 \\
0.42 \\
0.04 \\
0.04\end{array}$ & $\begin{array}{l}0.42 \\
0.40 \\
0.08 \\
0.01\end{array}$ \\
\hline Vegetable production & --- & --- & $-\infty$ & 0.05 & $-\infty$ & $-\infty$ & \\
\hline Meat production & $-\infty$ & 0.03 & 0.01 & $-\overline{0}$ & --- & --- & -- \\
\hline Annual rainfall & & 0.0 & -- & 0.02 & $=--$ & $--\overline{0}$ & --- \\
\hline Plume exit radius & 0.01 & & 0.02 & -- & 0.01 & 0.01 & --- \\
\hline $\begin{array}{l}\text { Morning mixing height } \\
\text { Total R2 }\end{array}$ & 0.91 & & $\begin{array}{l}0.01 \\
0.92\end{array}$ & $\begin{array}{l}0.01 \\
0.91\end{array}$ & $\overline{0.92}$ & 0.90 & $\overline{0.92}$ \\
\hline
\end{tabular}


As can be seen in Table 3.9, air temperature and the temperature at which the contaminant plume exits the stack are the most important variables for determining the HPI values for all seven constituents. Together, these two variables account for $70 \%$ to $83 \%$ of the variability in the HPI score of approximately 2 to $3 \mathrm{HPI}$ units. These two variables are important because their difference is used in the plume rise calculation, and the plume rise determines the distance at which the plume reaches ground level. The greater the difference between the plume exit temperature and the air temperature, the higher the rise of the contaminant plume, and the farther the plume travels before reaching the ground. As the air temperature and exit temperature become closer in value, the case approaches that with downwashing. As observed in the case with downwashing, the remaining important variables are those required to define the exposure routes (Table 3.10 ) for the different constituents. However, these exposure route-related variables explain less of the variability in the HPI values than they did for the case with downwashing (Table 3.6). In fact, for the case without downwashing, all the important variables taken together explain less of the variability than they did in the previous case with downwashing. This is due to the fact that the distance to touchdown of the plume and the coincidence of this touchdown point with the greatest exposed population is much more complicated and

TABLE 3.10. Percent Contribution of Exposure Route to Dose from Stack Release Scenario Nondownwashing Case

\begin{tabular}{|c|c|c|c|c|c|c|}
\hline Variable & As & $\underline{\mathrm{Hg}}$ & PCB & $90 s r$ & Toluene & PCE \\
\hline $\begin{array}{l}\text { Leafy vegetable } \\
\text { consumption }\end{array}$ & 5 & 3 & 1 & 12 & 8 & 12 \\
\hline $\begin{array}{l}\text { Other vegetable } \\
\text { consumption }\end{array}$ & 54 & 19 & 31 & 82 & $-(a)$ & 8 \\
\hline Meat consumption & 5 & 66 & 67 & - & - & - \\
\hline Milk consumption & 3 & 11 & 4 & 4 & - & - \\
\hline Soil ingestion & - & - & - & - & - & - \\
\hline Inhalation & 32 & - & - & 1 & 92 & 79 \\
\hline
\end{tabular}

(a) - indicates $1 \%$ contribution. 
variable in the case without downwashing than in the case with downwashing, where the plume reaches the ground very close to the release point.

\section{1 .4 Conclusions}

The range in HPI values for both the downwashing and nondownwashing cases are smal1; however, the nondownwashing case has a slightly larger range of HPI values (approximately $2.0 \mathrm{HPI}$ units) than the downwashing case (approximately $1.0 \mathrm{HPI}$ unit). For both stack release cases, the most important variables are those that determine the behavior of the plume, the concentrations to which people will be exposed, and the distances at which they will be exposed. For the case with downwashing, these variables are constituent emission rates, building height, and morning mixing height. For the case without downwashing, these variables are average annual temperature, plume exit temperature, constituent emission rates, plume exit radius, and morning mixing height. In addition, variables related to the exposure routes for the different constituents account for a significant proportion of the approximately 1 to 2 HPI unit variation in the HPI scores. However, the variables that define the plume behavior are much more important than those used for defining the exposure route. Typically, the plume behavior parameters account for $55 \%$ to $83 \%$ of the HPI variability, with these parameters accounting for less of the variability in the case with downwashing, whereas the exposure route parameters account for only $1 \%$ to $24 \%$ of the HPI variability, with these parameters accounting for less of the variability for the nondownwashing case.

\subsection{RESUSPENSION SCENARIO}

\subsubsection{Site Description}

The representative site used to model the effects of resuspension is located in a mining district of a mountainous region of the United States. The site is approximately $11.2 \mathrm{~km}$ long and $4.8 \mathrm{~km}$ wide, with populous areas to the west and east. It is close to an interstate highway. The site is assumed to be contaminated by the deposition of constituents on to the surface soils in the area. The transport occurs via resuspension to the atmosphere by wind action and by activity on or near the site such as mechanical 
disturbances or vehicle traffic. The exposure routes are through inhalation, soil ingestion, ingestion of contaminated crops (i.e., leafy vegetables and other vegetables), and ingestion of animal products ( $\mathbf{i} . \mathbf{e} .$, meat and $\mathrm{mi}$ l $\mathbf{k}$ ) tainted by contaminated crops.

\subsubsection{Variable Descriptions}

The atmospheric model of resuspension requires data such as description of the source, meteorological data, exposure data, and population distribution data. The variables used in this analysis for the atmospheric pathway and the ranges defined for them are given in Table 3.11. Unless otherwise stated, all variables are assumed to vary $\$ 10 \%$ to represent a well. characterized site.

The nominal values for the constituent concentration in the surface soil were chosen to ensure nonzero HPI values. Because the soil at the site is assumed to be silty loam, the percent sand in the topsoil was assumed to be $25 \%$ based on Table 2.1 in Droppo et a1. (1989a). The value used for the area of the ranking unit was $11.2 \mathrm{~km} \times 4.8 \mathrm{~km}$, or $5.4 \mathrm{E}+07 \mathrm{mi}^{2}$, and was estimated using topographical maps.

The precipitation-evaporation index (PEI) for the site was estimated from the map of PEI values (Figure 3.4) in Droppo et al. (1989a). A representative PEI value for mountainous regions of the United States is about 77: therefore, this value was used as the nominal value for the PEI.

Because the site is assumed to have roads on $i t$, the values of several variables controlling the resuspension of contaminated soil by vehicle traffic had to be determined. Because the soil is characterized as silty loam, the silt content of the soil in the area of the roads was estimated to be $63 \%$ based on Table 2.1 in Droppo et al. (1989a). Because Table 2.1 was constructed from data that varied $\star 15 \%$, the variation range for this variable was $\pm 15 \%$. 
IABLE 3.11. Nominal Values and Variation Range of Variables for Resuspension Scenario

\begin{tabular}{|c|}
\hline \\
\hline $\begin{array}{l}\text { As concentration }(\mu \mathrm{g} / \mathrm{g}) \\
\mathrm{Hg} \text { concentration }(\mu \mathrm{g} / \mathrm{g}) \\
\text { PCB concentration }(\mu \mathrm{g} / \mathrm{g}) \\
\text { gOSr concentration }(\mathrm{pC} / \mathrm{g}) \\
\text { Toluene concentration }(\mu \mathrm{g} / \mathrm{g}) \\
\text { PCE concentration }(\mu \mathrm{g} / \mathrm{g}) \\
\text { Area of source }\left(\mathrm{m}^{2}\right) \\
\text { Mean annual wind speed }(\mathrm{m} / \mathrm{s}) \\
\text { Fastest wind speed }(\mathrm{m} / \mathrm{s}) \\
\text { Percent sand in topsoil } \\
\text { PEI } \\
\text { Surface roughness of ranking unit (cm) } \\
\text { Fraction of vegetative cover } \\
\text { Average round trips/month } \\
\text { Travel distance/round trip (m) } \\
\text { Silt content of dirt roads (o\%) } \\
\text { Average vehicle speed (km/h) } \\
\text { Average vehicle weight (kg) } \\
\text { Morning mixing height (m) } \\
\text { Afternoon mixing height (m) } \\
\text { Precipitation days/year } \\
\text { Average thunderstorm days/year } \\
\text { Average annual precipitation (cm) }\end{array}$ \\
\hline
\end{tabular}

\begin{tabular}{|c|c|}
\hline Nominal Value & $\begin{array}{l}\text { Variation } \\
\text { Range, } \%\end{array}$ \\
\hline $\begin{array}{c}5.00 \mathrm{E}-10 \\
7.50 \mathrm{E}-10 \\
2.50 \mathrm{E}-10 \\
5.00 \mathrm{E}-11 \\
5.00 \mathrm{E}-08 \\
3.50 \mathrm{E}-10 \\
5.40 \mathrm{E}+07 \\
4.023 \\
26.375 \\
15.0 \\
77.0 \\
25.0 \\
0.10 \\
830.0 \\
3.20 \mathrm{E}+05 \\
63.0 \\
70.0 \\
4 \times 103 \\
350.0 \\
1600.0 \\
39.0 \\
39.0 \\
107.7\end{array}$ & $\begin{array}{l} \pm 10 \\
\pm 10 \\
\pm 10 \\
\pm 10 \\
\pm 10 \\
\pm 10 \\
\pm 10 \\
\pm 10 \\
\pm 10 \\
\pm 10 \\
\pm 10 \\
\pm 10 \\
\pm 10 \\
\pm 10 \\
\pm 10 \\
\pm 15 \\
\pm 29 \\
\pm 25 \\
\pm 25 \\
\pm 25 \\
\pm 10 \\
\pm 10 \\
\pm 10\end{array}$ \\
\hline
\end{tabular}

The ranking unit was estimated to contain $11.2 \mathrm{~km}$ of interstate highways and $21 \mathrm{~km}$ of town roads for a total of $32.2 \mathrm{~km}$, or $32,000 \mathrm{~m}$ of roads on the ranking unit. An interstate is a heavily traveled road, and its usage was estimated at 2000 round trips per month. The town roads are moderately traveled, and their usage was estimated at 200 round trips per month. The average usage based on the lengths of the roads and their individual usage values was 830 round trips per month for the $32,000 \mathrm{~m}$ of road on the site.

The variables that describe the vehicles using the roads are weight, speed, and number of wheels. Industrial vehicles are assumed to account for one half of the interstate traffic. These vehicles are assumed to have six wheels and weigh $1.5 \times 10^{4} \mathrm{~kg}$ each. Passenger vehicles are assumed to account for one half of the interstate traffic and all of the local traffic. Passenger vehicles are assumed to have four wheels and weigh $2 \times 10^{3} \mathrm{~kg}$ each. Under these assumptions, the average vehicle traveling the ranking unit roads 
weighs $4 \times 10^{3} \mathrm{~kg}$ and has four wheels. Traffic on the interstate was assumed to travel $97 \mathrm{~km} / \mathrm{h}$ and rural traffic to travel $56 \mathrm{~km} / \mathrm{h}$. Based on these assumptions about the vehicles and on the previous assumptions concerning length of roads on the site and traffic type on the respective types of road, the average vehicle speed on the ranking unit was estimated to be $70 \mathrm{~km} / \mathrm{h}$. For the sensitivity analysis, the number of wheels per vehicle was assumed to be fixed at four. The average vehicle weight varied $\pm 1 \times 10^{3} \mathrm{~kg}$, and the average vehicle speed varied $\pm 20 \mathrm{~km} / \mathrm{h}$.

Additional information required to calculate the atmospheric transport of contaminants is provided by the meteorological data. The morning and afternoon mixing heights at the site were estimated using the default maps (Figures 3.1 and 3.2) in Droppo et al. (1989a). The site is assumed to be near the $1600-m$ isopleth of the afternoon mixing heights map. A range of $\pm 25 \%$ was chosen for the afternoon mixing height. On the morning mixing height map, the site is assumed to be in a region surrounded on the east and west by $400-m$ isopleths and on the south by a $300-m$ isopleth. Thus, the nominal value for the morning mixing height was chosen to be $350 \mathrm{~m}$, with a range of $\pm 25 \%$.

The number of thunderstorm days per year (i.e., 39 days per year) was estimated from the National Weather Service data for mountainous regions. The average annual rainfall $(107.7 \mathrm{~cm})$ and the number of days per year that precipitation exceeded $0.025 \mathrm{~cm}$ (39 days) were also estimated from the National Weather Service data.

The joint frequency distribution (Appendix $C$ ), based on National Weather Service data, was used to define the frequency by wind speed, stability class, and direction of winds for the site and surrounding area. For this analysis, the wind joint frequency data was not varied. The average annual wind speed and the fastest wind speed values used for the site were estimated based on weather data for mountainous regions. Wind speeds have only small variations within a limited geographic area, so they were varied $\pm 10 \%$.

Values for the surface roughness variable were defined for the ranking unit and the area around the ranking unit. The surface roughness at the ranking unit was set at $25.0 \mathrm{~cm}$ because the site is assumed to have sparse 
vegetation represented by an average vegetative cover of $10 \%$. Surface roughness values were also defined for the area surrounding the ranking unit, which was composed of 32 sectors formed by eight compass direction sectors subdivided into four distances from the ranking unit covering a 35-km radius. These values varied from $2 \mathrm{~cm}$ for sectors with very sparse vegetation to $50 \mathrm{~cm}$ for sectors covered by forests. The nominal values for surface roughness are given in Table 3.12. The variation in the surface roughness values for the area surrounding the site was assumed to be $\pm 10 \%$. These roughness values for the area surrounding the ranking unit vary dependently by multiplying them all by the same proportionality factor. The roughness value for the ranking unit varies independently of the roughness values for the area surrounding the ranking unit.

Because exposure is assumed to occur by direct contact with the atmosphere and through consumption of agricultural products, the total population and the sector populations for the area within $80.5 \mathrm{~km}$ of the site are required to calculate the effects of exposure through inhalation and/or soil ingestion. The total population is 119,453 and was varied by $\pm 10 \%$. The nominal values for sector populations are given in Table 3.13 and were varied dependently by $\pm 10 \%$. As described in the stack release, the dependent variation in the sector populations was accomplished by multiplying all the sector populations and the total population by the same proportionality factor.

The production rates for leafy vegetables, other vegetables, meat, and milk for nine towns assumed to lie within a $75-\mathrm{km}$ radius of the ranking unit are given in Table 3.14. The total production rates for leafy vegetables,

TABLE 3.12. Surface Roughness Values for Area Surrounding the Ranking Unit

\begin{tabular}{crrrr}
$\begin{array}{c}\text { Direction } \\
\text { from Facility }\end{array}$ & & \multicolumn{4}{c}{ Distance, km } \\
\hline N & & $\underline{1-3}$ & $\frac{3-10}{2}$ & $\underline{10-70}$ \\
NE & 2 & 2 & 30 & 50 \\
E & 2 & 2 & 30 & 45 \\
SE & 2 & 5 & 30 & 30 \\
S & 7 & 15 & 40 & 25 \\
SW & 10 & 10 & 25 & 50 \\
W & 3 & 2 & 25 & 30 \\
NW & 2 & 2 & 20 & 30 \\
& 2 & 2 & 30 & 50
\end{tabular}


TABLE 3.13. Population Data for the Site

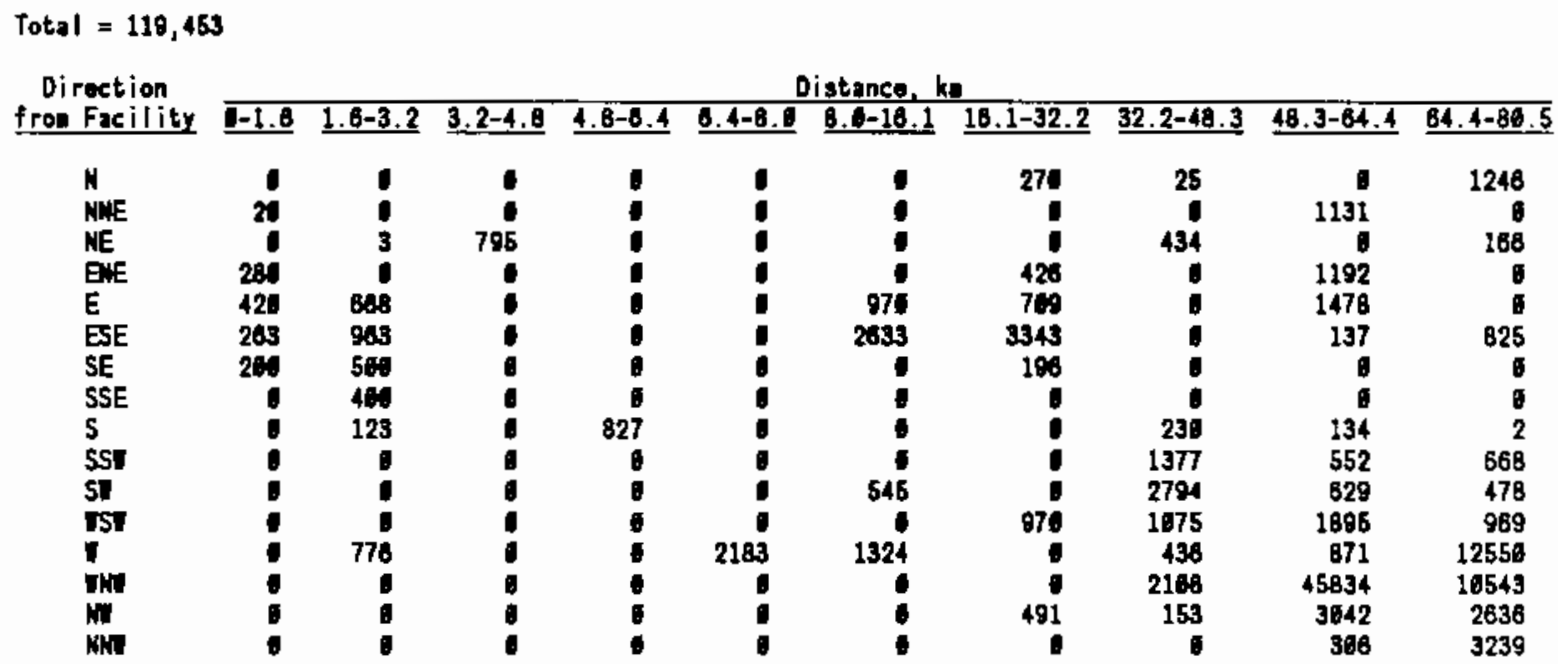

TABLE 3.14. Production Rates for the Resuspension Scenario Site

\begin{tabular}{|c|c|c|c|c|}
\hline Location & $\begin{array}{l}\text { Leafy Vegetabies, } \\
\mathrm{kg} / \mathrm{yr} \\
\end{array}$ & $\begin{array}{c}\text { Vegetables, } \\
\mathrm{kg} / \mathrm{yr}\end{array}$ & $\begin{array}{l}\text { Meat, } \\
\mathrm{kg} / \mathrm{yr}\end{array}$ & $\begin{array}{l}\text { Milk, } \\
\text { L/yr }\end{array}$ \\
\hline $\begin{array}{l}\text { City } \# 1 \\
\text { City } \# 2 \\
\text { City } \# 3 \\
\text { City } \# 4 \\
\text { City } \# 5 \\
\text { City } \# 6 \\
\text { City } \# 7 \\
\text { City } \# 8 \\
\text { City } \# 9\end{array}$ & $\begin{array}{l}0.0 \mathrm{E}+0 \\
0.0 \mathrm{E}+0 \\
5.3 \mathrm{E}+7 \\
0.0 \mathrm{E}+0 \\
0.0 \mathrm{E}+0 \\
0.0 \mathrm{E}+0 \\
0.0 \mathrm{E}+0 \\
0.0 \mathrm{E}+0 \\
0.0 \mathrm{E}+0\end{array}$ & $\begin{array}{l}2.1 \mathrm{E}+6 \\
6.2 \mathrm{E}+6 \\
2.8 \mathrm{E}+7 \\
6.3 \mathrm{E}+6 \\
7.2 \mathrm{E}+6 \\
2.1 \mathrm{E}+7 \\
8.6 \mathrm{E}+6 \\
1.7 \mathrm{E}+7 \\
3.3 \mathrm{E}+7\end{array}$ & $\begin{array}{l}6.2 \mathrm{E}+6 \\
1.2 \mathrm{E}+6 \\
1.5 \mathrm{E}+6 \\
1.2 \mathrm{E}+6 \\
7.6 \mathrm{E}+6 \\
8.5 \mathrm{E}+6 \\
1.4 \mathrm{E}+6 \\
1.5 \mathrm{E}+6 \\
1.0 \mathrm{E}+6\end{array}$ & $\begin{array}{l}5.0 \mathrm{E}+6 \\
4.1 \mathrm{E}+6 \\
7.8 \mathrm{E}+6 \\
5.6 \mathrm{E}+6 \\
2.7 \mathrm{E}+6 \\
6.3 \mathrm{E}+6 \\
2.2 \mathrm{E}+6 \\
3.4 \mathrm{E}+6 \\
1.1 \mathrm{E}+6\end{array}$ \\
\hline
\end{tabular}

other vegetables, meat, and milk were varied independently by $\pm 10 \%$; however, the production rates for each of the farm products were assumed to vary dependently at each of the cities.

\subsubsection{Resuspension Scenario Sensitivity Analysis Results}

Within the ranges that are appropriate for the input variables, the variables are assumed to be statistically independent. The population size and production rates for the individual receptor locations are not independent, but if population and production rates are treated as single variables, they can be treated independently. Likewise, the roughness values at the different geographic locations are assumed to vary dependently, al though the total roughness varies independently of the other variables. Therefore, in 
this analysis, 30 variables (i.e., the 24 variables in Table 3.11 , roughness, population size, and the four production rates) were varied independently. Because of wind erosion, this analysis had to consider more variables than did the stack release analysis.

The 30 variables were sampled randomly within the ranges defined in Table 3.11 according to the Lat in Hypercube sampling method described in Appendix B. Sixty input vectors were obtained, and 60 runs of the code were completed. The minimum, median, and maximum HPI values and their ranges obtained from the 60 runs are summarized in Table 3.15, and the most important variables for determining HPI and their partial R2 values are given in Table 3.16.

The maximum range in the HPI values was $2.5 \mathrm{HPI}$ units for As and $90 \mathrm{Sr}$. This range in HPI value is comparable to that found for the stack release without downwashing and greater than that determined for the stack release with downwashing. For this analysis, the resuspension parameters were

TABLE 3.15. Hazard Potential Index Scores for the Resuspension Scenario Constituent

\begin{tabular}{|c|c|c|c|c|c|c|}
\hline lue & $90 \mathrm{sr}$ & PCE & As & PCBS & $\mathrm{Hg}$ & Toluene \\
\hline & & 2.2 & $\begin{array}{c}55.2 \\
56.45 \\
57.7 \\
2.5\end{array}$ & & & \\
\hline
\end{tabular}

TABLE 3.16. Most Important Variables in Determining Hazard Potential Index Value for Resuspension Scenario Constituent, Partial R2 Value

\begin{tabular}{|c|c|c|c|c|c|c|}
\hline Vari & As & $\mathrm{Hg}$ & $\underline{\text { PCBS }}$ & $90 \mathrm{sr}$ & Toluene & PCE \\
\hline ation & $\begin{array}{l}0 . \\
0 . \\
0 .\end{array}$ & $\begin{array}{l}0.6 \\
0.0 \\
0.0 \\
0.0\end{array}$ & $\begin{array}{l}0.66 \\
0.08 \\
0.07 \\
0.06\end{array}$ & $\begin{array}{l}0.68 \\
0.08 \\
0.07 \\
0.06\end{array}$ & & \\
\hline in topsoil & $\begin{array}{l}0.06 \\
0.08\end{array}$ & 0.06 & $\begin{array}{l}0.06 \\
0.05\end{array}$ & & & \\
\hline $\begin{array}{l}\text { egetable production rat } \\
\text { otal } \mathrm{R}^{2}\end{array}$ & 0.99 & 0.97 & 0.98 & & & $\begin{array}{l}0.06 \\
0.99\end{array}$ \\
\hline
\end{tabular}


assumed to be well known; however, generally these parameters are more uncertain, so greater variability in HPI score would be expected. Future studies should evaluate the effect of greater variability in one or more of the important resuspension parameters given in Table 3.16.

From Table 3.16, it is clear that the major transport pathway for all contaminants for the resuspension scenario is via wind erosion, because the mean annual wind speed was by far the most important variable for all constituents. Mean annual wind speed accounts for $66 \%$ to $68 \%$ of the total HPI variation, which was approximately 2 HPI units. The partial $R^{2}$ values of contaminant concentration, area of contamination (which defines the inventory), surface roughness of the ranking unit, and percent sand (which with wind speed contributes to the emission rate from the ranking unit), are approximately equal and together account for $24 \%$ to $27 \%$ of the variability in the HPI value. The importance of the remaining variables, which account for $1 \%$ to $8 \%$ of the total HPI variability, reflect differences in the exposure routes for the different contaminants (Table 3.17). For example, exposure to $\mathrm{As}, \mathrm{Hg}, \mathrm{PCBs}$, and $3 \mathrm{H}$ occurs through inhalation and soil ingestion. Thus, population size should be a very important variable. The predominant exposure route for toluene and PCE is the ingestion of contaminated vegetables; therefore, vegetable production rate is found to be an important variable. The higher contribution of the vegetable exposure routes to the dose for the resuspension analysis compared to the stack release analysis is due to the form in which these constituents are released. In the stack release scenario, they are released as gases and do

not deposit (see Table 1.2). In the resuspension scenario, however, they are released and remain in particulate form, contributing to soil concentrations and to uptake by plants, resulting in a higher contribution of this route to the HPI.

\section{2 .4 Conclusions}

The range in HPI scores for the resuspension scenario is approximately 2.0 HPI units when the variability of the parameters is assumed to represent that of a well-characterized site. The most important variable is wind speed, which accounts for more than twice the amount of variability in the 
TABLE 3.17. Percent Contribution of Exposure Route to Dose for Resuspension Transport Pathway

\section{Constituent}

\begin{tabular}{|c|c|c|c|c|c|c|}
\hline Variable & As & $\mathrm{Hg}$ & $\mathrm{PCB}$ & $90 \mathrm{sr}$ & Toluene & PCE \\
\hline $\begin{array}{l}\text { Leafy regetable } \\
\text { consumption }\end{array}$ & $-(a)$ & - & - & - & - & - \\
\hline $\begin{array}{l}\text { Other vegetable } \\
\text { consumption }\end{array}$ & 2 & 16 & 14 & 57 & 94 & 95 \\
\hline Meat consumption & - & 55 & 21 & - & - & - \\
\hline Milk consumption & - & 10 & 4 & 3 & - & - \\
\hline Soil ingestion & 2 & - & 28 & 3 & 5 & 4 \\
\hline Inhalation & 93 & 19 & 33 & 33 & 1 & - \\
\hline
\end{tabular}

(a) - indicates that route contributes $<1 \%$ to dose.

HPI compared to the group of variables that account for the inventory and the group of variables that, along with wind speed, account for the emissions rate from the ranking unit. Variables related to the exposure routes account for very little of the HPI variability. Parameters describing resuspension resulting from vehicular traffic were not found to be significant in this case because wind erosion dominates the resuspension. For cases where wind erosion would not be as important (i.e., when the site was well vegetated and wind speeds were (ow), then the road variables will become important.

\subsection{VOLATILIZATION SCENARIO}

MEPAS provides two methods of treating ranking units with volatilization: 1) either the volatilization rates are input, or 2) the volatilization rates are computed by the model. For the input method, emission rates are obtained from sources, such as flux measurements at the ranking unit, computation with an alternative volatilization model, or back-calculation using monitoring data. For the computation method, MEPAS provides a component for computing potential volatilization rates based on the chemical and site characteristics. 
Several models have been proposed for computing volatilization rates from soil and water surfaces. The resolution of these models is generally at best an order-of-magnitude estimate of the volatilization rate for a given chemical contaminant. The complexity of the interactions between the contaminants and their containment media limits the accuracy expected from these models. A summary of recommended model formulations is contained in EPA's Superfund Exposure Assessment Manual (EPA 1988). This report was used as a starting point for developing the MEPAS volatilization mathematical formulations (Droppo et al. 1989b). Some components are used directly; others are modified to simplify input data requirements, and the pond/lagoon component has been completely replaced with a new model developed by Thibodeaux and Becker (1982).

The only volatilization case that was evaluated in the sensitivity analysis was subsurface contamination from an old spill. This case was selected because it was the case most applied during the Environmental Survey (DOE 1988). An old spill is defined as where the spill materials have soaked into soil and are no longer pooled on the surface. Loss of volatile materials from the soil to the air develops a "dry layer" at the soil surface with low concentrations of these materials. Ranking units to which the old spill model may be applied are the result of past operations, such as spills, leaks, spraying, washing, treating, or dumping of materials onto a ground surface.

An old spill model developed by Thibodeaux and Hwang (1982) is used in MEPAS. The loss of contaminant is computed as a function of time assuming that the soil-phase controls the vapor diffusion. Also, the concentration in the contaminant pool is assumed to remain constant until all the liquid-phase contaminant has been entirely lost to the atmosphere. A layering of the contaminant is assumed to occur in the soil consisting of a "dry" surface layer with low contaminant concentrations located over a "wet" layer with high contaminant concentrations. The terms wet and dry refer to the presence or absence of significant quantities of the contaminant in liquid form, respectively. The contaminant is assumed to have pooled in the wet layer and thus has uniform concentrations within the layer. Total diffusion from liquid phases and gas phases is defined in terms of the flux of the compound. The 
compound first evaporates into voids in the soil and then diffuses into the atmosphere through the dry layer. As noted above, this method of estimating the volatilization rate from old spills assumes that a constant pool of concentration of the compound exists in the soil until all of the compound has been volatilized to the atmosphere.

\subsubsection{Site Description}

The representative site used to model the effects of volatilization covers 15 acres and is located in a small low-altitude town in the United States. The area is classified as a grassy wetland. There are populous areas northeast, southeast, and northwest of the site.

Chemical constituents entered the environment through a previous spill and have soaked into the soil and undergone loss through weathering and volatilization. Contaminant layering thus occurs in the soil. There is a surface layer with low contaminant concentrations located over a layer with high contaminant concentrations. The contaminant is assumed to have pooled in the lower layer and has uniform concentrations within that layer. The constituents will volatilize and be released into the atmosphere as a gas. These atmospheric contaminants are deposited on the ground and may become resuspended by wind erosion. The exposure routes are through inhalation and soil ingestion.

\subsubsection{Variable Descriptions}

The atmospheric model of volatilization using the old spill type requires a source description, meteorological data, population distribution data, and exposure data. The contaminants considered in the analysis of the volatilization scenario are PCBs, toluene, and PCE because, of the eight constituents considered (see Table 1.2), only these three chemicals volatilize.

The variables used in the atmospheric transport pathway are given in Table 3.18. For each variable used in this analysis, a nominal value and a variable range are given. With the exception of the mixing heights, all variables are varied $\$ 10 \%$. The morning and afternoon mixing heights are more difficult to estimate; therefore, the mixing heights are varied $* 25 \%$. 
TABLE 3.18. Nominal Values and Variation Ranges of Variables for Volatilization Release Scenario

\begin{tabular}{lcc}
\multicolumn{1}{c}{ Variable } & Nominal value & $\begin{array}{c}\text { Variation } \\
\text { in Range, }\end{array}$ \\
\cline { 1 - 1 } PCB concentration $(\mu \mathrm{g} / \mathrm{g})$ & $2.50 \mathrm{E}-10$ & \pm 10 \\
Toluene concentration $(\mu \mathrm{g} / \mathrm{g})$ & $5.00 \mathrm{E}-08$ & \pm 10 \\
PCE Concentration $(\mu \mathrm{g} / \mathrm{g})$ & $3.50 \mathrm{E}-10$ & \pm 10 \\
Average air temperature $\left({ }^{\circ} \mathrm{K}\right)$ & 294.3 & \pm 10 \\
Bulk density at ranking unit & 1.50 & \pm 10 \\
( $\mathrm{g} / \mathrm{cm} 3$ ) & & \\
Depth of the dry zone (m) & 0.10 & \pm 10 \\
Depth of contaminated layer (m) & 10.0 & \pm 10 \\
Topsoil water capacity at ranking & 0.320 & \pm 10 \\
unit (cm) & & \\
Area of source (m2) & $3.67 \mathrm{E}+04$ & \pm 10 \\
Mean annual wind speed (m/s) & 4.917 & \pm 10 \\
Highest wind speed (m/s) & 40.234 & \pm 10 \\
PEI & 132.0 & \pm 10 \\
Morning mixing height (m) & 675.0 & \pm 25 \\
Afternoon mixing height (m) & 1000.0 & \pm 25 \\
Precipitation days/year & 124.0 & \pm 10 \\
Average thunderstorm days/year & 20.0 & \pm 10 \\
Average annual precipitation (cm) & 115.0 & \pm 10
\end{tabular}

The values used for the mean soil concentration fraction were chosen to ensure HPI values greater than -250 . The average annual temperature for the site was estimated to be equal to the temperature recorded at the major population area to the northeast of the site. Other climatological variables are the average annual wind speed, the fastest wind speed recorded, the number of days per year that precipitation exceeded $0.025 \mathrm{~cm}$, the number of days per year on which thunderstorms occurred, and the average annual rainfall. These values were all estimated from National Weather Service data.

The PEI and the afternoon and morning mixing heights were estimated from Figures 3.4, 3.2, and 3.1, respectively, in Droppo et al. (1989a). The PEI used in this scenario is 132 . The site is assumed to lie on the $1000-m$ isopleth of the afternoon mixing height map, so this value was used for the base case. The value used for the morning mixing height was $675 \mathrm{~m}$.

The site is assumed to have a sandy loam soil. Both the bulk density of the topsoil and the percent sand in the topsoil were estimated using 
Table 2.1 in Droppo et al. (1989a). The topsoil water capacity was estimated from SCS County Soil Survey data.

The area of contamination can be estimated from topographic maps of the site. The depth of contamination was estimated to be $10 \mathrm{~m}$. Because the area is a swamp, the depth of the dry zone was estimated to be $10 \mathrm{~cm}$.

Table 3.19 contains estimates of surface roughness for the area surrounding the ranking unit. This area is divided into 16 sectors corresponding to the compass directions and is further subdivided into six predetermined distances up to $75 \mathrm{~km}$ from the waste unit. The values represent coverage by grassland to shrub woodland. The surface roughness value for the surrounding area varied $\pm 10 \%$, and surface roughness values for the surrounding area varied dependently with each other as described for the previous analyses (Sections 3.1 .2 and 3.2.2).

Because inhalation and soil ingestion were the only exposure routes evaluated, no farm crop production rates were required. To calculate the HPI, the population of the area within $80.5 \mathrm{~km}$ of the ranking unit is specified. The total population is 5,533,089, and the population distribution data is given in Table 3.20. The total population and the sector populations were varied dependently by $\pm 10 \%$.

TABLE 3.19. Surface Roughness Values for the Area Surrounding the Ranking Unit

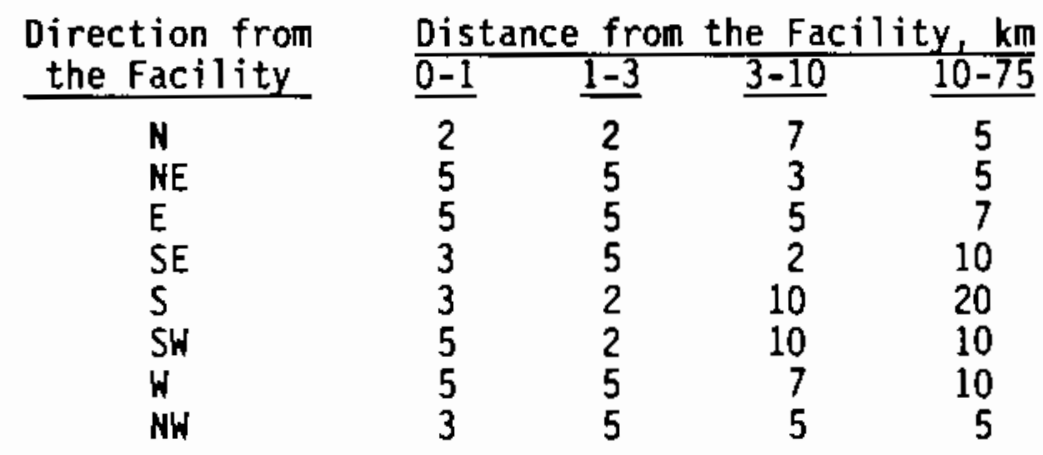


TABLE 3.20. Population Distribution Data for the Hypothetical Site Total $=5,532,997$

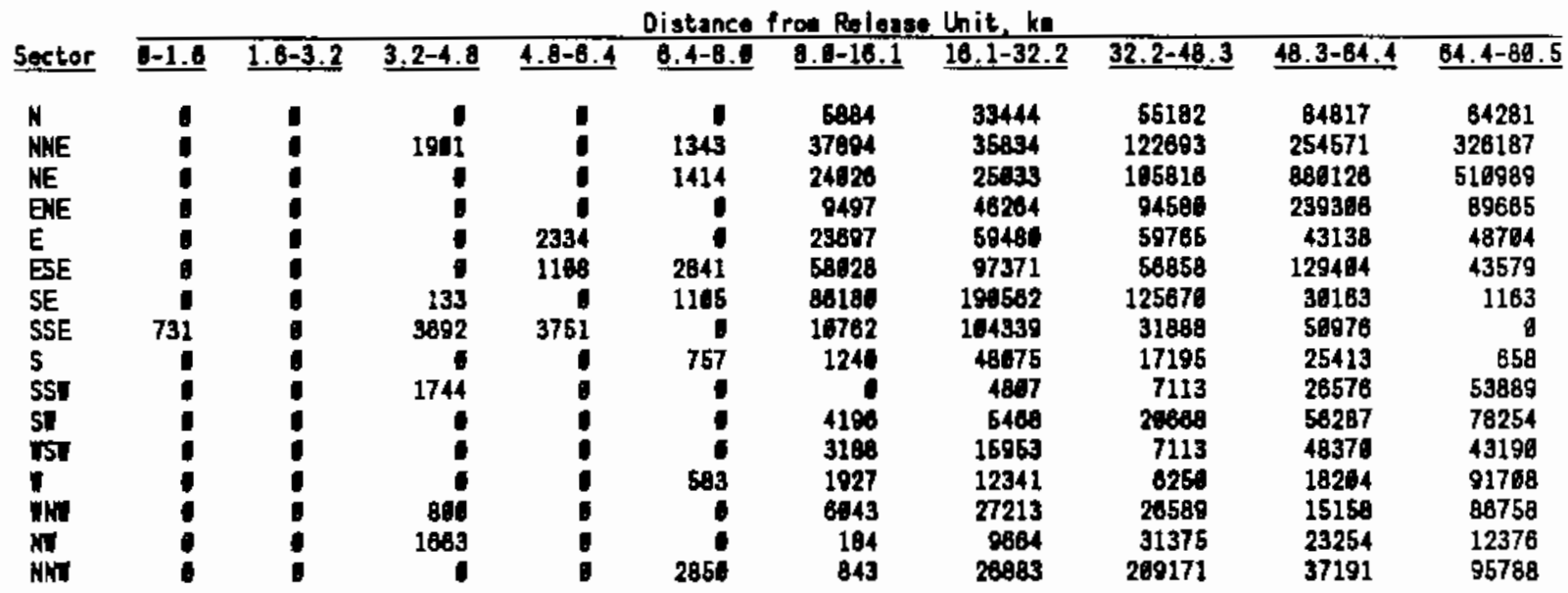

\subsubsection{Volatilization Scenario Sensitivity Analys is Results}

Within the ranges that are appropriate for the input variables, the variables are assumed to be statistically independent. Population size for the individual receptor locations is not independent, but if population is treated as a single variable, it can be treated independently. Likewise, the roughness values at the different geographic locations are assumed to vary dependently, although the total roughness varies independently of the other variables. Therefore, 20 variables (i.e., the 17 variables in Table 3.18 , the roughness variables for site and area, and the population size) varied independently in this analysis.

For the sensitivity analysis, the 20 variables were sampled randomly within the ranges defined in Table 3.18 using the Latin Hypercube method described in Appendix B. Sixty input vectors, resulting in 60 runs of the code, were obtained. The minimum, median, and maximum HPI values and their ranges obtained from the 60 runs are sumarized in Table 3.21, and the most important variables for determining HPI and their partial $\mathrm{R}^{2}$ values are summarized in Table 3.22 .

The range in the HPI scores for the volatilization scenario are much larger than the ranges for the other atmospheric release scenarios. 
TABLE 3.21. Hazard Potential Index Scores for Volatilization Scenario Constituent

\begin{tabular}{|c|c|c|c|c|c|c|c|c|}
\hline Value & $90 \mathrm{Sr}$ & $90 \mathrm{Y}$ & $3 \mathrm{H}$ & PCE & As & PCBS & $\mathrm{Hg}$ & Toluene \\
\hline $\begin{array}{l}\overline{\min } \\
\operatorname{med} \\
\max \\
\text { range }\end{array}$ & $\begin{array}{l}\text { NR } \\
\text { NR } \\
\text { NR }\end{array}$ & $\begin{array}{l}\text { NR } \\
\text { NR } \\
\text { NR }\end{array}$ & $\begin{array}{l}\text { NR } \\
\text { NR } \\
\text { NR }\end{array}$ & $\begin{array}{l}18.1 \\
29.7 \\
34.4 \\
16.3\end{array}$ & $\begin{array}{l}\overline{N R} \\
\text { NR } \\
\text { NR }\end{array}$ & $\begin{array}{c}-12.0 \\
-0.05 \\
4.5 \\
16.5\end{array}$ & $\begin{array}{l}\overrightarrow{N R} \\
\text { NR } \\
\text { NR }\end{array}$ & $\begin{array}{r}-22.7 \\
-10.95 \\
-6.4 \\
16.3\end{array}$ \\
\hline
\end{tabular}

TABLE 3.22. Most Important Variables in Determining Hazard Potential Index values for the Volatilization Release Scenario

\begin{tabular}{|c|c|c|c|}
\hline \multirow[b]{2}{*}{ Variable } & \multicolumn{3}{|c|}{ Constituent } \\
\hline & $\overline{\text { PCBS }}$ & Toluene & PCE \\
\hline $\begin{array}{l}\text { Bulk density of ranking unit } \\
\text { Field capacity of ranking unit } \\
\text { Total } R^{2}\end{array}$ & $\begin{array}{l}0.63 \\
0.30 \\
0.93\end{array}$ & $\begin{array}{l}0.64 \\
0.29 \\
0.93\end{array}$ & $\begin{array}{l}0.64 \\
0.29 \\
0.93\end{array}$ \\
\hline
\end{tabular}

As can be seen from Table 3.22, the most important variables for determining the HPI values and for accounting for the HPI range of approximately 16 HPI units for all three constituents are soil parameters. These parameters, the soil's bulk density and its field capacity, are used to calculate the emission rate from the site. Ambient air temperature, contaminant concentration, and population each accounted for less than $1 \%$ of the variability in the HPI value. The dominant exposure route for all three constituents is inhalation (Table 3.23).

TABLE 3.23. Percent Contribution of Exposure Routes to Dose for Volatilization Scenario

\begin{tabular}{|c|c|c|}
\hline & & onstituen \\
\hline Variable & $\overline{\mathrm{PCBS}}$ & Toluene \\
\hline $\begin{array}{l}\text { Soil inge } \\
\text { Inhalatio }\end{array}$ & $\begin{array}{r}4 \\
96\end{array}$ & $10 \overline{0}$ \\
\hline
\end{tabular}




\subsubsection{Conclusions}

The only important variables for determining the HPI for the volatilization scenario are those that influence the emission rate from the ranking unit. These variables are the bulk density and field capacity of the ranking unit. The variability in HPI values for a well-characterized site of approximately 16 HPI units is larger than for other atmospheric pathways. 


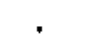




\subsection{SUMMARY AND CONCLUSIONS}

MEPAS is a computer-based methodology for estimating health impacts resulting from the release of hazardous chemical and radioactive materials. The health impacts are estimated from the environmental inventory and release or enission rate, constituent transport, constituent uptake and toxicity, and exposure route parameters such as exposed population and food production rates. The MEPAS output parameter used as input to DOE's preliminary rankings of environmental problems at DOE's Defense Production Facilities (DOE 1988) was the Hazard Potential Index (HPI). The HPI is a time-weighted index designed to reflect level of concern for human health impacts to an affected population.

This sensitivity analysis evaluated the effect of variations in the parameters that are typically specified by the user on HPI values. These user-specified parameters are used to include the constituent inventory and release rates, transport parameters, and the exposure route parameters. The parameters that define the physical, chemical, and toxicological properties of the constituents are obtained from the constituent database (Strenge and Peterson 1989). Because these constituent properties are typically not entered by the user, the effect of variations in these parameters was not evaluated in the sensitivity analysis.

The specific transport pathways and exposure routes evaluated and the site parameters used in the sensitivity analysis were chosen to represent environmental problems of concern to DOE. The transport pathways and exposure routes were chosen based on an analysis of the pathways and routes used in the Environmental Survey (DOE 1988). The base-case parameter values and the variability in these parameters were chosen to represent a wellcharacterized site with representative transport and exposure pathways. Because the range in HPI values is dependent on the assumed variability of the input variables and the mathematical representations of the transport pathways and exposure routes used in MEPAS, the results of the sensitivity analysis represent the baseline variability for MEPAS and the HPI output. The results, especially the range in HPI values, do not necessarily indicate 
the range of health impacts in the real world. The reported HPI ranges are not a measure of the uncertainty in HPI values.

The environmental emission/release rate parameters determine the quantity of material released into the environment. MEPAS allows the user to enter the emission/release rates (in units of quantity per time, grams per second, or Curies per year) or to have the rate computed by MEPAS using site characteristics. For example, MEPAS can compute the atmospheric release rates resulting from volatilization and resuspension as well as the groundwater contaminant fluxes for precipitation-driven groundwater transport from the recharge rate.

The environmental transport parameters detemine the environmental concentrations through migration, dispersion, and dilution of the material in the environment. The environmental processes are simulated by MEPAS using standard transport and dispersion methods for the atmosphere, groundwater, surface water, and overland transport pathways.

The exposure routes are defined by population size and distribution, and by the production rates for foods that are consumed by the population. In MEPAS, there are two types of exposed populations, one that is based on a census of people at identified locations and one based on food production rates and average-annual consumption rates per person.

For groundwater pathways, the sensitivity analysis considered two methods for defining the emission rate from the source. For the nonprecipitation-driven transport pathway, the emission rate is assumed to be constant, resulting in the complete release of the inventory in a specified time period, in this case $16 \mathrm{yr}$. For the precipitation-driven transport pathway, the emission rate is based on the amount of water that leaches through the source.

Within the analysis of the nonprecipitation-driven transport pathway, the effects of several of the parameters and ranges in variation of the parameters were evaluated in the five cases that were run (see Table 2.2). The results of the analyses for dependent (Case 1) and independent (Case 2) variation in the hydrologic parameters indicated that the hydrologic parameters should be varied independently because the amount of variability in 
the HPI value explained by the important parameters was significantly increased. Therefore, the hydrologic parameters were assuned to vary independently in all subsequent analyses. The results of the analyses to evaluate the effect of the magnitude of pore-water velocity variation on the sensitivity analysis (Cases 2 and 3 ) showed that the magnitude of variation in the pore-water velocity influenced the ordering of the other important variables. These results also illustrate the importance of quantifying the variation for the important parameters. The results of the other cases (Cases 4 and 5) illustrated that $K_{d}$ values in the saturated zone have a significant effect on the risk estimates and on the designation of the important parameters.

For the groundwater analyses, the HPI values and their ranges (Table 4.1) for most of the constituents were approximately 1 to 2 HPI units. Higher ranges in HPI values (up to 85 HPI units) were seen for the radionuclides $(90 \mathrm{Sr}, 90 \mathrm{Y}$, and $3 \mathrm{H})$ and for the constituent with a large $\mathrm{K}_{\mathrm{d}}$ (As) for the groundwater-to-surface-water transport pathways. Notably, the constituents that have the smallest range in HPI values; that is, toluene and PCE, have small $K_{d} s$ for all cases. HPI values for $\mathrm{Hg}$ and $\mathrm{PCB}$ were not calculated for nonprecipitation-driven groundwater Cases 4 and 5 because the high $K_{d} s$ for these constituents resulted in HPI values of -250 for the base case, as a result of very long travel times. Although not evaluated in this case, experience has shown that small changes in the transport parameters, especially a small reduction in $K_{d}$, can reduce the travel time enough to allow some of the constituent to reach the receptor population within the modeled time period of $7000 \mathrm{yr}$.

For the groundwater pathways, the important variables and the range in HPI values depends on the constituent characteristics. For example, for the radionuclides $90 \mathrm{Sr}$ and $90 \mathrm{Y}$, which were only analyzed for the nonprecipitation-driven transport pathway, the dominant variables are those used to define their transport, namely, the pore-water velocity and the $K_{d}$ in the saturated zone (Table 4.2). For $3 \mathrm{H}$, which has a $K_{d}$ value of 0 , the important transport parameter is pore-water velocity in the saturated zone when it has high variability, $\pm 95 \%$ (Table 4.2). In contrast, when this 
TABLE 4.1. Hazard Potential Index Values and Ranges

\begin{tabular}{|c|c|c|c|c|c|c|c|c|c|}
\hline Case & $90 \mathrm{~s} r$ & $90 Y$ & $3 \mathrm{H}$ & PCE & As & PCBS & $\mathrm{Hg}$ & Toluene & Value \\
\hline GW-1 & $\begin{array}{r}-15.1 \\
28.4 \\
40.3 \\
55.4\end{array}$ & $\begin{array}{c}-26.0 \\
17.55 \\
29.4 \\
55.4\end{array}$ & $\begin{array}{l}16.8 \\
21.25 \\
22.0 \\
5.2\end{array}$ & $\begin{array}{r}24.5 \\
25.0 \\
25.4 \\
0.9\end{array}$ & $\begin{array}{r}22.2 \\
22.6 \\
23.1 \\
0.9\end{array}$ & $\begin{array}{c}25.3 \\
25.95 \\
26.4 \\
1.1\end{array}$ & $\begin{array}{c}21.5 \\
21.95 \\
22.4 \\
0.9\end{array}$ & $\begin{array}{r}22.5 \\
23.1 \\
23.5 \\
1.0\end{array}$ & $\begin{array}{l}\min \\
\text { med } \\
\max \\
\text { range }\end{array}$ \\
\hline GW-2 & $\begin{array}{r}5.2 \\
29.4 \\
37.0 \\
31.8\end{array}$ & $\begin{array}{l}-5.6 \\
18.6 \\
26.2 \\
31.8\end{array}$ & $\begin{array}{r}18.1 \\
21.3 \\
22.1 \\
4.0\end{array}$ & $\begin{array}{r}24.5 \\
25.0 \\
25.5 \\
1.0\end{array}$ & $\begin{array}{r}22.0 \\
22.7 \\
23.1 \\
0.9\end{array}$ & $\begin{array}{l}25.4 \\
25.95 \\
26.4 \\
1.0\end{array}$ & $\begin{array}{r}21.6 \\
22.0 \\
22.7 \\
1.1\end{array}$ & $\begin{array}{r}22.6 \\
23.1 \\
23.5 \\
0.9\end{array}$ & $\begin{array}{l}\text { min } \\
\text { med } \\
\text { max } \\
\text { range }\end{array}$ \\
\hline GH-3 & $\begin{array}{l}24.0 \\
29.7 \\
35.1 \\
11.1\end{array}$ & $\begin{array}{l}13.2 \\
18.85 \\
24.2 \\
11.0\end{array}$ & $\begin{array}{r}20.6 \\
21.3 \\
21.9 \\
1.3\end{array}$ & $\begin{array}{r}24.5 \\
25.0 \\
25.5 \\
1.0\end{array}$ & $\begin{array}{r}22.0 \\
22.7 \\
23.1 \\
0.9\end{array}$ & $\begin{array}{c}25.4 \\
25.95 \\
26.4 \\
1.0\end{array}$ & $\begin{array}{r}21.6 \\
22.0 \\
22.7 \\
1.1\end{array}$ & $\begin{array}{r}22.6 \\
23.1 \\
23.5 \\
1.1\end{array}$ & $\begin{array}{l}\min \\
\text { med } \\
\text { max } \\
\text { range }\end{array}$ \\
\hline$G W-3 b$ & $\begin{array}{l}24.2 \\
29.65 \\
34.9 \\
10.7\end{array}$ & $\begin{array}{l}13.4 \\
18.75 \\
24.1 \\
11.3\end{array}$ & $\begin{array}{r}20.7 \\
21.3 \\
21.7 \\
1.0\end{array}$ & $\begin{array}{r}24.4 \\
25.0 \\
25.4 \\
1.0\end{array}$ & $\begin{array}{l}22.1 \\
22.65 \\
23.2 \\
1.1\end{array}$ & $\begin{array}{r}25.5 \\
26.0 \\
26.4 \\
1.1\end{array}$ & $\begin{array}{r}21.5 \\
22.0 \\
22.6 \\
1.1\end{array}$ & $\begin{array}{r}22.6 \\
23.1 \\
23.5 \\
1.1\end{array}$ & $\begin{array}{l}\min \\
\text { med } \\
\text { max } \\
\text { range }\end{array}$ \\
\hline$G H-3 c$ & $\begin{array}{l}24.0 \\
29.75 \\
35.1 \\
11.1\end{array}$ & $\begin{array}{l}13.2 \\
18.85 \\
24.2 \\
11.0\end{array}$ & $\begin{array}{r}20.9 \\
21.3 \\
21.8 \\
0.9\end{array}$ & $\begin{array}{r}24.4 \\
24.9 \\
25.4 \\
1.0\end{array}$ & $\begin{array}{r}22.0 \\
22.7 \\
23.0 \\
1.0\end{array}$ & $\begin{array}{r}25.6 \\
26.0 \\
26.3 \\
0.7\end{array}$ & $\begin{array}{r}21.6 \\
22.0 \\
22.7 \\
0.9\end{array}$ & $\begin{array}{r}22.5 \\
23.1 \\
23.5 \\
1.0\end{array}$ & $\begin{array}{l}\min \\
\text { med } \\
\text { max } \\
\text { range }\end{array}$ \\
\hline GW-4 & $\begin{array}{l}9.1 \\
29.35 \\
53.2 \\
44.1\end{array}$ & $\begin{array}{l}-1.7 \\
18.55 \\
42.4 \\
44.1\end{array}$ & $\begin{array}{r}20.8 \\
21.3 \\
21.8 \\
1.0\end{array}$ & $\begin{array}{r}24.0 \\
24.6 \\
25.3 \\
1.3\end{array}$ & $\begin{array}{l}20.5 \\
25.6 \\
30.2 \\
10.3\end{array}$ & $\begin{array}{l}\text { NR } \\
\text { NR } \\
\text { NR }\end{array}$ & $\begin{array}{l}\mathrm{NR} \\
\mathrm{NR} \\
\mathrm{NR}\end{array}$ & $\begin{array}{r}22.2 \\
22.8 \\
23.5 \\
1.3\end{array}$ & $\begin{array}{l}\min \\
\text { med } \\
\text { max } \\
\text { range }\end{array}$ \\
\hline GH-5 & $\begin{array}{l}-24.6 \\
33.05 \\
60.4 \\
85.0\end{array}$ & $\begin{array}{l}-35.5 \\
22.25 \\
49.6 \\
85.1\end{array}$ & $\begin{array}{r}19.4 \\
21.2 \\
21.9 \\
2.5\end{array}$ & $\begin{array}{l}23.6 \\
24.55 \\
25.2 \\
1.6\end{array}$ & $\begin{array}{l}12.7 \\
25.45 \\
30.7 \\
18.0\end{array}$ & $\begin{array}{l}\text { NR } \\
\text { NR } \\
\text { NR }\end{array}$ & $\begin{array}{l}\text { NR } \\
\text { NR } \\
\text { NR }\end{array}$ & $\begin{array}{l}21.8 \\
22.75 \\
23.5 \\
1.7\end{array}$ & $\begin{array}{l}\min \\
\text { med } \\
\max \\
\text { range }\end{array}$ \\
\hline OVL & $\begin{array}{l}18.8 \\
42.0 \\
49.0 \\
30.2\end{array}$ & $\begin{array}{r}-11.1 \\
12.1 \\
32.7 \\
43.8\end{array}$ & $\begin{array}{r}8.7 \\
26.1 \\
29.9 \\
21.2\end{array}$ & $\begin{array}{r}3.1 \\
28.3 \\
32.9 \\
29.8\end{array}$ & $\begin{array}{r}2.0 \\
25.2 \\
34.3 \\
32.3\end{array}$ & $\begin{array}{r}1.1 \\
25.1 \\
33.8 \\
32.7\end{array}$ & $\begin{array}{r}3.2 \\
28.0 \\
37.3 \\
34.1\end{array}$ & $\begin{array}{r}3.6 \\
26.4 \\
30.9 \\
27.3\end{array}$ & $\begin{array}{l}\min \\
\text { med } \\
\text { max } \\
\text { range }\end{array}$ \\
\hline PDGW & $\begin{array}{l}\text { NR } \\
\text { NR } \\
\text { NR }\end{array}$ & $\begin{array}{l}\text { NR } \\
\text { NR } \\
\text { NR }\end{array}$ & $\begin{array}{r}22.4 \\
23.5 \\
24.5 \\
2.1\end{array}$ & $\begin{array}{r}27.1 \\
28.6 \\
30.0 \\
2.9\end{array}$ & $\begin{array}{l}14.6 \\
29.6 \\
42.2 \\
27.6\end{array}$ & $\begin{array}{l}\text { NR } \\
\text { NR } \\
\text { NR }\end{array}$ & $\begin{array}{l}\text { NR } \\
\text { NR } \\
\text { NR }\end{array}$ & $\begin{array}{r}26.1 \\
27.3 \\
28.8 \\
2.7\end{array}$ & $\begin{array}{l}\min \\
\text { med } \\
\text { max } \\
\text { range }\end{array}$ \\
\hline
\end{tabular}


TABLE 4.1. (contd)

\begin{tabular}{|c|c|c|c|c|c|c|c|c|c|}
\hline Case & $90 \mathrm{sr}$ & $90 Y$ & $3 \mathrm{H}$ & PCE & As & PCBS & $\mathrm{Hg}$ & Toluene & Value \\
\hline STACK-DH & $\begin{array}{r}39.9 \\
40.2 \\
40.5 \\
0.6\end{array}$ & $\begin{array}{l}-250.0 \\
-250.0 \\
-250.0\end{array}$ & $\begin{array}{r}35.0 \\
35.4 \\
35.9 \\
0.9\end{array}$ & $\begin{array}{r}38.9 \\
39.5 \\
40.0 \\
1.1\end{array}$ & $\begin{array}{r}53.4 \\
53.9 \\
54.4 \\
1.0\end{array}$ & $\begin{array}{r}45.2 \\
45.8 \\
46.1 \\
0.9\end{array}$ & $\begin{array}{r}46.3 \\
46.8 \\
47.2 \\
0.9\end{array}$ & $\begin{array}{r}44.3 \\
45.3 \\
45.6 \\
1.3\end{array}$ & $\begin{array}{l}\min \\
\text { med } \\
\max \\
\text { range }\end{array}$ \\
\hline STACK & $\begin{array}{c}36.7 \\
37.85 \\
38.6 \\
1.9\end{array}$ & $\begin{array}{l}-250.0 \\
-250.0 \\
-250.0\end{array}$ & $\begin{array}{r}31.6 \\
33.0 \\
33.7 \\
2.1\end{array}$ & $\begin{array}{r}33.4 \\
35.5 \\
36.3 \\
2.9\end{array}$ & $\begin{array}{r}48.2 \\
50.1 \\
50.9 \\
2.7\end{array}$ & $\begin{array}{r}41.7 \\
43.4 \\
44.0 \\
2.3\end{array}$ & $\begin{array}{r}43.6 \\
44.7 \\
45.2 \\
1.6\end{array}$ & $\begin{array}{r}38.9 \\
41.1 \\
41.7 \\
2.8\end{array}$ & $\begin{array}{l}\min \\
\text { med } \\
\text { max } \\
\text { range }\end{array}$ \\
\hline RESUS & $\begin{array}{r}29.1 \\
30.4 \\
31.6 \\
2.5\end{array}$ & $\begin{array}{l}-250.0 \\
-250.0 \\
-250.0\end{array}$ & $\begin{array}{l}\text { NR } \\
\text { NR } \\
\text { NR }\end{array}$ & $\begin{array}{r}34.5 \\
35.6 \\
36.7 \\
2.2\end{array}$ & $\begin{array}{c}55.2 \\
56.45 \\
57.7 \\
2.5\end{array}$ & $\begin{array}{r}45.2 \\
46.4 \\
47.3 \\
2.1\end{array}$ & $\begin{array}{r}27.0 \\
28.0 \\
29.1 \\
2.1\end{array}$ & $\begin{array}{c}13.2 \\
14.35 \\
15.3 \\
2.1\end{array}$ & $\begin{array}{l}\min \\
\text { med } \\
\text { max } \\
\text { range }\end{array}$ \\
\hline VOL & $\begin{array}{l}\text { NR } \\
\text { NR } \\
\text { NR }\end{array}$ & $\begin{array}{l}\text { NR } \\
\text { NR } \\
\text { NR }\end{array}$ & $\begin{array}{l}\text { NR } \\
\text { NR } \\
\text { NR }\end{array}$ & $\begin{array}{l}18.1 \\
29.7 \\
34.4 \\
16.3\end{array}$ & $\begin{array}{l}\text { NR } \\
\text { NR } \\
\text { NR }\end{array}$ & $\begin{array}{c}-12.0 \\
-0.05 \\
4.5 \\
16.5\end{array}$ & $\begin{array}{l}N R \\
N R \\
N R\end{array}$ & $\begin{array}{l}-22.7 \\
-10.95 \\
-6.4 \\
16.3\end{array}$ & $\begin{array}{l}\min \\
\text { med } \\
\text { max } \\
\text { range }\end{array}$ \\
\hline
\end{tabular}

GW-1 = Nonprecipitation-driven groundwater transport pathways, Case 1.

PDGW = Precipitation-driven groundwater transport pathway.

OVL $=$ Overland transport pathway.

STACK-DW = Stack release scenario with downwashing.

STACK = Stack release without downwashing.

RESUS = Resuspension scenario.

VOL = Volatilization scenario.

$N R=$ Not run.

transport parameter has variability comparable to that for the other parameters $( \pm 15 \%)$, the inventory that establishes the release rate for the nonprecipitation-driven transport or in the case of precipitation-driven transport, precipitation and partially saturated zone depth, the exposure-related parameter (population), and the transport parameters (river discharge or distance to receptor; called length) become important. The range in HPI values is greatest for the radionuclides $90 \mathrm{Sr}$ and $90 \mathrm{Y}$ probably as a result of the effects of transport parameters (i.e., pore-water velocity and/or $K_{d}$ in saturated zone and river discharge and distance to receptor) on travel times to the receptor. Travel time affects the HPI values because longer travel times allow more radioactive decay, thus less concentration, to reach the receptor. 
IABLE 4.2. Important Variables for Groundwater and Overland Transport Pathways

Constituent Group

\begin{tabular}{|c|c|c|c|c|c|}
\hline \multirow[b]{2}{*}{ Rolease Scenarios } & \\
\hline & $94 \mathrm{Sr}, 90 Y$ & $3 \mathrm{H}$ & PCE, Toluene & $\mathrm{Ha}, \mathrm{PCB}$ & As \\
\hline \multicolumn{6}{|l|}{$\begin{array}{l}\text { Nonprecipitation- } \\
\text { driven groundenter }\end{array}$} \\
\hline Case 1 & $\begin{array}{l}\text { S-rel } \\
\text { S-1Kd }\end{array}$ & S-rel & $\begin{array}{l}\text { Inventory } \\
R \text {. discharge } \\
\text { Population }\end{array}$ & $\begin{array}{l}\text { Inventory } \\
\text { R. discharge } \\
\text { Fish production }\end{array}$ & $\begin{array}{l}\text { Inventory } \\
\text { R. discharge } \\
\text { Population }\end{array}$ \\
\hline Case 2 & $\begin{array}{l}\text { S-yel } \\
\text { S-Kod }\end{array}$ & S-Yol & $\begin{array}{l}\text { R. discharge } \\
\text { Inventory } \\
\text { Population }\end{array}$ & $\begin{array}{l}\text { Inventory } \\
R \text {. diacharge } \\
\text { Fish production }\end{array}$ & $\begin{array}{l}\text { R. discharge } \\
\text { Inventory } \\
\text { Population }\end{array}$ \\
\hline Case 3 & $S-K_{d}$ & $\begin{array}{l}\text { Population } \\
\text { R. diacharge } \\
\text { Invontory }\end{array}$ & $\begin{array}{l}\text { R. discharge } \\
\text { Inventory } \\
\text { Population }\end{array}$ & $\begin{array}{l}\text { R. discharge (PCB) } \\
\text { Inventory } \\
\text { Population } \\
\text { Fish production }\end{array}$ & $\begin{array}{l}\text { R. dischargo } \\
\text { Inventory } \\
\text { Population }\end{array}$ \\
\hline Case 4 & $\begin{array}{l}\text { S-Kd } \\
\text { PS-K } K_{d}\end{array}$ & $\begin{array}{l}\text { Invontory } \\
\text { Population } \\
\text { Length }\end{array}$ & $\begin{array}{l}\text { Inventory } \\
\text { Population } \\
\text { R. diacharge } \\
\text { Length }\end{array}$ & Kode & $S-K_{d}$ \\
\hline Case 5 & $\begin{array}{l}S-r_{0} \mid \\
S-k_{d}\end{array}$ & S-vol & $\begin{array}{l}\text { Inventory } \\
\text { S-rel } \\
\text { Discharge } \\
\text { Population }\end{array}$ & $K_{d} *$ & $\begin{array}{l}\text { S-Yel } \\
\text { S-Kd }\end{array}$ \\
\hline \multicolumn{6}{|l|}{$\begin{array}{l}\text { Precipitation- } \\
\text { driven groundwator }\end{array}$} \\
\hline & 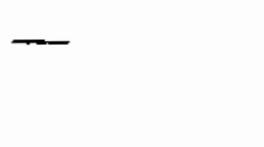 & $\begin{array}{l}\text { S-rel } \\
\text { Rain } \\
\text { PS-depth } \\
\text { Population }\end{array}$ & $\begin{array}{l}\text { S-Kd } \\
\text { PS- } x_{d} \\
\text { Ruin }\end{array}$ & ـ & $\begin{array}{l}\text { PS-Kd } \\
\text { Rain }\end{array}$ \\
\hline \multicolumn{6}{|l|}{ Overland pathway } \\
\hline & $\begin{array}{l}\text { Tenp } \\
\text { of Precip. Oays } \\
\text { R. depth }\end{array}$ & $\begin{array}{l}\text { Tomp } \\
\text { SCS eurve }\end{array}$ & $\begin{array}{l}\text { Tonp } \\
\text { SCS curvo }\end{array}$ & $\begin{array}{l}\text { Tenp } \\
\text { 1 of Precip. Days } \\
\text { R. depth }\end{array}$ & $\begin{array}{l}\text { Temp } \\
\text { of Precip. Days }\end{array}$ \\
\hline
\end{tabular}

$\bar{S}=$ Saturated zone.

PS = Partially saturated zone.

$R=$ River.

*Assumed to be important because with realistic $K_{d}$ values, an HPI of -250 is calculated for base case. 
For groundwater transport pathways for the chemical constituents with small (approximately 1) $K_{d}$ values, PCE and toluene, the important parameters are inventory and rainfall. These two parameters establish the release rate for the nonprecipitation-driven and precipitation-driven transport pathways, respectively; the exposure route parameters of population or fish production are also important, depending on the dominant route of exposure; and some transport parameters, such as river discharge, distance to receptor (length), and $K_{d}$ values in one or more of the groundwater zones (Table 4.2). For those constituents with high $K_{d}$ values--As, $H g$, and PCBs-- $K_{d}$ is extremely important. When realistic $K_{d} s$ were assumed for $\mathrm{Hg}$ and PCBs, the constituents did not result in exposure in $7000 \mathrm{yr}$. The variation in HPI values also reflects the range in variability of the most important parameters (Table 4.1). For example, the HPI values for As range from only 1 to 2 HPI units when no $K_{d}$ is assumed and increase to $>10 \mathrm{HPI}$ units when $K_{d}$ is included.

The overland-to-surface-water pathway resulted in a very large range in HPI values and very low $\mathrm{R}^{2}$ values for all eight constituents using the linear model between HPI and the simple representation of the input variables; therefore, the identification of important variables is tentative. The most important variables are temperature, number of precipitation days, and some of the variables (such as SCS curve number) that determine whether the contaminated surface material will be carried in the overland flow to the river. The overland model uses empirical and step-function relationships to describe complex contaminant movement. The contaminant movement is based on annual-average runoff volume, which is in turn a function of the number of months of below-freezing temperatures and the amount of precipitation received during that period, and sediment movement caused by the runoff. If the annual-average runoff results in sediment reaching the surface water, then the HPI value is generally high. If the annual-averaged runoff does not result in sediment reaching the surface water, then an HPI score of -250 occurs. The large range in the HPI values is probably related to the discontinuous nature of the function used to model the transport. A further evaluation of the overland transport pathway could use more complex representations of the variables for the linear model, such as the monthly meteorological parameters, and possibly interaction terms to increase the 
amount of the variability in HPI values explained by the important variables and confidence in the important variables identified.

For the atmospheric pathways, the effect of three methods for estimating the emission rates on HPI values was evaluated. These methods included direct release represented by release from a stack, release through resuspension of particulates, and release through volatilization. The variation in important variables for the atmospheric pathways (Table $4.3)$ is not related to the chemical characteristics of the constituents but to the variables that represent the release rate from the site and, to a lesser extent, the primary exposure routes. For example, for the stack release with downwashing, the important variables are the emission rate and one of the exposure route variables (i.e., meat or vegetable production or population). The range in HPI values for the different constituents are similar, illustrating that their HPI values are all dependent on the same variables. For the atmospheric pathway, the sensitivity to input parameter variations resulted in HPI variations in the manner that was expected based on the definition of the HPI (Whelan et al, 1987). That is, $\pm 10 \%$ variation in emission rate and exposed population result in an HPI variation on the order of \pm 1 to 2 points. The increased range in HPI values for the volatilization scenario was in part a result of the way that input parameters are used to calculate the emission rate (Droppo et al. 1989a, 1989b).

The cases considered in this study were selected to provide a representative cross section of the actual cases considered in DOE preliminary rankings (DOE 1988). The sensitivity results can be used to define a probable HPI range for applications with similar constituents and analogous pathways. Some grouping of results is possible based on constituent properties. For example, the waterborne transport constituents may be considered according to decay rate and transport properties.

As an illustration, Table 4.4 summarizes the HPI ranges for the baseline runs. In Table 4.3 the four constituent types are 1) radionuclides with short half-lives $(<140 \mathrm{yr})$ and low $\left.k_{d}(<1.0) ; 2\right)$ radionuclides with short half-lives and high $K_{d}$, represented by $90 \mathrm{Sr}$ and $90 Y_{;} 3$ ) either organic or inorganic radionuclides with long half-lives and low $K_{d}$, represented by PCE 
TABLE 4.3. Most Important Variables for the Atmospheric Transport Pathway

Release Scenario

Stack Release Scenario

Downwashing

Nondownwashing

Resuspension

Volatilization
Constituent emission rate for all constituents

Population for As, PCE, and toluene

Meat production for $\mathrm{Hg}$ and PCBs

Vegetable production for $3_{\mathrm{H}}$ and $90 \mathrm{Sr}$

Annual temperature

Exit temperature

Constituent emission rate for $\mathrm{Hg}, \mathrm{PCBs}, 90 \mathrm{Sr}$, and $3 \mathrm{H}$

Annual wind speed

Bulk density of ranking unit

Field capacity of ranking unit

and toluene; and 4) either organic or inorganic radionuclides with long halflives and high $K_{d}$, represented by $A S, P C E$, and $\mathrm{Hg}$. A short half-life with respect to groundwater travel times is considered to be less than $140 \mathrm{yr}$ because the constituents would decay significantly during the first two, and most highly weighted, 70-yr time periods.

The 15: variability for pore-water velocity is unrealistically low. For most applications the $95 \%$ variability is a more realistic estimate. The HPI ranges for the nonprecipitation-driven groundwater are based on Case 2 with minimal $K_{d}$ and Case 5 with realistic $K_{d}$. In applications that are sufficiently analogous, Table 4.4 will provide an indication of the baseline HPI range that is expected for a well-characterized site. Less wellcharacterized sites will have greater variability.

These results can also be used to assist the user in identifying the important variables. The user can then run additional analyses to evaluate the effect on the HPI resulting from their variability. For example, for groundwater pathways, the release rate from the ranking unit is very important. To evaluate the effect of uncertainties in the release rate or the effects of added water as either precipitation or irrigation water on the release rate and subsequent risk estimate, several complementary analyses can be run using the user-friendly MEPAS shell. The user can also put resources 
into measuring the important variables for the pathway with greater accuracy, if possible, and not focus effort on less-important variables. Generally, a pathway is dominated by only one to three important variables. For radioactive constituents, variables affecting travel time need to be evaluated with greater accuracy. For nonradionuclides, the important variables are $\mathrm{K}_{\mathrm{d}}$ (for those constituents that sorb), inventory, and exposure route variables. The results indicate that the HPI values are not sensitive to a large number of variables and that the model is stable. The overland route, which is modeled using step functions, is less stable.

The HPI ranges were explained by parameters that are used in the various MEPAS computational steps. For small ranges of input variability, the list of important parameters included parameters that were used to estimate 1) environmental releases (e.g., inventory, emission rate), 2) transport (e.g., $K_{d}$, surface-water velocity), and 3 ) exposure (e.g., population, food production rates) and resulted in a relatively small range in HPI ( 1 or 2 points). For the cases where the range in HPI was larger, the list of important variables included parameters used to calculate the environmental release and transport, but not exposure. For example, for waterborne releases the largest HPI range resulted from variability in transport parameters, and for airborne releases the largest HPI range resulted from variability in environmental release parameters.

In summary, for the representative site considered and the transport pathways and exposure routes analyzed, the important variables are physically reasonable, given the chemical nature and the biological activity of the constituents; therefore, the sensitivity analysis results can be extrapolated to other sites and constituents. To verify this for different assumptions of variability, however, additional analyses may be needed. Although additional runs may result in quantitative differences in the partial $R^{2}$ values for the important variables, at a qualitative level, differences in the patterns are not expected. The groundwater and atmospheric pathways are used most often to model the risks from ranking units. The results indicate that these pathways are well behaved and that the important variables are consistent with previous experience. 
TABLE 4.4. Sensitivity Analysis Model Variability as a Function of Transport Scenarios and Constituent Type

\begin{tabular}{|c|c|c|c|c|}
\hline Iransport Sconario & $\begin{array}{c}\text { Short Half-Lito, } \\
\text { Lov } K_{d} \\
(3 H)\end{array}$ & 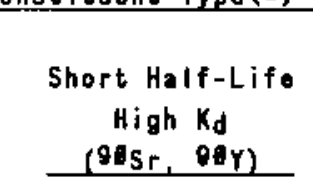 & $\begin{array}{l}\text { Long Half-Lifo } \\
\text { Inorganic, } \\
\text { Organic, Lor } K_{d} \\
\text { (PCE_tolveng) }\end{array}$ & $\begin{array}{l}\text { Long Half-Life } \\
\text { Inorganic, } \\
\text { Organic, Low } K_{d} \\
\text { (As, PCB. Hg) }\end{array}$ \\
\hline $\begin{array}{l}\text { Ranking unit to } \\
\text { groundwater to } \\
\text { aurface water. } \\
\text { procipitation- } \\
\text { driven }\end{array}$ & 2 & $\geq 28$ (b) & 3 & 28 \\
\hline $\begin{array}{l}\text { Ranking unit to } \\
\text { groundwater to } \\
\text { surfaco ustor. } \\
\text { nonprocipitation- } \\
\text { drivon }\end{array}$ & 4 & $\geq 32^{(c)}$ & 2 & $\geq 18$ \\
\hline $\begin{array}{l}\text { Ranking unit to } \\
\text { overland to } \\
\text { surface auter, } \\
\text { procipitation- } \\
\text { driven }\end{array}$ & $\geq 22^{\text {(d) }}$ & 30 & 29 & 33 \\
\hline \multicolumn{5}{|c|}{ 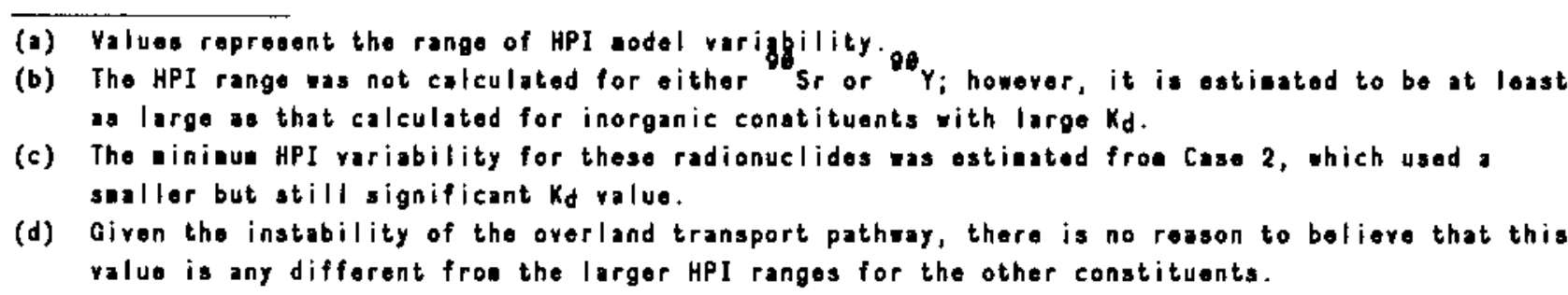 } \\
\hline
\end{tabular}




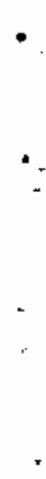




\subsection{REFERENCES}

Busse, A. D., and J. Zimmerman. 1973. User's Guide for the Climatological Dispersion Model. EPA-RA-73-024, U.S. Environmental Protection Agency, Research Triangle Park, North Carolina.

Codel1, R. B., K. T. Key, and G. Whelan. 1982. A Collection of Mathematical Models for Dispersion in Surface Water and Ground Water. NUREG-0868, U.S. Nuclear Regulatory Comíssion, Office of Nuclear Reactor Regulation, Washington, D.C.

Cowherd, C., G. E. Muleski, P. J. Englehart, and D. A. Gillette. 1984. Rapid Assessment of Exposure to Particulate Emissions from Surface Contamination Sites. Final Report EPA Contract 68-03-3116, Project 7972-L, Midwest Research Institute, Kansas City, Missouri.

Donigian, A. S., Jr., T. Y. R. Lo, and E. W. Shanahan. 1983. Rapid Assessment of Potential Groundwater Contamination Under Emergency Response Conditions. Prepared by Anderson-Nichols and Co., Inc., for the U.S. Environmental Protection Agency, Athens, Georgia.

Droppo, J. G., Jr., D. L. Strenge, J. H. Buck, B. L. Hoopes, R. D. Brockhaus, M. B. Walter, and G. Whelan. 1989a. Multimedia Environmental Pollutant Assessment System (MEPAS) Application Guidance, Volume 2 - Guidelines for Evaluating MEPAS Input Parameters. PNL-7216 Vo1. 2, Pacific Northwest Laboratory, Richland, Washington.

Droppo, J. G., Jr., G. Whelan, J. H. Buck, D. L. Strenge, B. L. Hoopes, and M. B. Walter. 1989b. Supplemental Mathematical Formulations: The Multimedia Environmental Pollutant Assessment System (MEPAS) . PNL-7201, Pacific Northwest Laboratory, Richland, Washington.

Eagleson, P. S. 1970. Dynamic Hydrology. McGraw-Hill, New York.

Goldman, S. J., K. Jackson, and T. A. Bursztynsky. 1986. Erosion and Sediment Control Handbook. McGraw-Hill, New York.

Hanks, R. J., and L. Ashcroft. 1980. Applied Soil Physics. SpringerVerlag, New York.

Haun, C. F., and B. J. Barfield. 1978. Hydrology and Sedimentology of Surface-Mined Lands. University of Kentucky, Lexington, Kentucky.

Hillel, D. 1980. Fundamentals of Soil Physics. Academic Press, New York.

Hjelmfelt, A. T., Jr. 1976. Modeling of Soil Movement Across a Watershed. Completion Report for Project A-076-M0, Missouri Water Resources Center, University of Missouri, Columbia, Missouri. 
Kent, K. M. 1973. A Method for Estimating Volume and Rate of Runoff in Smal1 Watersheds. SCS-TP-149, U.S. Department of Agriculture, Soil Conservation Service, Washington, D.C.

Pasquill, F., and F. B. Smith. 1983. Atmospheric Diffusion. 3rd ed. Wiley, New York.

Soil Conservation Service (SCS). 1972. "Hydrology Guide for Use in Watershed Planning." SCS National Engineering Handbook, Section 4, Hydrology, Supplement A. U.S. Department of Agriculture, Soif Conservation Service, Washington, D.C.

Soil Conservation Service (SCS). 1982. SCS National Engineering Handbook, Section 4, Hydrology, 1982 Update. U.S. Department of Agriculture, Soil Conservation Service, Washington, D.C.

Strenge, D. L., and S. R. Peterson. 1989. Chemical Data Bases for the Multimedia Environmental Pollutant Assessment System (MEPAS): Version 1. PNL-7145, Pacific Northwest Laboratory, Richland, Washington.

Thibodeaux, L. J., and B. Becker. 1982. "Chemical Transport Rates Near the Sediment in Waste Water Impoundment." Environmental Progress 1(4):296-300.

Thibodeaux, L. J., and S. T. Hwang. 1982. "Landfarming of Petroleum WastesModeling the Air Emission Problem." Environmental Progress 1(1):42-46.

U.S. Department of Energy (DOE). 1988. Environmental Survey Preliminary Summary Report of the Defense Production Facilities. D0E/EH-0072, U.S. Department of Energy, Environment, Safety, and Health, Office of Environmental Audit, Washington, D.C.

U.S. Department of the Interior, Bureau of Reclamation (USBR). 1977. Design of Small Dams. Government Printing Office, Washington, D.C.

U.S. Environmental Protection Agency (EPA). 1988. Superfund Exposure Assessment Manual. OSWER Directive 9285.5-1, Office of Remedial Response, Office of Solid Waste and Emergency Response, U.S. Environmental Protection Agency, Washington, D.C.

Van Genuchten, M. T., and W. J. Alves. 1982. Analytical Solutions of the One-Dimensional Convective-Dispersive Solute Transport Equation. Technical Bulletin No. 1661, U.S. Department of Agriculture, Washington, D.C.

Whelan, G. 1980. Distributed Model for Sediment Yield. Master's Thesis, Iowa Institute of Hydraulic Research, University of Iowa, Iowa City, Iowa.

Whelan, G., D. L. Strenge, J. G. Droppo, Jr., and B. L. Steelman. 1987. The Remedial Action Priority System (RAPS): Mathematical Formulations. PNL-6200, Pacific Northwest Laboratory, Richland, Washington.

Witinok, P. M. 1979. Distributed Watershed and Sedimentation Model. Master's Thesis, University of Iowa, Iowa City, Iowa. 
Witinok, P. M., and G. Whelan. 1980. "Distributed Parameter Sedimentation Model." Proc. Iowa Acad. Sci. 87(3)103-111.

Yeh, G. T. 1981. AT123D: Analytical Transient One-, Two-, and ThreeDimensional Simulation of Waste Transport in the Aquifer System. Publication No. 1439, ORNL-5602, Oak Ridge National Laboratory, Oak Ridge, Tennessee. 


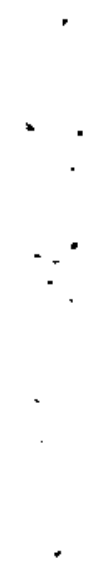


APPENDIX A

CONSTITUENT DATABASE 
APPENDIX A

\section{CONSTITUENT DATABASE}

Data Summary for STRONTIUM-90

ID: SR90

Common Synonyms: STRONTIUM-90

Physical Properties:

Molecular weight

Water solubility, $\mathrm{mg} / \mathrm{L}$

Radiological decay half-life, d
Value

90.00

$1.1 \mathrm{E}+04$
Source

Isotope

No value in database

Napier et al. (1980)

Environmental Transfer Factors:

Transfer Parameter

Bioaccumulation in fish

Bioaccumulation in shellfish

Soil-to-edible plant

Feed-to-animal meat, $d / \mathrm{kg}$

Feed-to-cow milk, d/L

Water purification factor

Deposition velocity, $\mathrm{m} / \mathrm{s}$

Atmospheric deposition class

Radiological Dosimetry Factors:

Ingestion dose factor, rem/pCi

Inhalation dose factor, $\mathrm{rem} / \mathrm{pCi}$

Air immersion factor, rem/h per $\mathrm{pCi} / \mathrm{m}^{3}$

Ground exposure factor, rem/h per $\mathrm{pCi} / \mathrm{m}^{2}$

Water immersion factor, rem/h per $\mathrm{pCi} / \mathrm{L}$
Value

$3.0 \mathrm{E}+01$

$1.0 \mathrm{E}+02$

2.0E-01

3.0E-04

1.5E-03

.20

$1.0 \mathrm{E}-03$

1

Value

1. $4 \mathrm{E}-07$

1.3E-06

$1.3 \mathrm{E}-12$

$6.7 \mathrm{E}-14$

1.3E-12
Source

Napier et al. (1980)

Napier et al. (1980)

Napier et al. (1980)

Napier et al. (1980)

Napier et al. (1980)

Napier et a1. (1980)

Default

Particulate

Source

Eckerman (a)

Eckerman

Eckerman

Eckerman

Eckerman

(a) Based on values generated by K. F. Eckeman of Oak Ridge National Laboratory. 
Data Summary for TRITIUM

ID : $\mathrm{H3}$

Common Synonyms: TRITIUM (as tritiated water, HTO)

Physical Properties:

Molecular weight

Water solubility, $\mathrm{mg} / \mathrm{L}$

Radiological decay half-life, d

Environmental Transfer Factors:

Transfer Parameter

Bioaccumulation in fish

Bioaccumulation in shellfish

Soil-to-edible plant

Feed-to-animal meat, $d / \mathrm{kg}$

Feed-to-cow milk, $d / L$

Water purification factor

Deposition velocity, $\mathrm{m} / \mathrm{s}$

Atmospheric deposition class

Radiological Dosimetry Factors:

Ingestion dose factor, rem/pCi

Inhalation dose factor, $\mathrm{rem} / \mathrm{pCi}$

Air immersion factor, rem/h per $\mathrm{pCi} / \mathrm{m}^{3}$

Ground exposure factor, rem $/ \mathrm{h}$ per $\mathrm{pCi} / \mathrm{m}^{2}$

water immersion factor, rem/h per $\mathrm{pCi} / \mathrm{L}$

\begin{tabular}{cl} 
Value & \multicolumn{1}{c}{ Source } \\
20.00 & $\quad \begin{array}{l}\text { Isotope } \\
\text { No value in data base }\end{array}$ \\
$4.5 E+03$ & $\begin{array}{l}\text { Napier et al. (1980) }\end{array}$
\end{tabular}

Value

Source

$1.0 \mathrm{E}+00$

$1.0 \mathrm{E}+00$

Napier et al. (1980)

Napier et al. (1980)

$0.0 E+00$

$0.0 \mathrm{E}+00$

$0.0 \mathrm{E}+00$

1.00

$0.0 \mathrm{E}+00$

4

see footnote (a)

see footnote (a)

see footnote (a)

Default

Not needed for $3 \mathrm{H}$

Depositing gas

Value

Source

6. $3 E-11$

6.3E-11

$0.0 \mathrm{E}+00$

$0.0 \mathrm{E}+00$

$0.0 \mathrm{E}+00$

\section{(b)}

Eckerman

Eckerman

Eckerman

Eckerman

(a) Special model used for $3_{H}$ transfer in farm products.

(b) Based on values generated by Dr. K. F. Eckerman of Oak Ridge National Laboratory. 
Common Synonyms: YTTRIUM-90

Physical Properties:

Molecular weight

Water solubility, $\mathrm{mg} / \mathrm{L}$

Radiological decay half-life, d

Environmental Transfer Factors:

Transfer Parameter

Bioaccumulation in fish

Bioaccumulation in shellfish

Soil-to-edible plant

Feed-to-animal meat, $d / \mathrm{kg}$

Feed-to-cow milk, d/L

Water purification factor

Deposition velocity, $\mathrm{m} / \mathrm{s}$

Atmospheric deposition class

Radiological Dosimetry Factors:

Ingestion dose factor, $\mathrm{rem} / \mathrm{pCi}$

Inhalation dose factor, $\mathrm{rem} / \mathrm{pC} i$

Air immersion factor, rem/h per $\mathrm{pCi} / \mathrm{m}^{3}$

Ground exposure factor, rem $/ \mathrm{h}$ per $\mathrm{pCi} / \mathrm{m}^{2}$

water immersion factor, rem/h per $\mathrm{pCi} / \mathrm{L}$

\begin{tabular}{|c|c|}
\hline Value & Source \\
\hline $\begin{array}{l}90.00 \\
2.7 \mathrm{E}+00\end{array}$ & $\begin{array}{l}\text { Isotope } \\
\text { No value in database } \\
\text { Eckerman }\end{array}$ \\
\hline
\end{tabular}

\begin{tabular}{|c|c|}
\hline Value & Source \\
\hline $\begin{array}{l}2.5 \mathrm{E}+01 \\
1.0 \mathrm{E}+03\end{array}$ & $\begin{array}{l}\text { Napier et al. }(1980) \\
\text { Napier et al. (1980) }\end{array}$ \\
\hline $2.5 \mathrm{E}-03$ & Napier et al. (1980) \\
\hline $5.0 \mathrm{E}-03$ & Napier et al. (1980) \\
\hline $5.0 \mathrm{E}-06$ & Napier et al. (1980) \\
\hline $\begin{array}{l}.20 \\
1.0 \mathrm{E}-03\end{array}$ & $\begin{array}{l}\text { Napier et al. (1980) } \\
\text { Default } \\
\text { Particulate }\end{array}$ \\
\hline Value & Source \\
\hline
\end{tabular}

1.1E-08 Eckerman (a)

8.4E-09 Eckerman

8.4E-12 Eckerman

1.2E-12 Eckerman

9.0E-12 Eckerman

(a) Based on values generated by Dr. K. F. Eckerman of Oak Ridge Nationa] Laboratory. 
Data Sunmary for PCBS (GENERAL)

CAS : 1336363

Common Synonyms: Aroclor, PCB (General Classification), Therminal

\section{Physical Properties:}

Molecular weight

Water solubility, $\mathrm{mg} / \mathrm{L}$

Vapor pressure, $\mathrm{mm} \mathrm{Hg}$

Henry's law constant, atm-m $3 /$ mole octonal-water partition coefficient

Carbon matter partition coefficient, $L / g$
Value

328.00

$3.1 E-02$

$7.7 \mathrm{E}-05$

$1.1 \mathrm{E}-03$

$1.1 \mathrm{E}+06$

$5.3 \mathrm{E}+05$
Source

Empirical

Mabey et al. (1982)

Mabey et al. (1982)

see footnote (a)

Mabey et a1. (1982)

Mabey et a $1 .(1982)$

Environmental Degradation/Removal Half-times:

Media of Transport

$$
\begin{aligned}
& \text { In air, d } \\
& \text { In water, d } \\
& \text { In soil, d }
\end{aligned}
$$

Value

$6.9 \mathrm{E}+07$

$6.9 \mathrm{E}+07$

$1.3 \mathrm{E}+07$
Source

Default

Default

VOL-S

Environmental Transfer Factors:

Transfer Parameter

Bioaccumulation in fish

Bioaccumulation in shellfish

Soil-to-edible plant

Feed-to-anima 1 meat, d/kg

Feed-to-cow milk, d/L

Water purification factor

Deposition velocity, $\mathrm{m} / \mathrm{s}$

Atmospheric deposition class

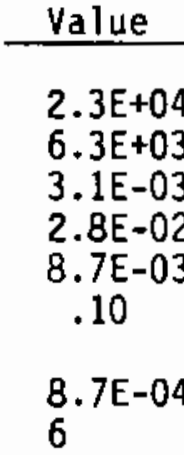

Value

$4.3 \mathrm{E}+00$

$4.3 E+00$
Source

Calculated from kow

Calculated from kow

Calculated from kow

Calculated from kow

Calculated from kow

0 'Brien and Gere (1981) Method DVM

Gas as Particulate

\section{Source}

Equal to ingestion

EPA (1984c)

(a) From ICF (1987) as calculated from solubility and vapor pressure. 
Data Summary for ARSENIC

CAS: 7440382

Common Synonyms: Arsenic

Physical Properties:

Molecular weight

Water solubility, $\mathrm{mg} / \mathrm{L}$

Vapor pressure, min $\mathrm{Hg}$
Value

75.00

$0.0 \mathrm{E}+00$

$0.0 \mathrm{E}+00$
Source

Empirical

Weast (1979)

EPA (1981)

Environmental Degradation/Removal Half-times:

Media of Transport

In air, d

In water, $d$

In soil, d

\begin{tabular}{|c|c|}
\hline Value & Source \\
\hline $\begin{array}{l}6.9 \mathrm{E}+07 \\
6.9 \mathrm{E}+07 \\
6.9 \mathrm{E}+07\end{array}$ & $\begin{array}{l}\text { Default } \\
\text { Default } \\
\text { Default }\end{array}$ \\
\hline
\end{tabular}

Environmental Transfer Factors:

Transfer Parameter

Bioaccumulation in fish

Bioaccumulation in shellfish

Soil-to-edible plant

Feed-to-animal meat, $d / \mathrm{kg}$

Feed-to-cow milk, d/L

Water purification factor

Deposition velocity, $\mathrm{m} / \mathrm{s}$

Atmospheric deposition class

Chemical Toxicity Parameters:

Inhalation cancer potency factor, $\mathrm{kg}-\mathrm{d} / \mathrm{mg}$ Ingestion cancer potency factor, $\mathrm{kg}-\mathrm{d} / \mathrm{mg}$

\begin{tabular}{|c|c|}
\hline Value & Source \\
\hline $1.0 \mathrm{E}+00$ & Spehar et al. (1980) \\
\hline $4.0 E+01$ & Strenge et a 1. (1986) \\
\hline $1.0 \mathrm{E}-02$ & Napier et al. (1980) \\
\hline $1.5 \mathrm{E}-03$ & Napier et al. (1980) \\
\hline $3.0 \mathrm{E}-03$ & Napier et al. (1980) \\
\hline $\begin{array}{l}.70 \\
1.0 \mathrm{E}-03\end{array}$ & $\begin{array}{l}\text { Napier et al. (1980) } \\
\text { Default } \\
\text { Particulate }\end{array}$ \\
\hline Value & Source \\
\hline $\begin{array}{l}5.0 \mathrm{E}+01 \\
1.5 \mathrm{E}+00\end{array}$ & $\begin{array}{l}\text { EPA (1984a) } \\
\text { IRIS }\end{array}$ \\
\hline
\end{tabular}


Common Synonyms: Mercury, Quicksilver

Physica] Properties:

Molecular weight

Water solubility, $\mathrm{mg} / \mathrm{L}$

Vapor pressure, mint $\mathrm{Hg}$
Value

201.00

$0.0 \mathrm{E}+00$

$2.0 \mathrm{E}-03$
Source

Empirical

Weast (1979)

EPA (1981)

Environmental Degradation/Removal Half-times:

Media of Transport

In air, $d$

In water, $d$

In soit, $d$
Value

$6.9 \mathrm{E}+07$

$6.9 \mathrm{E}+07$

$6.9 \mathrm{E}+07$
Source

Default Default Default

Environmenta] Transfer Factors:

Transfer Parameter

Bioaccumulation in fish

Bioaccumulation in shellfish

Soil-to-edible plant

Feed-to-animal meat, d/kg

Feed-to-cow milk, d/L

Water purification factor

Deposition velocity, $\mathrm{m} / \mathrm{s}$

Atmospheric deposition class

Chemical Toxicity Parameters:

Inhalation reference dose, $\mathrm{mg} / \mathrm{kg} / \mathrm{d}$ Ingestion reference dose, $\mathrm{mg} / \mathrm{kg} / \mathrm{d}$
Value

$2.0 \mathrm{E}+05$

2.0E+05 Napier et al. (1980)

3.8E-01 Napier et al. (1980)

1.0E-01 Napier et a]. (1980)

1.9E-02 Napier et al. (1980)

.50

$1.0 \mathrm{E}-03$

1

Napier et al. (1980)

Default

Particulate

Value

5.1E-05

$2.0 \mathrm{E}-03$
Source

EPA (1984b)

EPA (1986) 
Data Summary for TETRACHLOROETHYLENE CAS: 127184

Common Synonyms: Tetrachloroethylene, Ankilostin, PCE

Physical Properties:

Molecular weight

Water solubility, $\mathrm{mg} / \mathrm{L}$

Vapor, pressure, nाm $\mathrm{Hg}$

Henry's law constant, atm- $\mathrm{m}^{3} / \mathrm{mole}^{\mathrm{a}}$

octonal-water partition coefficient

Carbon matter partition coefficient, L/g
Value

165.85

$1.5 \mathrm{E}+02$

$1.8 \mathrm{E}+01$

2.6E-02

$4.0 \mathrm{E}+02$

$3.6 \mathrm{E}+02$
Source

Empirical

EPA (1984d)

EPA (1984d)

see footnote (a)

EPA (1984d)

Mabey et al. (1982)

Environmental Degradation/Removal Half-times:

Media of Transport

In air, d

In water, $d$

In soil, d
Value

$6.9 \mathrm{E}+07$

$6.9 \mathrm{E}+07$

$6.1 E+01$

\section{Source}

Default

Default VOL $-S$

Environmental Transfer Factors:

Transfer Parameter

Bioaccumulation in fish

Bioaccumulation in shellfish

Soil-to-edible plant

Feed-to-animal meat, $d / \mathrm{kg}$

Feed-to-cow milk, d/L Water purification factor

Deposition velocity, $\mathrm{m} / \mathrm{s}$

Atmospheric deposition class

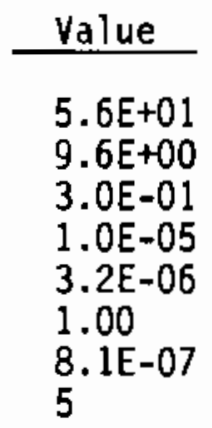

Chemical Toxicity Parameters:

Inhalation cancer potency factor, $\mathrm{kg}-\mathrm{d} / \mathrm{mg}$ Ingestion cancer potency factor, $\mathrm{kg}-\mathrm{d} / \mathrm{mg}$ Ingestion reference dose, $\mathrm{mg} / \mathrm{kg} / \mathrm{d}$
Value

1.7E-03

5.1E-02

1. $0 \mathrm{E}-02$
Source

Calculated from Kow

Calculated from Kow

Calculated from Kow

Calculated from Kow

Calculated from Kow

Default

Method DVM

Non-depositing gas

Source

EPA (1984d)

EPA (1984d)

IRIS

(a) From ICF (1987) as calculated from solubility and vapor pressure. 
Data Summary for TOLUENE

CAS: 108883

Comnon Synonyms: Toluene, Toluot

Physical Properties:

Molecular weight

Water solubility, $\mathrm{mg} / \mathrm{L}$

Vapor pressure, im $\mathrm{Hg}$

Henry's law constant, atm-m $3 /$ mole

Octonal-water partition coefficient

Carbon matter partition coefficient, $L / g$

\begin{tabular}{cll} 
Value & & Source \\
\cline { 1 - 1 } 92.15 & & Empirical \\
$5.4 E+02$ & & EPA (1984e) \\
$2.8 E+01$ & & EPA (1984e) \\
$6.4 E-03$ & & See footnote (a) \\
$5.4 E+02$ & & EPA (1984e) \\
$3.0 E+02$ & & Mabey et al. (1982)
\end{tabular}

Environmental Degradation/Removal Half-times:

Media of Transport

In air, d
In water, d
In soil, d
Value

$6.9 \mathrm{E}+07$

$6.9 \mathrm{E}+07$

$4.2 \mathrm{E}+01$
Source

Default

Default

VOL-S

Environmental Transfer Factors:

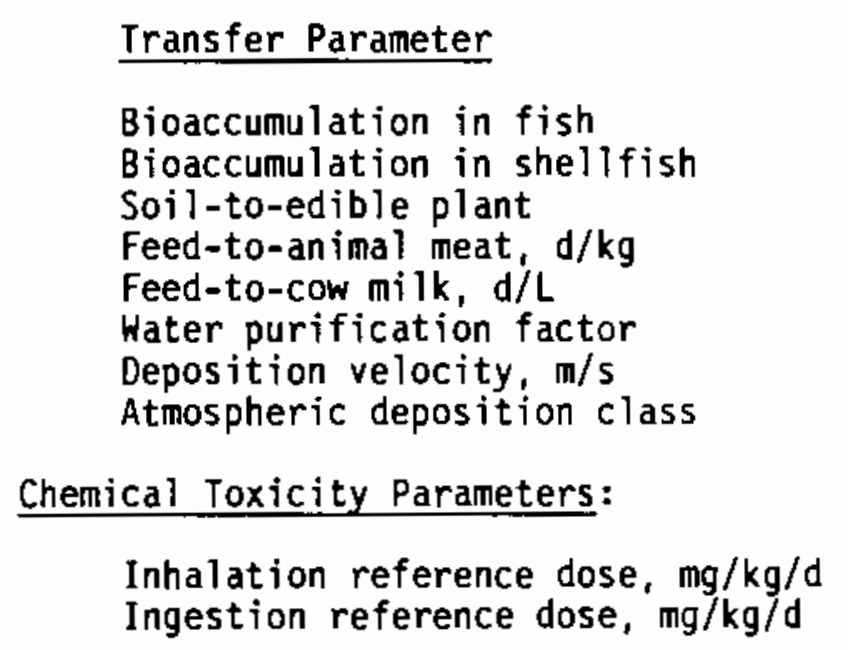

Transfer Parameter

Bioaccumulation in fish

Bioaccumulation in shellfish

Soil-to-edible plant

Feed-to-animal meat, $d / \mathbf{k g}$

Feed-to-cow milk, d/L

Deposition velocity $\mathrm{m} / \mathrm{s}$

Atmospheric deposition class
Value
$7.0 \mathrm{E}+01$
$1.2 \mathrm{E}+01$
2.6E-01
$1.3 \mathrm{E}-05$
$4.3 \mathrm{E}-06$
1.00
$2.9 \mathrm{E}-06$
5

Value

$1.5 \mathrm{E}+00$

$3.0 \mathrm{E}-01$
Source

Calculated from Kow

Calculated from Kow

Calculated from Kow

Calculated from kow

Calculated from kow

Default

Method DVM

Non-depositing gas

Source

EPA (1984e)

IRIS

(a) From ICF (1987) as calculated from solubility and vapor pressure. 


\section{REFERENCES}

ICF. 1987. Memorandum, "Chemical Data Base Development," from S. Sager of ICF-Clement Associates, Inc., to G. Whelan of Pacific Northwest Laboratory, Richland, Washington, dated July 20, 1987.

Mabey, W. R., J. H. Smith, R. T. Podoll, H. L. Johnson, T. Mill, T. W. Chou, J. Gates, I. W. Patridge, H. Jaber, and D. Vandenberg. 1982. Aquatic Fate Process Data for Organic Priority Pollutants. Prepared by SRI International for Monitoring and Data Support Division, Office of Water Regulations and Standards, Washington, D.C.

Napier, B. A., R. L. Roswel1, W. E. Kennedy, Jr., and D. L. Strenge. 1980. Assessment of Effectiveness of Geologic Isolation Systems: ARRRG and FOOD: Computer Programs for Calculating Radiation Dose to Man from Radionuclides in the Environment. PNL-3180, Pacific Northwest Laboratory, Richland, Washington.

0'Brien, and Gere. 1981. Hudson River Water Treatability Study. New York State Department of Ecology and Conservation, Albany, New York.

Spehar, R. L., J. T. Fiandt, R. L. Anderson, and D. L. Defoe. 1980. "Comparative Toxicity of Arsenic Compounds and Their Accumulation in Invertebrates and Fish." Arch. Environ. Contam. Toxicol. 9:53-63.

Strenge, D. L., R. A. Peloquin, and G. Whelan. 1986. LADTAP II - Technical Reference and User Guide. NUREG/CR-4013, U.S. Nuclear Regulatory Commission, Washington, D.C.

U.S. Environmental Protection Agency (EPA). 1981. Treatability Manual, Vol. I. EPA-600/2-82-001a, Office of Research and Development, Washington, D.C.

U.S. Environmental Protection Agency (EPA). 1984a. Health Effects Assessment for Arsenic. EPA/540/1-86-020, Environmental Crittria and Assessment Office, Cincinnati, Ohio.

U.S. Environmental Protection Agency (EPA). 1984b. Health Effects Assessment for Mercury. EPA/540/1-86-042, Environmental Criteria and Assessment office, Cincinnati, Ohio.

U.S. Environmental Protection Agency (EPA). 1984c. Health Effects Assessment for Polychlorinated Biphenyls (PCBS). EPA/540/1-86-004, Environmental Criteria and Assessment office, Cincinnati, ohio.

U.S. Environmental Protection Agency (EPA). 1984d. Health Effects Assessment for Tetrachloroethylene. EPA/540/1-86-009, Environmental Criteria and Assessment Office, Cincinnati, Ohio.

U.S. Environmental Protection Agency (EPA). 1984e. Health Effects Assessment for Toluene. EPA/540/1-86-033, Environmental Criteria and Assessment Office, Cincinnati, Ohio. 
U.S. Environmental Protection Agency (EPA). 1986. Verified Reference Doses (RFDs) of the USEPA. ECAO-CIN-475, Office of Health and Environmental Assessment, Washington, D.C.

Weast, R. C. 1979. Handbook of Chemistry and Physics. Chemical Rubber Co., Cleveland, Ohio. 
APPENDIX B

SENSITIVITY ANALYSIS METHODOLOGY 


\section{APPENDIX B}

\section{SENSITIVITY ANALYSIS METHODOLOGY}

Sensitivity analysis methods are numerical methods for determining the relative importance of the input variables on the output variables of a mathematical model. Several of the models used in the MEPAS methodology contain many input variables, and the sequential organization of the models make it difficult to detemine the actual impact of individual variables on the final model output (HPI). There are two types of sensitivity analysis methods, pointwise and statistical. Although the statistical approach was used here, the pointwise approach is described as a means of introducing the statistical approach.

\section{POINTWISE SENSITIVITY ANALYSIS}

The sensitivity of one variable to another in a mathematical relationship is described by the partial derivative. If $Y$ is a function $f$ of $n$ input variables $x_{1}, \ldots, x_{n}$, say,

$$
Y=f\left(x_{1}, \ldots, x_{n}\right)
$$

then

$$
\frac{\delta \mathrm{Y}}{\delta \mathrm{x}_{1}} \mid \mathrm{x}_{1}, \ldots, \mathrm{x}_{\mathrm{n}}
$$

is the partial derivative of $Y$ with respect to $x_{1}$ at the fixed point $\left(x_{1}\right.$, $\left.\ldots, x_{n}\right)$ in the input variable space. The numerical estimate of the partial derivative of $Y$ with respect to $x_{1}$ at the point $x_{1}, \ldots, x_{n}$, for example, as

$$
\frac{Y\left(x_{1}+(1 / 2) \Delta, x_{2}, \ldots x_{n}\right)-Y\left(x_{1}-(1 / 2) \Delta, x_{2}, \ldots, x_{n}\right)}{\Delta}
$$


where all variables but $X_{1}$ are held fixed. Because the units and numerical scale of $Y$ and the $X_{i}$ are often different, the partial derivatives are usually normalized by dividing the differential by the nominal value so the partial derivatives are on a more comparable basis. Therefore, the normalized sensitivity of $Y$ with respect to $x_{1}$ at $x_{1}, \ldots, x_{n}$ in Equation (B.2) above is given by:

$$
\frac{\delta Y / Y}{\delta X_{1} / X_{1}} \mid x_{1}, \ldots, x_{n}
$$

Determining the sensitivity of the variable $Y$ to each of the input variables $x_{1}, \ldots, x_{n}$ at the point $\left(x_{1}, \ldots, x_{n}\right)$ requires the calculation of $n$ partial derivatives. Calculating the numerical estimate of the partial derivative of $Y$ with respect to each variable $X_{i}$ can be rather time consuming if the model has many variables.

The adjoined form of a partial differential equation has been exploited to produce a system of linear equations (Tomovic et al. 1972; 0blow 1978). The solution of the system of equations at a fixed point produces estimates of the partial derivatives with respect to all input variables simultaneously. The process of adjoining a large model with many variables by hand can be very time consuming. The process of computing partial derivatives has been computerized, for example, in the GRESS and ADGEN codes (0blow 1983a, 1983b; Horwedel and Pin 1986; Pin et al. 1987), but the partials are computed only at one point in the domain of the input variables. However, once the equation has had the adjoined form computed, the partial derivatives at additional points can be evaluated in a straightforward manner.

The standardized partial derivatives can be ordered from largest to smallest, and the variable with the largest partial derivative is the one that has the largest effect on the output variable. However, these partial derivatives do not reflect the case where two input variables appear to be equally important and highly correlated. For complex models with nonlinear behavior in some or all of the input variables, the ordering of the variables at different points in the input variable space will not be the same. 
In a review of sensitivity analysis methods, Porn and Akerlund (1985) have suggested that a pointwise sensitivity analysis approach is not meaningfu] when the input variables are subject to large uncertainties, that is, when the input variables behave are environmental measurements.

\section{STATISTICAL SENSITIVITY ANALYSIS}

The difficulty that the deterministic sensitivity analysis methods have in dealing with the effect of the correlation of input variables on the interpretation of the partial derivatives led Iman et a]. (1978) to develop a statistical approach to sensitivity analysis. The method, based on partial regression techniques, consists of evaluating the model at a number of points in the input space and fitting a response surface (linear model) of the input variables to the output variables. The linear model is of the form

$$
Y=a+\sum \beta_{i} X_{i}+\epsilon
$$

The coefficients $\beta_{i}$, the partial regression coefficients, are analogous to the partial derivatives. However, because the units of the input variables may differ substantially, it is recommended that the model be reparametrized so that it does not have the usual intercept (a) as

$$
Y \star=\Sigma \beta^{\star} i X^{\star} i+\epsilon,
$$

where the coefficients $\beta^{\star} i$ are now the standardized partial regression coefficients. Iman et al. (1985) developed a computer code to calculate the standardized partial regression coefficients specifically for sensitivity analysis applications.

Before the standardized partial regression coefficients can be accepted as measures of the importance of the individual variables, the linear model approximation to the original model must be sufficiently close. A criterion of the adequacy of the fit is given by the model multiple correlation coefficient, R2, defined as follows: 


$$
R^{2}=1-\frac{\Sigma\left(Y^{*}-\hat{Y^{*}}\right)^{2}}{\Sigma\left(Y^{*}-Y^{*}\right)^{2}}-
$$

where $\hat{Y}^{*}$ is the estimated value of $Y^{*}$ and $\bar{Y}^{*}$ is the mean of $Y^{*}$. If $R^{2}$ it is sufficiently large, then the response surface gives an adequate representation of the function, and the partial regression coefficients are estimates of the "average" partial derivative over the range of the input variables. The relative magnitudes of these standardized partial regression coefficients give the relative importance of the input variables over the range of the input variable regression.

Another statistical measure of importance of the variables besides the partial regression coefficient is the partial $R^{2}$, which gives the amount of variation attributable to a particular variable. It is given by

$$
R i^{2}=\frac{\sum\left(Y^{*}-\hat{Y}^{\star}(i)\right)^{2}-\sum\left(Y^{\star}-\hat{Y}^{\star}\right)^{2}}{\sum\left(Y^{\star}-Y^{\star}\right)^{2}}
$$

where $\hat{Y}(i)$ is the estimated value of $Y^{*}$ when $X_{i}$ is deleted from the model. The partial $R^{2}$ is the measure of importance used when a detailed sensitivity analysis was performed for this report.

Even for complex models with nonlinear behavior, the output variable is at least a monotonic function of the input variables in subregions of the input space. Iman and Conover (1979) suggested the use of the rank transformation to linearize a monotonic relationship, so the response function can be used to estimate the sensitivity coefficients in the subregions. Therefore, the response surface approach to sensitivity analysis can be applied to a larger class of models than just linear models.

For large models with many input variables that are usually not mutually independent, Iman et al. (1978) recommended the use of a step-wise regression procedure to approximate the model output by sequentially adding and/or deleting variables to the response surface model based on the values of model diagnostic statistics. There are several algorithms for selecting the 
variables, the method used here is the stepwise procedure based on the $F$ statistic, given by

$$
F=\frac{R^{2} i(m-n-1)}{R^{2}}
$$

where $m$ is the number of points where the model was evaluated. A variable is added to the model if $F$ is greater than a prespecified value ( 0.15 was used for this analysis) or deleted if it is less than a prespecified value (also 0.15 in this analysis). When no variables can be either added or deleted by the criteria in Equation (B.9), the variables that are in the linear model can be considered to have a significant effect on the model output. The advantage to doing a stepwise regression is that working with a reduced set of the important variables makes the interpretation of the results easier.

The statistical sensitivity analysis method requires that the model be evaluated at multiple points in the input variable space. However, that presents the problem of how to select the points. The next subsection discusses Latin Hypercube sampling, a method of selecting input variables that is more efficient than random sampling.

\section{LATIN HYPERCUBE SAMPLING}

Latin Hypercube sampling was first proposed by McKay et al. (1979) to efficiently select values of input variables for performing sensitivity analyses for complex computer codes. The method gets its name from a statistical experimenta] design called the Latin Square (Kempthorne 1952), which is an efficient method of assigning treatments to experimental units that have been categorized by two independent schemes. The concept of the Latin Square is also used in the context of statistical sampling as a means of stratifying populations to reduce the variance of the estimates of the characteristics of interest (Cochran 1963).

Latin Hypercube sampling is a generalization of Latin Square sampling to $K$ dimensions, which correspond to the number of input variables of the model. Each input variable is assumed to be a random variable, which is governed by 
a probability density function ( $p d f)$. (Input variables which are constants can be described by a degenerate density function.) The stratification is accomplished by dividing the range of the input variable into $N$ intervals of equal (1/N) probability. Each equiprobable interval is randomly sampled once for each variable. The output of the sampling can be considered an NxK matrix $\underline{Y}$, where the columns represent variables and the rows contain the sample values for the appropriate interval. The values within a column are then randomly permuted, so that a row represents a random vector of the input variables. The computer model is then run $N$ times with the values of the input variables equal to the rows of the matrix. Iman et al. (1980) developed a computer code to generate Latin Hypercube samples from arbitrary pdfs.

The advantages of Latin Hypercube sampling over unconstrained sampling methods are that

- It provides an efficient method for sampling the entire range of each variable in accordance with the assumed probability distribution

- The estimate of the pdf of the model output variables is an unbiased estimate of the true pdf.

The reduction in variance of the estimates is a property of the stratification of the probability density function.

The Latin Hypercube sampling methodology assumes that the input variables are uncorrelated; however, that is not always the case in practice, and a simple Latin Hypercube sample may contain combinations of input variables that are physically unreasonable. Iman and Conover (1982) developed a method to induce the desired dependence among the variables in a Latin Hypercube sample using a rank correlation matrix. The method is very effective when rank correlations among all pairs of variables can be obtained (see Doctor et al. 1988). A practical difficulty in using the method is that one must have an estimate for the rank correlation between each pair of variables. An alternative method is to assume a strict dependency among variables that are known to be correlated, vary them the same amount, and have only one input variable for the linear model as was done for the hydrologic variables for Case 1 in Chapter 2.0 . 


\section{REFERENCES}

Cochran, W. G. 1963. Sampling Statistics. 2nd ed. John Wiley and Sons, New York.

Doctor, P. G., E. A. Jacobson, and J. A. Buchanan. 1988. A Comparison of Uncertainty Analys is Methods Using a Groundwater Flow Model. PNL-5649, Pacific Northwest Laboratory, Richland, Washington.

Horwedel, J. E., and F. G. Pin. 1986. Upgrade of the GRESS (test version D) Precompiler to Allow Triply-0imensioned Arrays. ORNL/CSD/TM-240, 0ak Ridge National Laboratory, Oak Ridge, Tennessee.

Iman, R. L., and W. J. Conover. 1979. "The Use of Rank Transformation in Regression." Technometrics 21:499-509.

Iman, R. L., J. M. Davenport, and D. K. Zeigler. 1980, Latin Hypercube Sampling (Program User's Guide). SAND79-1473, Sandia National Laboratories, Albuquerque, New Mexico.

Iman, R. L., and W. J. Conover. 1982. "A Distribution-Free Approach to Reducing Rank Correlation Among Input Variables." Communications in Statistics B11(3):311-334.

Iman, R. L., J. C. Helton, and J. E. Campbel1. 1978. Risk Methodology for Geologic Disposal of Radioactive Waste: Sensitivity Analys is Techniques. SAND78-0912, Sandia National Laboratories, Albuquerque, New Mexico.

Iman, R. L., M. J. Shortencarier, and J. D. Johnson. 1985. A Fortran 77 Program and User's Guide for the Calculation of Partial Regression Coefficients. NUREG/CR-4122, SAND83-2365, prepared by Sandia National Laboratories for the U.S. Nuclear Regulatory Commission, Washington, D.C.

Kempthorne, 0. 1952. Design and Analysis of Experiments. John Wiley and Sons, New York.

McKay, M. D., W. J. Conover, and R. J. Beckman. 1979. "A Comparison of Three Methods for Selecting Values of Input Variables in the Analys is of Output from a Computer Code." Technometrics 21(2):239-245.

Oblow, E. M. 1978. "Sensitivity Theory for General Nonlinear Algebraic Equations with Constraints." Nucl. Sci. Engineer. 65:187-191.

Oblow, E. M. 1983a. An Automated Procedure for Sensitivity Analysis Using Computer Calculus. ORNL/TM-8776, Oak Ridge National Laboratory, 0ak Ridge, Tennessee.

Oblow, E. M. 1983b. GRESS Gradient-Enhanced Software System Version B User's Guide. ORNL/TM-8339, Oak Ridge National Laboratory, Oak Ridge, Tennessee. 
Pin, F. G., E. M. Oblow, J. E. Horwedel, and J. L. Lucius. 1987. "ADGEN: An Automated Adjoint Code Generator for Large-Scale Sensitivity Analysis." Trans. Am. Nucl. Soc. $55: 311$.

Porn, K., and 0. Akerlund. 1985. Procedures for Uncertainty and Sensitivity Analysis in Repository Performance Assessment. Technical Report 85-18, Swedish Nuclear Fuel and Waste Management Company,

Tomovic, R., and M. Vukobratoric. 1972. General Sensitivity Theory. Elsevier, New York. 


\section{APPENDIX C}

WIND SPEED, WIND DIRECTION, AND STABILITY SUMMARY 
APPENDIX C

\section{WIND SPEED, WIND DIRECTION, AND STABILITY SUMMARY}

Stab- wind

Class $(b)$ N NHE NE ENE E ESE SE SSE S SSH SW WSW W WNW NW NNW

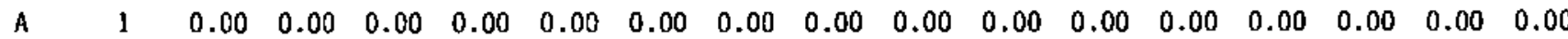
$\begin{array}{lllllllllllllllll}0.02 & 0.00 & 0.02 & 0.01 & 0.02 & 0.01 & 0.01 & 0.00 & 0.05 & 0.01 & 0.01 & 0.02 & 0.02 & 0.04 & 0.02 & 0.03\end{array}$ $\begin{array}{lllllllllllllllll}0.01 & 0.00 & 0.00 & 0.01 & 0.02 & 0.01 & 0.01 & 0.01 & 0.02 & 0.02 & 0.01 & 0.05 & 0.06 & 0.01 & 0.02 & 0.02\end{array}$

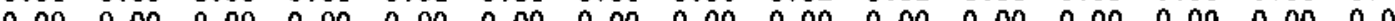
0.000 .000 .00 $\begin{array}{lllllllllllllllll}0.00 & 0.00 & 0.00 & 0.00 & 0.00 & 0.00 & 0.00 & 0.00 & 0.00 & 0.00 & 0.00 & 0.00 & 0.00 & 0.00 & 0.00 & 0.00\end{array}$ \begin{tabular}{llllllllllllllll}
0.00 & 0.00 & 0.00 & 0.00 & 0.00 & 0.00 & 0.00 & 0.00 & 0.00 & 0.00 & 0.00 & 0.00 & 0.00 & 0.00 & 0.00 & 0.00 \\
\hline 0.00 & 0.00 & 0.00 & 0.00 & 0.00 & 0.00 & 0.00 & 0.00 & 0.00 & 0.00 & 0.00 & 0.00 & 0.00 & 0.00 & 0.00 & 0.00
\end{tabular} $\begin{array}{llllllllllllllllll}0.00 & 0.00 & 0.00 & 0.00 & 0.00 & 0.00 & 0.00 & 0.00 & 0.00 & 0.00 & 0.00 & 0.00 & 0.00 & 0.00 & 0.00 & 0.00 \\ 0.10 & 0.03 & 0.05 & 0.06 & 0.09 & 0.03 & 0.07 & 0.00 & 0.15 & 0.04 & 0.07 & 0.11 & 0.11 & 0.10 & 0.06 & 0.07 & & \\ 0.19 & 0.12 & 0.09 & 0.15 & 0.15 & 0.14 & 0.14 & 0.12 & 0.21 & 0.11 & 0.25 & 0.30 & 0.27 & 0.12 & 0.12 & 0.14\end{array}$ $\begin{array}{llllllllllllllll}0.10 & 0.03 & 0.05 & 0.06 & 0.09 & 0.03 & 0.07 & 0.08 & 0.15 & 0.04 & 0.07 & 0.11 & 0.11 & 0.10 & 0.06 & 0.07\end{array}$ $\begin{array}{llllllllllllllll}0.04 & 0.01 & 0.03 & 0.05 & 0.03 & 0.02 & 0.02 & 0.02 & 0.02 & 0.11 & 0.25 & 0.30 & 0.27 & 0.12 & 0.12 & 0.14\end{array}$ $\begin{array}{lllllllllllllllll}0.00 & 0.00 & 0.00 & 0.00 & 0.00 & 0.00 & 0.00 & 0.00 & 0.00 & 0.00 & 0.00 & 0.00 & 0.00 & 0.00 & 0.00 & 0.00 & 0.00 \\ 0.00 & 0.00 & 0.00 & 0.00 & 0.00 & 0.00 & 0.00 & 0.00 & 0.00 & 0.00 & 0.00 & 0.01 & 0.00 & 0.00 & 0.00 & 0.00\end{array}$

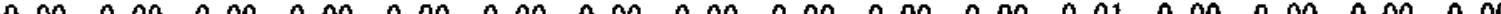
\begin{tabular}{llllllllllllllll}
0.00 & 0.00 & 0.00 & 0.00 & 0.00 & 0.00 & 0.00 & 0.00 & 0.00 & 0.00 & 0.00 & 0.01 & 0.00 & 0.00 & 0.00 & 0.00 \\
\hline 0.00 & 0.00 & 0.00 & 0.00 & 0.00 & 0.00 & 0.00 & 0.00 & 0.00 & 0.00 & 0.00 & 0.00 & 0.00 & 0.00 & 0.00 & 0.00
\end{tabular}

$\begin{array}{llllllllllllllll}0.10 & 0.07 & 0.05 & 0.07 & 0.08 & 0.08 & 0.07 & 0.03 & 0.10 & 0.05 & 0.07 & 0.10 & 0.11 & 0.11 & 0.05 & 0.07\end{array}$

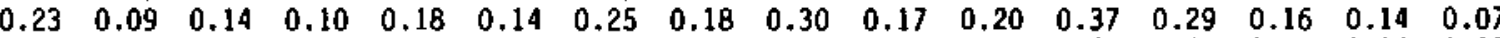
$\begin{array}{lllllllllllllllll}0.21 & 0.11 & 0.19 & 0.22 & 0.22 & 0.17 & 0.23 & 0.17 & 0.51 & 0.35 & 0.63 & 0.59 & 0.53 & 0.30 & 0.35 & 0.25\end{array}$ $\begin{array}{lllllllllllllllll}0.05 & 0.02 & 0.03 & 0.02 & 0.05 & 0.01 & 0.01 & 0.02 & 0.05 & 0.05 & 0.10 & 0.15 & 0.10 & 0.04 & 0.04 & 0.01\end{array}$ $\begin{array}{llllllllllllllllll}0.00 & 0.00 & 0.00 & 0.00 & 0.00 & 0.00 & 0.00 & 0.00 & 0.00 & 0.01 & 0.01 & 0.02 & 0.00 & 0.00 & 0.00 & 0.00\end{array}$

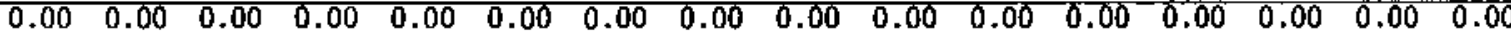

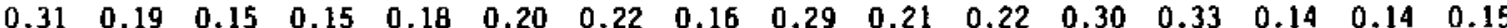
$\begin{array}{lllllllllllllllll}0.90 & 0.42 & 0.50 & 0.46 & 0.51 & 0.70 & 0.95 & 0.65 & 1.39 & 0.65 & 0.69 & 0.85 & 1.17 & 0.78 & 0.71 & 0.57\end{array}$

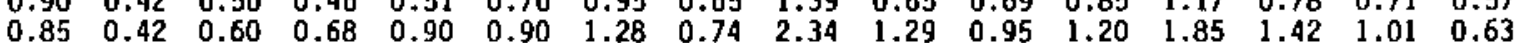
$\begin{array}{llllllllllllllll}0.59 & 0.36 & 0.47 & 0.41 & 0.70 & 0.61 & 0.46 & 0.38 & 2.56 & 1.74 & 1.67 & 1.79 & 3.37 & 1.51 & 1.21 & 0.63\end{array}$

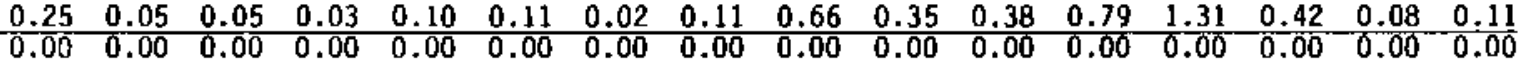

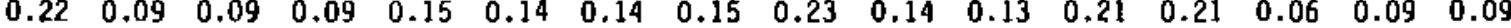
$\begin{array}{llllllllllllllll}0.38 & 0.22 & 0.21 & 0.29 & 0.43 & 0.45 & 0.69 & 0.36 & 0.92 & 0.43 & 0.55 & 0.42 & 0.65 & 0.45 & 0.38 & 0.37\end{array}$ $\begin{array}{llllllllllllllllll}0.11 & 0.10 & 0.15 & 0.11 & 0.22 & 0.22 & 0.21 & 0.15 & 0.87 & 0.42 & 0.34 & 0.42 & 0.52 & 0.23 & 0.25 & 0.21\end{array}$

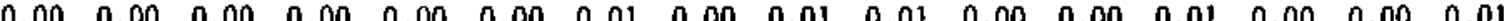
$0.00 \quad 0.00 \quad 0.00 \quad 0.00 \quad 0.000 .00$ 0.00 0.00 0.00 0.000 .000 .000000 $\begin{array}{lllllllllllllllll}0.00 & 0.00 & 0.00 & 0.00 & 0.00 & 0.00 & 0.00 & 0.00 & 0.00 & 0.00 & 0.00 & 0.00 & 0.00 & 0.00 & 0.00 & 0.00 \\ 0.00 & 0.00 & 0.00 & 0.00 & 0.00 & 0.00 & 0.00 & 0.00 & 0.00 & 0.00 & 0.00 & 0.00 & 0.00 & 0.00 & 0.00 & 0.00\end{array}$ $\begin{array}{llllllllllllllll}0.55 & 0.28 & 0.14 & 0.20 & 0.30 & 0.26 & 0.30 & 0.48 & 0.36 & 0.30 & 0.35 & 0.38 & 0.64 & 0.19 & 0.24 & 0.31\end{array}$ $\begin{array}{llllllllllllllll}0.38 & 0.18 & 0.25 & 0.24 & 0.39 & 0.44 & 0.53 & 0.51 & 0.83 & 0.46 & 0.59 & 0.45 & 0.56 & 0.39 & 0.27 & 0.39\end{array}$ $\begin{array}{lllllllllllllllllll}0.00 & 0.00 & 0.00 & 0.00 & 0.01 & 0.00 & 0.00 & 0.00 & 0.00 & 0.00 & 0.00 & 0.00 & 0.00 & 0.00 & 0.00 & 0.00\end{array}$ $\begin{array}{llllllllllllllll}0.00 & 0.00 & 0.00 & 0.00 & 0.00 & 0.00 & 0.00 & 0.00 & 0.00 & 0.00 & 0.00 & 0.00 & 0.00 & 0.00 & 0.00 & 0.00\end{array}$

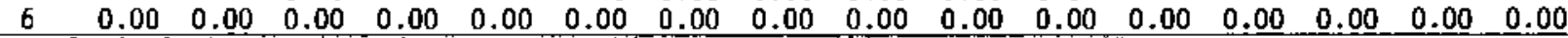

a) Meteorological observations from Dayton Ohio, Jan, 1,1970 to Dec, $31,1974$.

(b) Wind Ranges $(\mathrm{m} / \mathrm{s}): 1(<.8), 2(.8$ to 2.2$), 3(2.2$ to 3.8$), 4(3.8$ to 6.0$), 5(6.0$ to 11.0$), 6(>11.0)$. 

APPENDIX D

EXPOSURE ROUTE PARAMETERS 
APPENDIX D

EXPOSURE ROUTE PARAMETERS

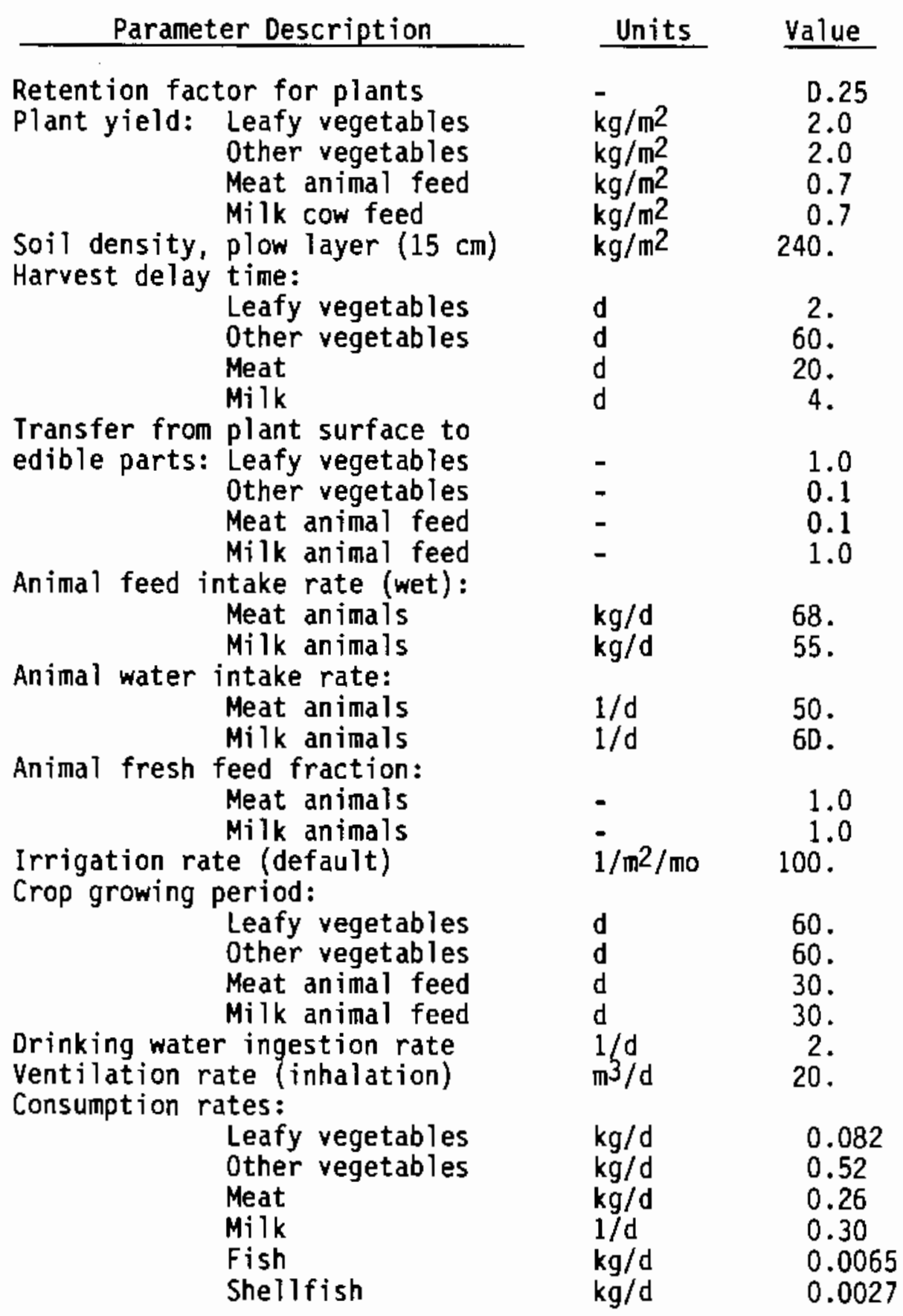


.

. 
PNL-7296

UC-602, 630

\section{DISTRIBUTION}

No. of

Copies

OFFSITE

2 DOE/Office of Scientific and Technical Information

P. Brush

Acting Assistant Secretary for

Environment, Safety and Health

U.S. Department of Energy, EH-1

1000 Independence Ave., SW

Washington, DC 20585

10 R. J. Aiken

Program Manager, Survey

Prioritization

Office of Environmental Audit

U.S. Department of Energy, EH-24

1000 Independence Ave., SW

Washington, DC 20585

\section{$\underline{\text { ONSITE }}$}

3 DOE Richland Operations Office

D. Dunigan

R. E. Gerton

R. D. Izatt

39 Pacific Northwest Laboratory

J. W. Buck

C. E. Cowan

P. G. Doctor

J. G. Droppo, Jr. (20)

J. W. Falco

M. D. Freshley

D. R. Friedrichs

J. M. Hales

P. C. Hays

B. L. Hoopes

T. B. Miley

W. T. Pennell

L. E. Rogers
No. of

Copies

R. L. Skaggs

D. L. Strenge

M. B. Walter

G. Whelan

Publishing Coordination

Technical Information (2) 


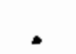

、

$+1$

,

$\because$

$+$ 